\title{
Radiological Emergency Response Health and Safety Manual
}

A U.S. Department of Energy Emergency Response Asset

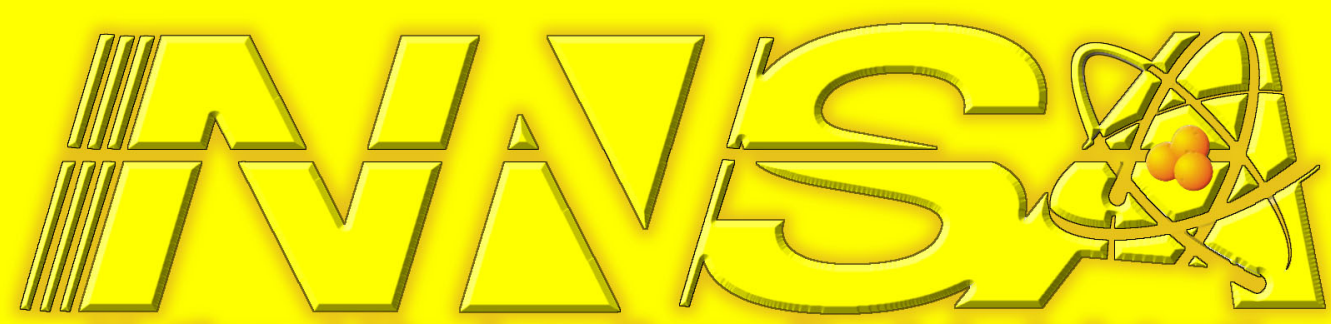

Nationa! Nuclear Securth 4dministration 


\section{DISCLAIMER}

This report was prepared as an account of work sponsored by an agency of the United States Government. Neither the United States Government nor any agency thereof, nor any of their employees, nor any of their contractors, subcontractors or their employees, makes any warranty, express or implied, or assumes any legal liability or responsibility for the accuracy, completeness, or any third party's use or the results of such use of any information, apparatus, product, or process disclosed, or represents that its use would not infringe privately owned rights. Reference herein to any specific commercial product, process, or service by trade name, trademark, manufacturer, or otherwise, does not necessarily constitute or imply its endorsement, recommendation, or favoring by the United States Government or any agency thereof or its contractors or subcontractors. The views and opinions of authors expressed herein do not necessarily state or reflect those of the United States Government or any agency thereof.

\section{AVAILABILITY STATEMENT}

Available for sale to the public, in paper, from:

U.S. Department of Commerce

National Technical Information Service

5285 Port Royal Road

Springfield, VA 22161-0002

Telephone: (800) 553-6847

Fax: (703) 605-6900

E-mail: orders@ntis.fedworld.gov

Online ordering: http://www.ntis.gov/ordering.htm

Available electronically at http://www.doe.gov/bridge

Available for a processing fee to the U.S. Department of Energy and its contractors, in paper, from:

U.S. Department of Energy

Office of Scientific and Technical Information

P.O. Box 62

Oak Ridge, TN 37831-0062

Telephone: (865) 576-8401

Fax: (865) 576-5728

E-mail: reports@adonis.osti.gov 


\section{Radiological Emergency Response Health and Safety Manual}

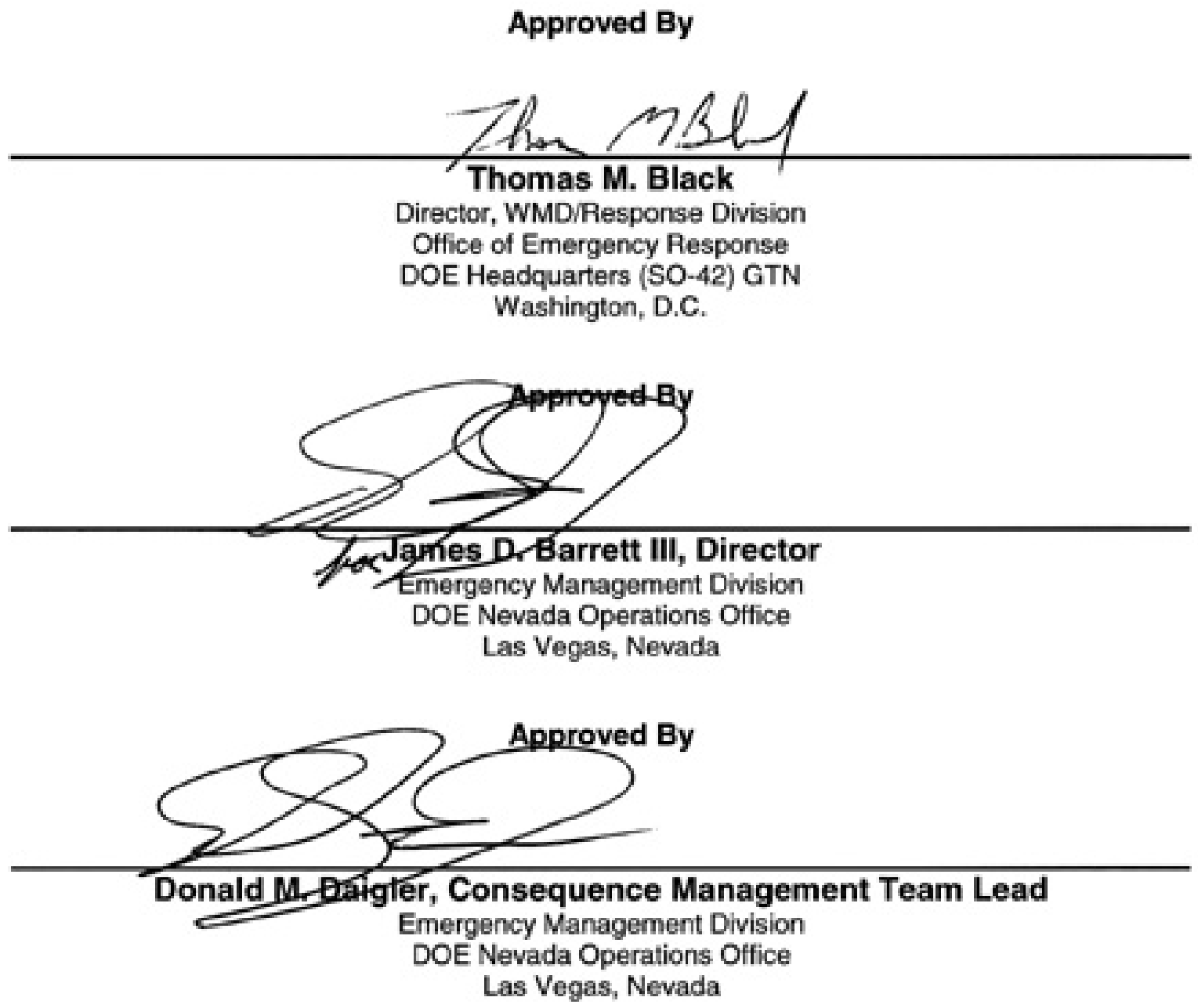

\section{Approved By}

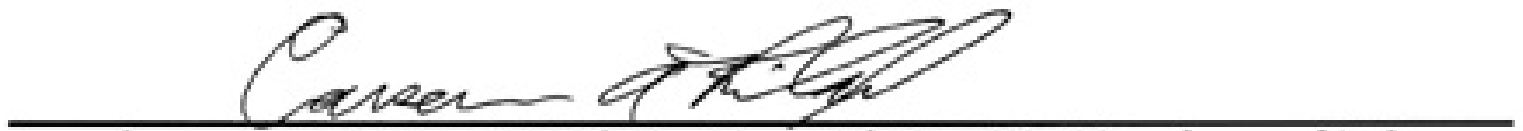

Carson A. Riland, FRMAC Health and Safety Working Group Chair

Remote Sensing Laboratory

Bechtel Nevada

Las Vegas, Nevada 


\section{TABLE OF CONTENTS}

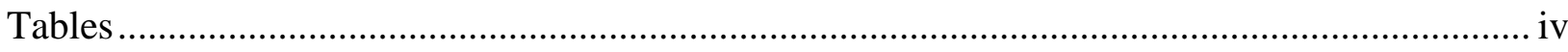

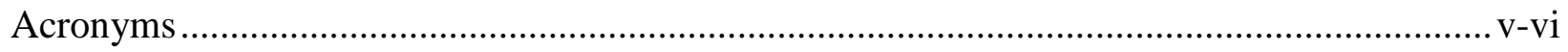

\section{OVERVIEW}

Scope.

Content

Application.....

Summary.....

CHAPTER 1 -- RESPONSIBILITIES

1.1 Health and Safety Responsibilities

1.2 Hazard Assessments............................. 3

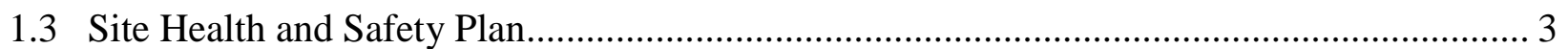

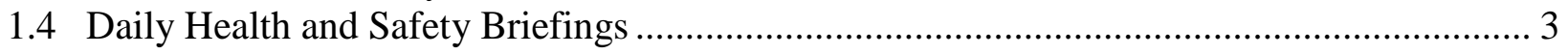

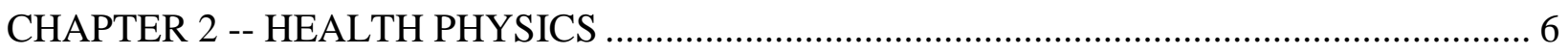

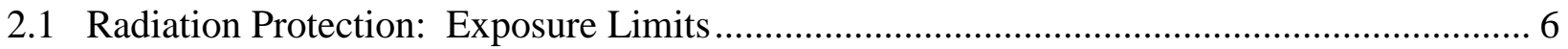

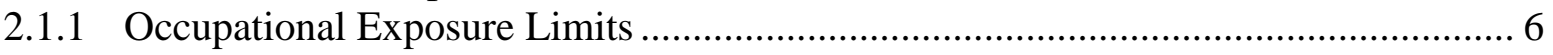

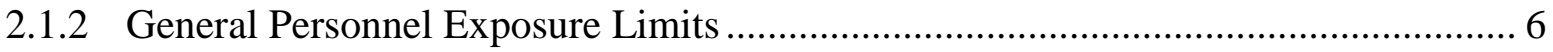

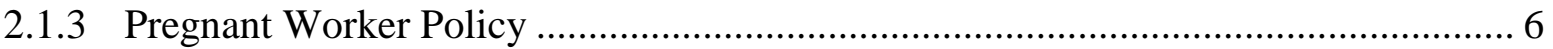

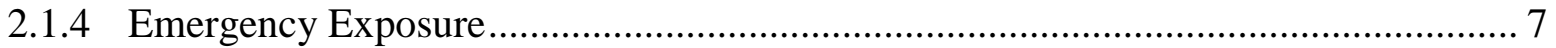

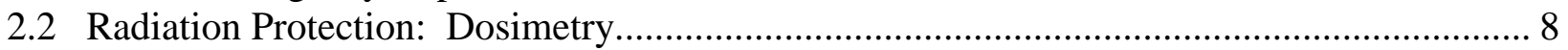

$2.2 .1 \quad$ External Dosimetry.......................................................................................... 8

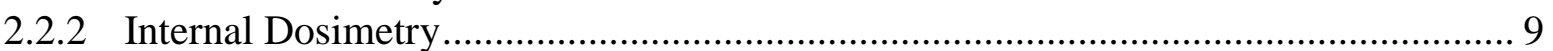

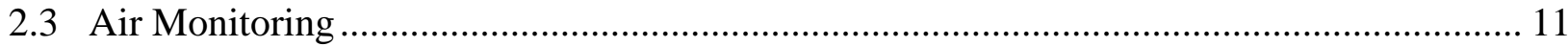

2.3.1 Assessment of Air Monitoring Needs ....................................................... 14

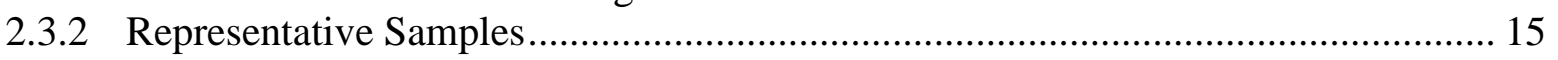

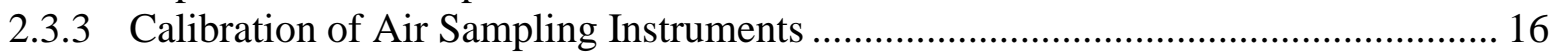

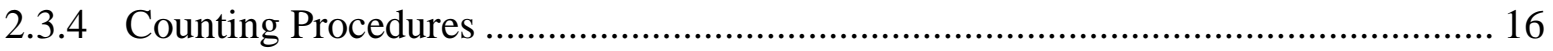

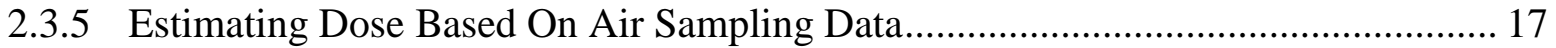

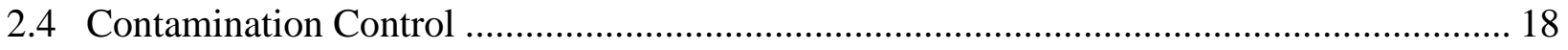

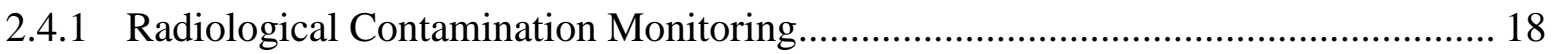

$2.4 .1 .1 \quad$ Area and Equipment Surveys ........................................................ 18

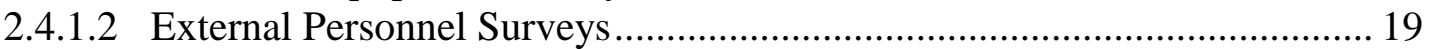

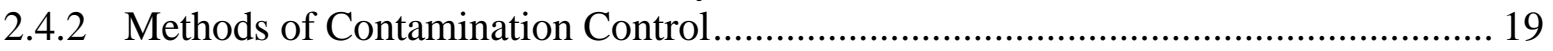

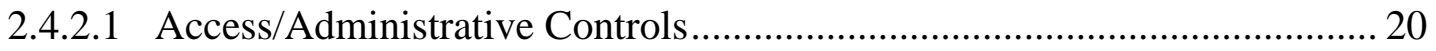

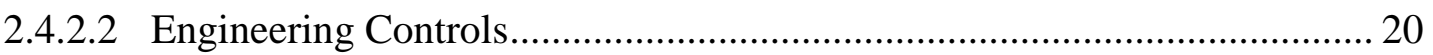

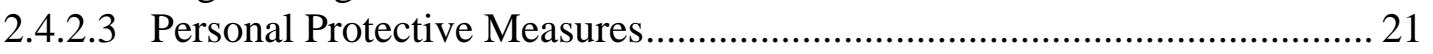

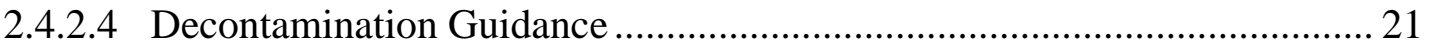

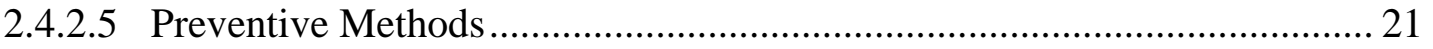

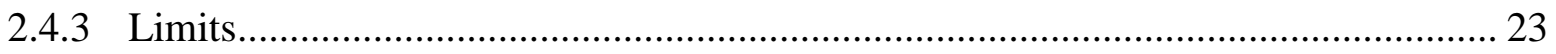

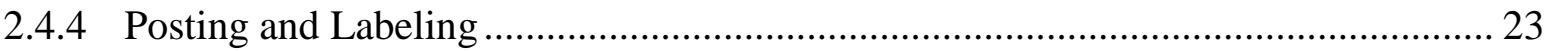

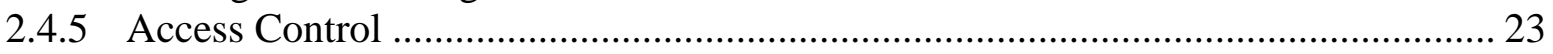

2.4.5.1 Entry and Exit Requirements for Radiological Areas ............................. 23

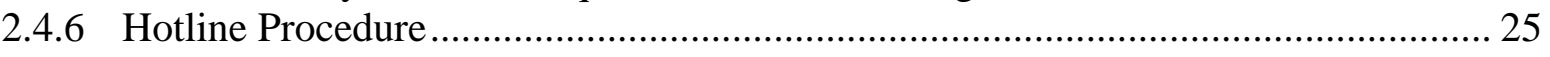


$2.4 .6 .1 \quad$ Personnel Surveys .......................................................................... 25

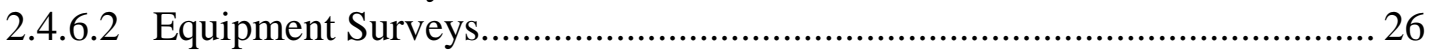

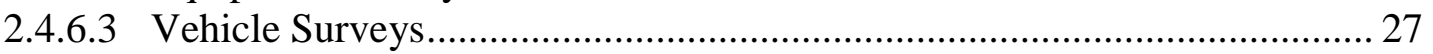

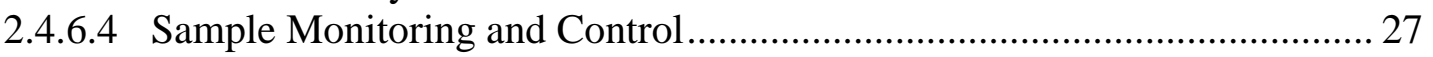

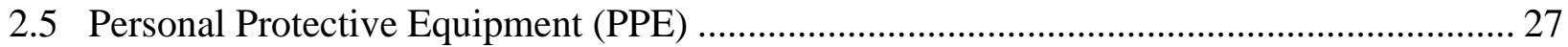

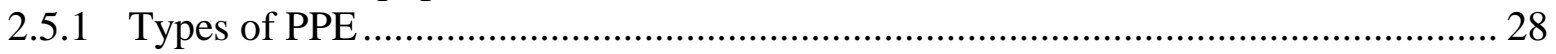

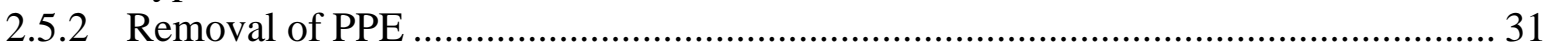

2.6 Survey Instruments and Methods............................................................................. 31

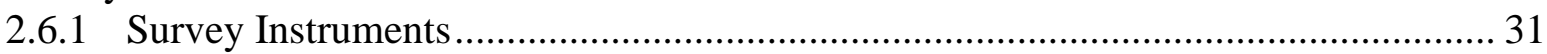

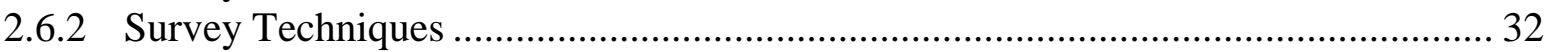

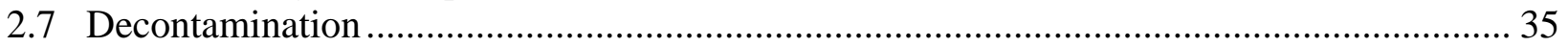

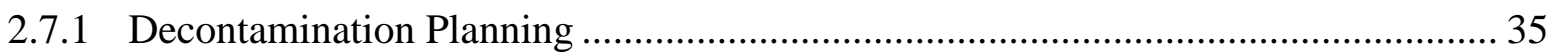

2.7 .2 Personnel Decontamination ......................................................................... 35

2.7 .3 Vehicle, Equipment, and Instrument Decontamination ................................. 38

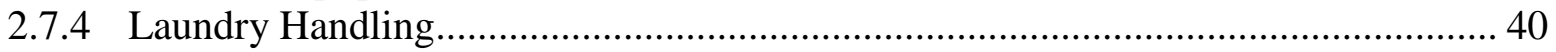

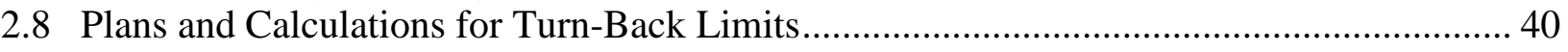

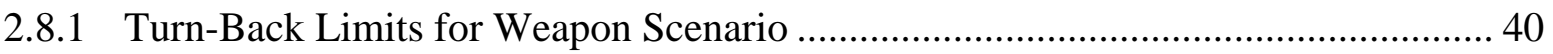

2.8 .2 Sample Bioassay Plan for Weapons Scenario ............................................ 42

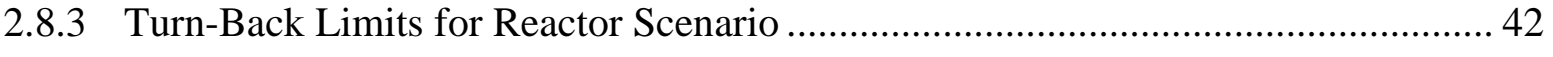

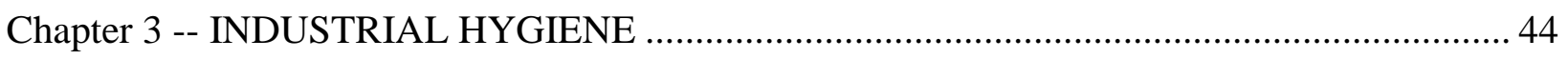

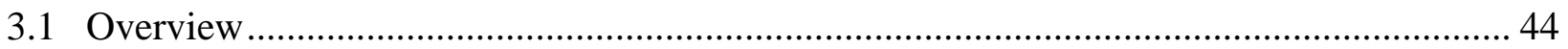

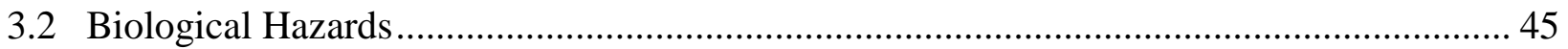

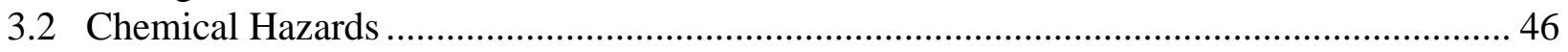

3.3.1 Personal Monitoring ................................................................................... 47

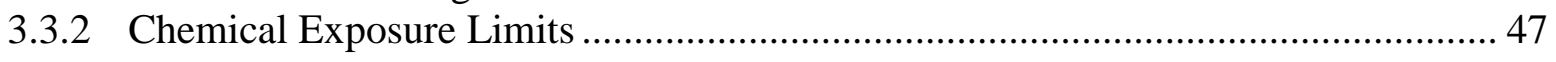

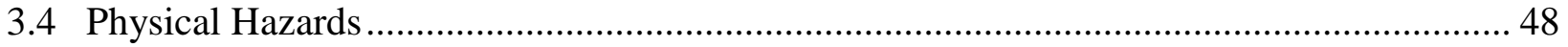

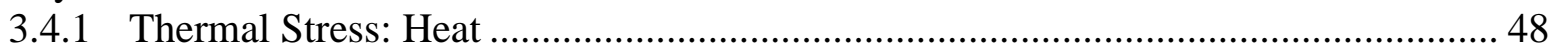

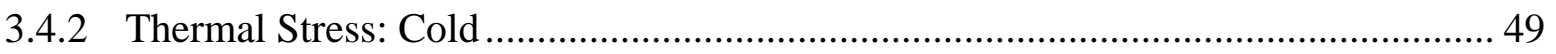

3.4 .3 High Noise Areas ...................................................................................... 50

3.4.4 Non-Ionizing Radiation (LASERS, UV, IR, MWFR Sources) ........................ 50

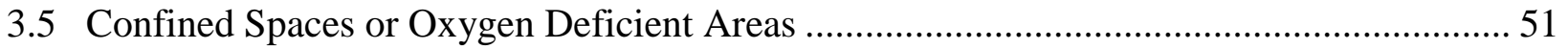

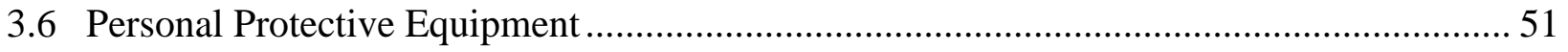

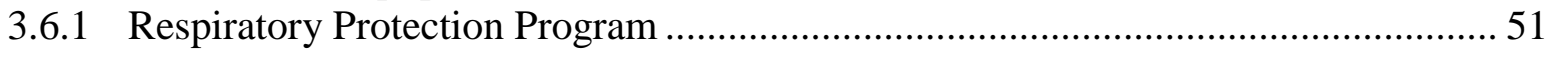

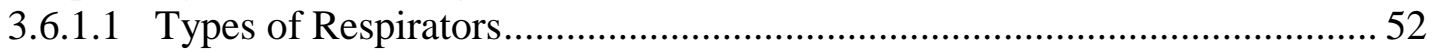

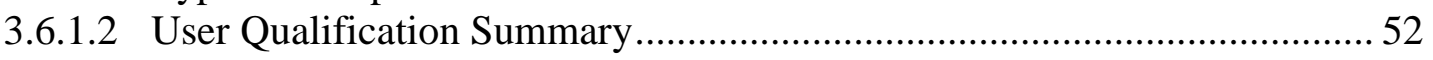

3.6.1.3 $\quad$ Respirator Inspection And Field Testing Instructions ........................53

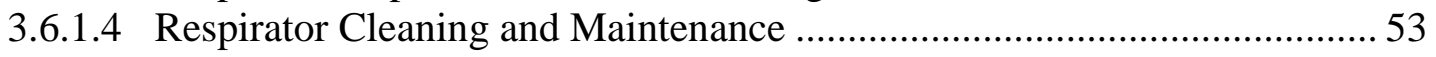

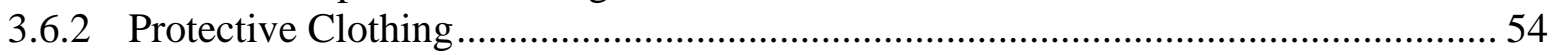

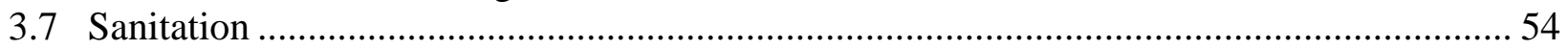

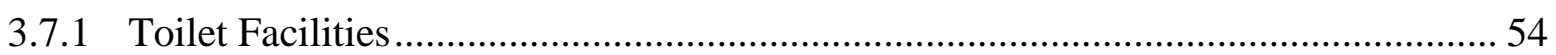

3.7.2 Water Supply for Hand Washing, Decontamination, and Human Consumption...... 54

3.7 .3 Food and Beverage Consumption ........................................................ 54

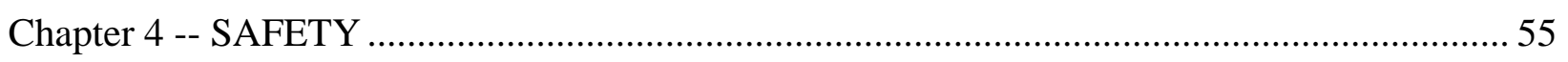

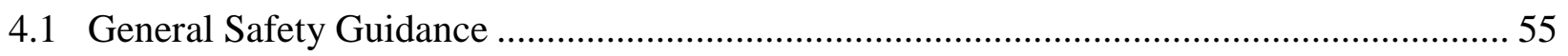

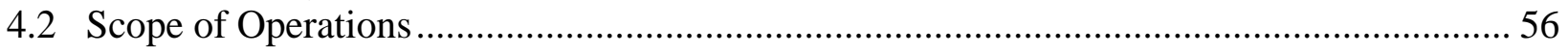


$4.2 .1 \quad$ Setup Operations .................................................................................... 56

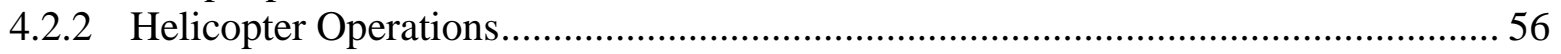

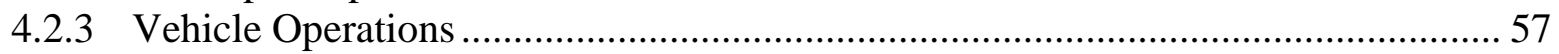

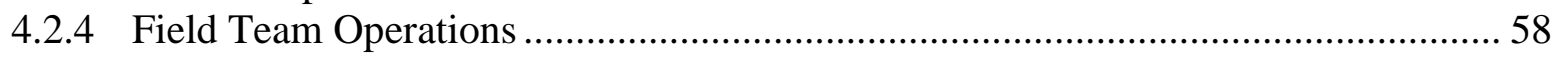

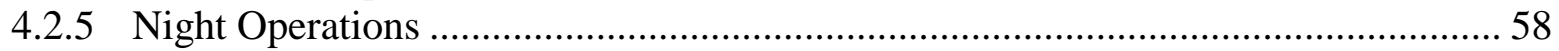

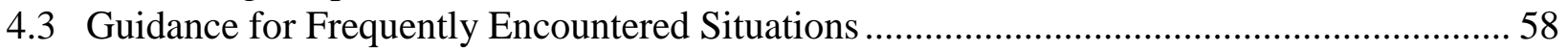

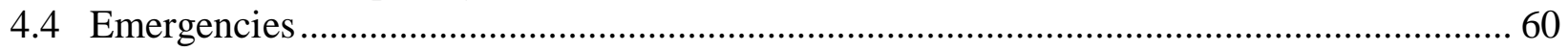

Chapter 5 -- ENVIRONMENTAL COMPLIANCE..................................................... 61

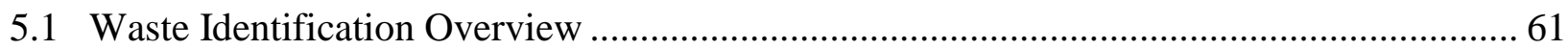

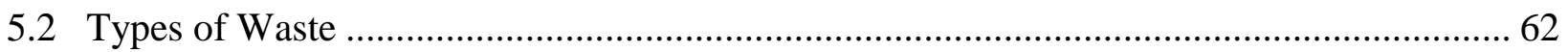

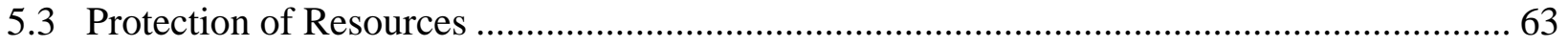

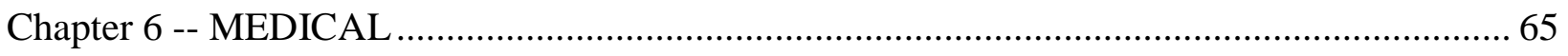

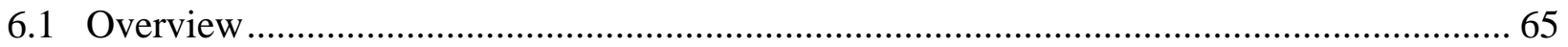

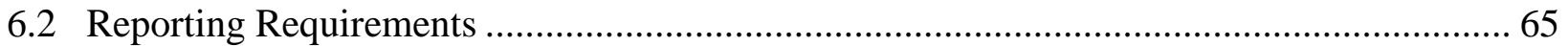

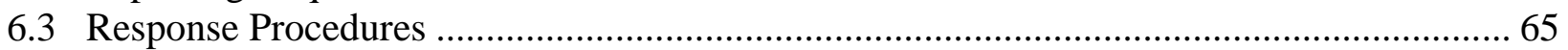

$6.3 .1 \quad$ Medical Emergencies at the Operations Center .......................................... 65

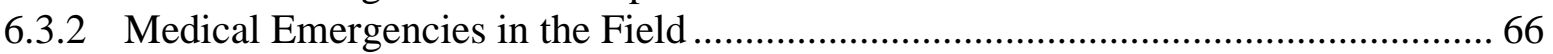

6.3.3 Management of Radiologically Contaminated Injured Persons .............................66 66

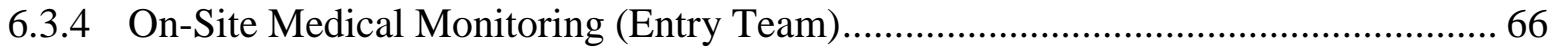

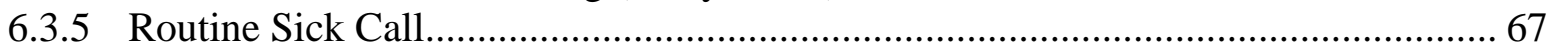

Chapter 7 -- RECORD MAINTENANCE................................................................................ 68

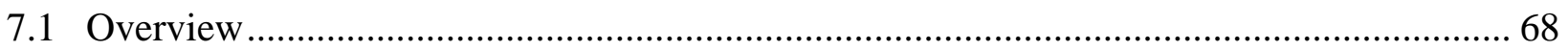

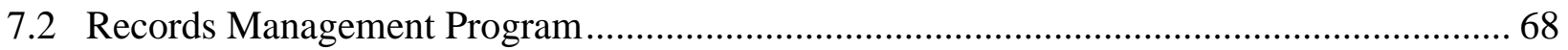

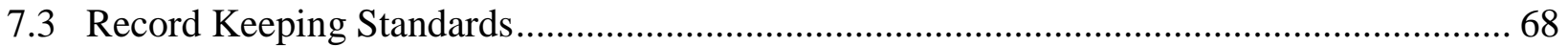

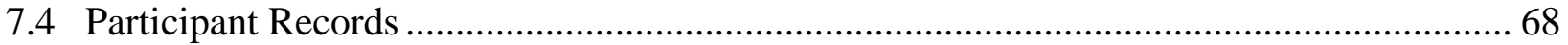

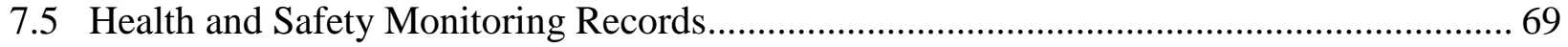

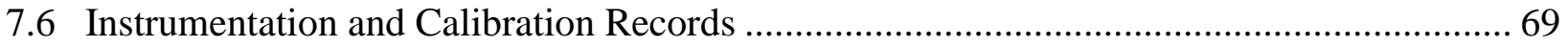

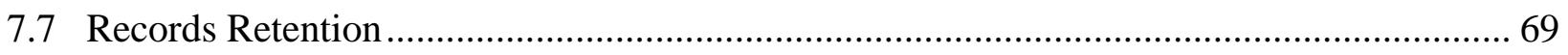

Acknowledgements........................................................................................................ 70

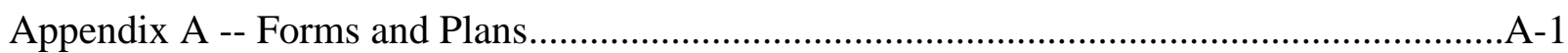

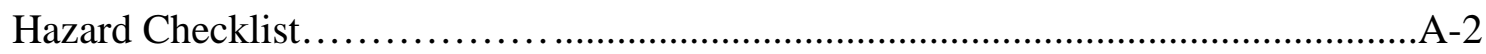

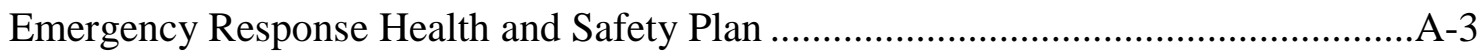

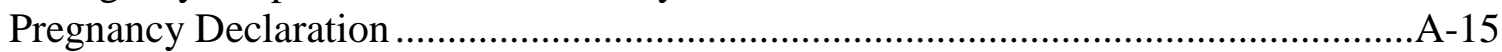

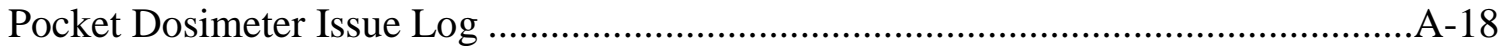

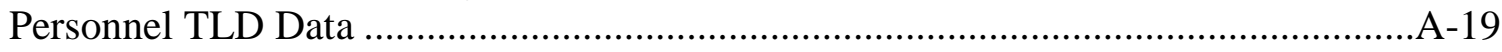

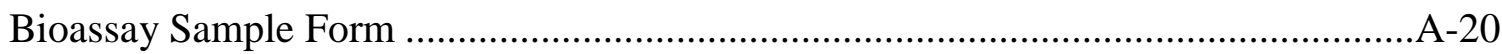

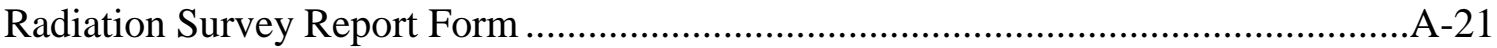

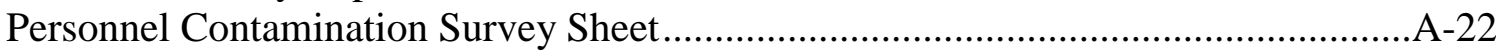

Medical Monitoring of Entry Team .......................................................................... 


\section{TABLES}

Table 2.1 Summary of Dose Limits ................................................................................ 8

Table 2.4.3a $\quad$ Radiation Area Limits.................................................................................. 24

Table 2.4.3b. Contamination Survey Limits .................................................................. 24

Table 2.5.1. Guidelines for Selecting Personal Protective Equipment .................................... 32

Table 2.8.3. $\quad$ LWR Core Damage Accident Turn-Back Guidance ............................................ 44 
ACRONYMS and ABBREVIATIONS

\begin{tabular}{|c|c|}
\hline AIHA & American Industrial Hygiene Association \\
\hline ALARA & as low as reasonably achievable \\
\hline ALI & annual limit of intake \\
\hline Anti-c & anti-contamination \\
\hline APR & air purifying respirator(s) \\
\hline $\mathrm{ARG}$ & Accident Response Group \\
\hline BZA & breathing zone area \\
\hline CAM & continuous air monitors \\
\hline $\mathrm{CDE}$ & committed dose equivalent \\
\hline CEDE & committed effective dose equivalent \\
\hline $\mathrm{cfm}$ & cubic feet per minute \\
\hline CL & confidence level \\
\hline $\mathrm{cm}$ & centimeters \\
\hline CRCPD & Conference of Radiation Control Program Directives \\
\hline DAC & derived air concentrations \\
\hline $\mathrm{dBA}$ & decibels \\
\hline DOE & U.S. Department of Energy \\
\hline $\begin{array}{l}\text { DOELAP } \\
\text { dpm }\end{array}$ & $\begin{array}{l}\text { U. S. Department of Energy Laboratory Accreditation Program } \\
\text { disintegrations per minute }\end{array}$ \\
\hline DRD & direct reading dosimeters \\
\hline $\mathrm{ED}$ & electronic dosimeter(s) \\
\hline ER & emergency response \\
\hline ERPG & Emergency Response Planning Guideline \\
\hline FRMAC & Federal Radiological Monitoring and Assessment Center \\
\hline GM & Geiger-Mueller \\
\hline $\mathrm{H} \& \mathrm{~S}$ & Health and Safety \\
\hline HazCom & Hazard Communication \\
\hline HEPA & high efficiency particulate air \\
\hline IDLH & immediately dangerous to life or health \\
\hline $\mathrm{KI}$ & potassium iodide \\
\hline$L_{C}$ & critical detection level \\
\hline$L_{D}$ & minimum significant activity level \\
\hline LLD & lower limit of detection \\
\hline lpm & liters per minute \\
\hline
\end{tabular}


ACRONYMS and ABBREVIATIONS (continued)

\begin{tabular}{|c|c|}
\hline $\mathrm{m}$ & meter \\
\hline MDA & minimum detectable activity \\
\hline MDD & minimum detectable dose \\
\hline $\mathrm{mph}$ & mile per hour \\
\hline $\mathrm{mR}$ & millirad \\
\hline mrem & millirem \\
\hline MSDS & material safety data sheets(s) \\
\hline $\mathrm{NIOSH}$ & National Institute of Occupational Safety and Health \\
\hline $\begin{array}{l}\text { OSHA } \\
\text { OSL }\end{array}$ & $\begin{array}{l}\text { Occupational Safety and Health Administration } \\
\text { optically stimulated luminescent }\end{array}$ \\
\hline PAPR & powered air purifying respirator(s) \\
\hline PAS & personal air samplers \\
\hline PEL & permissible exposure limit(s) \\
\hline PPE & personal protective equipment \\
\hline RAP & Radiological Assistance Program \\
\hline $\begin{array}{l}\text { REAC/TS } \\
\text { RF }\end{array}$ & $\begin{array}{l}\text { Radiation Emergency Assistance Center/Training Site } \\
\text { radio frequency }\end{array}$ \\
\hline SCBA & self-contained breathing apparatus \\
\hline$T_{B}$ & background count time \\
\hline TEDE & total effective dose equivalent \\
\hline TLD & thermoluminescence dosimeter \\
\hline TLV & Threshold Limit Value(s) \\
\hline$T_{S}$ & sample count time \\
\hline WGBT & wet globe bulb temperature \\
\hline $\mathrm{ZnS}$ & zinc sulfide \\
\hline
\end{tabular}




\section{Scope}

The Radiological Emergency Response Health and Safety Manual will be the document used for implementing radiological health and safety protection plans for Federal Radiological Monitoring and Assessment Center (FRMAC) and DOE Nevada asset deployments. This manual was written to comply with all applicable regulations. However, there is very little applicable formal guidance available, particularly for Chapter Two (Health Physics). Therefore that chapter is written to be compliant with existing radiological protection regulations (10 CFR 20 and 10 CFR 835) even though these regulations are intended for facility operations.

\section{Content}

This manual was created to provide health and safety $(H \& S)$ guidance for emergency response operations. The manual is organized in sections that define each aspect of $\mathrm{H} \& \mathrm{~S}$ Management for emergency responses. The sections are as follows:

- Responsibilities

- Health Physics

- Industrial Hygiene

- Safety

- Environmental Compliance

- Medical

- Record Maintenance

Each section gives guidance on the types of training expected for managers and responders, safety processes and procedures to be followed when performing work, and what is expected of managers and participants.

Also included are generic forms that will be used to facilitate or document activities during an emergency response. These ensure consistency in creating useful real-time and archival records and help to prevent the loss or omission of information.

\section{Application}

The manual describes how radiological health and safety plans will be implemented for FRMAC and DOE Nevada Operations asset deployments. The manual is designed for use during emergency response activities and for helping the responding organizations prepare for deployment. Since this manual was written to provide overall ER requirement guidance, certain sections will only apply to specific response situations. It is suggested that all management personnel study the manual prior to deployment in order to be prepared to provide instruction to responders on what is expected during deployment. It is suggested that all other deployed H\&S personnel also review the manual enroute to the deployment. 
Responders are expected to arrive fully trained. In the event of an emergency, there will be little time available to provide training to participants, and it is not advisable to send untrained workers into the field. Any organization, which deploys personnel to an emergency response, should establish a Deployment Authorization Program that tracks personnel's training and medical qualifications for deployment. This recommendation is especially true for personnel who may deploy outside the continental United States (OCONUS).

The definition of exposure limits is important for all personnel to understand. If these limits are understood prior to deployment, team members will be prepared to take the necessary actions to prepare for the limits. The circumstances and protocol for exceeding these limits are also defined. Managers can also provide the guidance required to address the needs of supporting operations.

\section{Summary}

As this is a DOE Nevada Operations Office publication it is directive in nature only to personnel, facilities and deployments under their authority. However, the manual is designed as a tool to help provide information to all responders and emergency planners and is suggested as a starting point for all organizations that provide personnel/assets for radiological emergency response. It defines the safety requirements for the protection of all participants required to respond to an emergency. Occupational exposure limits will apply in most situations. However, some responses may require the application of emergency exposure limit recommendations. The intent is to comply with appropriate regulations or provide an equal level of protection when the situation makes it necessary to deviate. When all else fails, an appropriate management level expert will define alternate requirements based on the specifics of the emergency situation. This manual is not intended to pertain to the general public. 


\subsection{Health and Safety Responsibilities}

An H\&S Manager will be assigned for all emergency response activities. The H\&S Manager is responsible for the health and safety of all personnel involved in operations. This section outlines the tasks associated with ensuring the health and safety of personnel throughout the duration of deployment.

The H\&S Manager reports to the senior management official and coordinates all H\&S issues. The H\&S Manager, or disignee, is also required to monitor and present the status of health and safety issues at the beginning of each shift and during shift safety briefings.

\subsection{Hazard Assessments}

Hazard Assessments are used to identify radiological, industrial hygiene, safety, and medical conditions, and are used to plan and control work as well as inform responders about work area conditions. A Hazard Checklist (Appendix A) provides a standard reference for the hazard identification process. All personnel shall be briefed on the hazards associated with operations.

\subsection{Site Health and Safety Plan}

An H\&S Plan will be developed for each deployment. Depending on the circumstances at the site, the plan may be as brief or complex as the situation warrants. The plan should identify hazards associated with the specific deployment and methods to mitigate those hazards.

The Emergency Response Health and Safety Plan (Appendix A) is a valuable template to be used upon arrival. This initial H\&S plan can be expanded or rewritten for a longer-term and/or more complex response. Computer software may be used to assist in developing the H\&S Plan.

\subsection{Daily Health and Safety Briefings}

Field teams will be briefed on a daily basis prior to the start of work. A recognized H\&S representative will conduct the briefing, and all responders for each shift are required to attend. The type of information to be included in the briefing follows.

\section{Scope of work to be performed}

Monitoring needs will vary depending on the emergency, the responding organization(s), and local emergency responders. The staff of the responding organization(s) may be 
required to operate in a wide variety of settings (in vehicles, in public facilities) and perform various functions, such as:

- Sample collection

- Area monitoring

- Monitoring in vehicles

- Personnel surveys

- In situ measurements

\section{Conditions of the deployment location}

Personnel should be aware of local surroundings. Weather conditions should be presented to personnel at regular intervals and as changing conditions warrant. Personnel should be briefed on local flora and fauna and any hazards they present.

During any emergency, the public may require attention and consideration. Responders could encounter panic and heightened emotional responses from the public. Traffic situations may require increased alertness and caution, particularly during initial response. If activities will require interaction with the public (e.g., getting a soil sample from a farmer's field) police, fire, or other local personnel should accompany the assigned monitoring team.

Existing radiological, chemical, biological or other hazards need to be communicated to monitoring teams. It allows them to be prepared for encountering any expected or possible circumstances such as:

- Climate (weather)

- Biohazards (snakes, ticks, etc.)

- Expected radiological contaminants/levels

- Expected chemical contaminants/levels

- Possibility of terrorist activity and use of weapons of mass destruction

- Traffic expected (is the area evacuated?)

- Response of local population

\section{Personal Protective Equipment (PPE)}

Field teams will be briefed on PPE requirements prior to potential exposure. Teams will be briefed on the PPE to be used for each hazard, as well as when to don and doff PPE, such as anti-contamination (anti-c) clothing and/or respiratory protection.

\section{Dosimetry}

Field teams will be briefed on the dosimetry requirements prior to any potential exposure and an H\&S representative will ensure personnel have the appropriate dosimetry, such as:

- Whole body dosimetry

- Supplemental dosimetry

- Neutron dosimetry 
- Extremity dosimetry

- Bioassay

- Personal air sampling

\section{Special hazard mitigation requirements}

Once existing or expected hazards are identified, the methods required to mitigate these hazards must also be communicated and provided. Work/rest regiments for hot or cold conditions should be identified and obeyed. Special clothing requirements for weather conditions should be identified and provided. Local climate conditions should be announced (e.g., roads that flood, roads that freeze, etc.). Traffic conditions and roads to be avoided based on traffic, climate, hazardous, and/or radiological conditions should also be noted, and include:

- Road safety

- Heat/cold/climate safety

\section{$\underline{\text { Hold points/ turn-around points }}$}

Turn-around or hold points will be established when the hazard exceeds the level of prescribed protection. Points shall be established for field teams where additional control (such as gloves/boots, anti-cs, or respiratory protection) will be required. The H\&S Manager will determine turn-around points based on expected conditions and risk involved, such as:

- Turn-back levels for radiological, chemical, heat/cold, etc.

- Call in points

- Access control points

\section{Emergency Procedures}

All personnel need to be made aware of emergency response procedures. This includes general reporting of fires or accidents and any unusual activities. Monitoring teams also need to understand proper handling of contaminated victims or materials.

\section{Debriefing}

Debriefing of participants should be incorporated into the daily routine (at the end of each shift) to identify hazards that should be discussed in the next shift's safety briefing. 


\section{CHAPTER 2}

HEALTH PHYSICS

\subsection{Radiation Protection: Exposure Limits}

The following are exposure limits for emergency response operations. The H\&S Manager, or designee, is responsible for assuring personnel understand and work within these requirements.

\subsubsection{Occupational Exposure Limits}

The annual maximum allowable sum of external and internal doses (total effective dose equivalent [TEDE]) for a radiological worker is 5 rem TEDE. An administrative limit of $2.5 \mathrm{rem}$ TEDE will be used. An investigation limit of $1.5 \mathrm{rem}$ TEDE will be used as a default value for emergency response operations. The administrative and investigative limits may be adjusted to replicate limits imposed by the respective host state, tribe, or country. The H\&S Manager may set lower administrative limits, based upon on-scene conditions. The senior management official must approve higher administrative limits. Additional dose limits are 15 rem for the lens of the eye, and 50 rem for the extremities, skin, thyroid, and other organs. The H\&S Manager must review any exposure above the investigation limit.

All response activities will be considered to be occupational exposure unless specifically designated as emergency activities. All responders with the potential to exceed 100 mrem will require dose monitoring. Responders will be asked to provide an estimate of annual year-to-date dose when dosimetry is requested. Any responder with a dose estimate greater than 2.5 rem (on arrival at the site), or no knowledge of dose history, will be limited to 100 mrem for response activities, until an official dose report is provided by the home organization.

\subsubsection{General Personnel Exposure Limits}

General personnel who have not completed appropriate training to perform radiological work are administratively limited to an annual dose of 0.1 rem.

\subsubsection{Pregnant Worker Policy}

A dose limit of 0.5 rem for the gestation period, or 0.05 rem per month, is established for pregnant radiation workers who have declared their pregnancy to the H\&S Manager in writing. The employee will be counseled regarding the risk of radiation exposure to the fetus. The Pregnancy Declaration (Appendix A) shall be used to document the declaration of pregnancy. The Declared Pregnant Worker Policy will be briefed during each field team briefing, as applicable. 


\subsubsection{Emergency Exposure}

Safety is the number one consideration in rescue and recovery operations. Management staff shall weigh actual and potential risks against the benefits to be gained. No individual shall be required to perform rescue actions that might involve substantial personal risk. Each individual authorized to perform emergency activities likely to result in occupational doses exceeding 5 rem shall be appropriately trained and briefed beforehand on the known or anticipated hazards. Table 2.1 provides a summary of dose limits.

The senior management official, or designee, must concur with any planned dose that exceeds the occupational limit. Emergency dose limits of 5 rem for basic work activities, 10 rem for protecting major property, and 25 rem for lifesaving or protecting large populations, are recommended only for emergency situations. Personnel will be subjected to doses above 5 rem on a voluntary basis only and must be informed of the risks associated with exposures exceeding 5 rem.

Table 2.1 - Summary of Dose Limits

\begin{tabular}{|c|c|c|}
\hline \multicolumn{2}{|c|}{ TYPE OF EXPOSURE } & ANNUAL LIMIT \\
\hline Radiological Worker*: & $\begin{array}{l}\text { Whole body (internal }{ }^{1}+ \\
\text { external) }\end{array}$ & $5 \mathrm{rem}$ \\
\hline Radiological Worker*: & Lens of eye & $15 \mathrm{rem}$ \\
\hline Radiological Worker*: & $\begin{array}{l}\text { Extremity (hands/arms below } \\
\text { the elbow; feet/legs below } \\
\text { the knees) }\end{array}$ & 50 rem \\
\hline Radiological Worker*: & $\begin{array}{l}\text { Any organ or tissue }{ }^{2} \text { (other } \\
\text { than lens of eye) and skin }\end{array}$ & $50 \mathrm{rem}$ \\
\hline Declared Pregnant Worker: & Embryo/Fetus & $\begin{array}{c}0.5 \mathrm{rem} \\
\text { (gestation period) }\end{array}$ \\
\hline $\begin{array}{l}\text { Minors/students } \\
\text { under age 18: }\end{array}$ & Whole body (internal + external) & $0.1 \mathrm{rem}$ \\
\hline Visitors ${ }^{\star *}$ and public: & Nhole body (internal + external) & $0.1 \mathrm{rem}$ \\
\hline
\end{tabular}

* Radiological workers are employees authorized to have unescorted access to radiological areas.

** Applies to visitors who have not been trained and must be escorted.

1. Internal dose to the whole body shall be calculated as committed effective dose equivalent. The committed effective dose equivalent is the resulting dose committed to the whole body from internally deposited radionuclides over a 50 -year period after intake.

2. The annual limit of exposure to "any organ or tissue" is based on the committed dose to that organ or tissue resulting from internally deposited radionuclides over a 50-year period after intake plus any external effective dose equivalent to that organ during the year.

Note: Exposures due to background radiation, therapeutic and diagnostic medical procedures, and voluntary participation in medical research programs shall not be included in either personnel radiation dose records or assessment of dose against the limits on this table. 


\subsection{Radiation Protection: Dosimetry}

Any participant with the potential to receive doses (TEDE) in excess of 100 mrem for the response period is required to participate in the dosimetry program. The type of dosimetry required will depend on the situation at the site of deployment.

For a Federal Radiological Monitoring and Assessment Center (FRMAC) response, a thermoluminescence dosimeter (TLD) badge processed by a U. S. Department of Energy Laboratory Accreditation Program (DOELAP) accredited processor, will be provided to all participants. FRMAC will provide a dose report to each participant's home organization after the conclusion of the individual's activities. A responder has the option to wear their home organization's dosimeter in addition to the FRMAC issued dosimeter. Each participant should wear their home organization's dosimeter in accordance with their home organization's policy.

\subsubsection{External Dosimetry}

Whole body dose due to gamma radiation will typically be measured through the use of TLDs and Direct Reading Dosimeters (DRDs). Some response organizations may use optically stimulated luminescent (OSL) dosimeters or film. Dosimeters will be provided and issued by the H\&S staff. DOELAP-accredited neutron dosimeters will be issued to an individual, if there is a potential to receive a neutron dose in excess of $100 \mathrm{mrem}$. DOELAP accredited extremity dosimeters will be issued when an extremity dose has the potential to exceed whole body dose. Electronic dosimeters (EDs) with the capability to alarm at preset exposure levels will be used when a potential exists for exposures above 1 $\mathrm{R} / \mathrm{hr}$ or $500 \mathrm{mR}$ cumulative exposure per shift, unless directed otherwise by H\&S staff.

The TLDs and DRDs will be issued and exchanged only by the H\&S staff at designated locations. Personnel must provide their name, social security number, home organization, and estimated year-to-date TEDE to the H\&S staff. Key information, including the identification number of the dosimeter issued and the time/date, will be recorded on the Pocket Dosimeter Issue Log or the Personnel TLD Data Sheet (Appendix A).

Guidance for wearing an external dosimetry device includes:

- The dosimeter must be worn on the chest area on or between the waist and the neck unless otherwise instructed by H\&S personnel.

- The dosimeter is to be worn only by the individual to whom it was issued.

- Lost, damaged, or contaminated dosimeters must be reported immediately to the H\&S staff. If a participant discovers that his/her dosimeter is missing while in a radiological area, he/she shall immediately notify the team leader and report the missing dosimeter to the H\&S Manager. A new dosimeter will be issued by H\&S.

- Dosimeters must be returned or exchanged at the time designated by the H\&S Manager, upon request, or at the end of the operation. 
Upon return of the dosimeters, H\&S staff must log in the time/date of return. The TLDs will be sent to the DOELAP accredited responsible laboratory for processing. Directreading dosimeters must be returned and read at the end of each shift by the H\&S staff. The exposure data shall be recorded for each individual. If a participant's DRD indicates an exposure over $0.5 \mathrm{rem}$, the $\mathrm{H} \& \mathrm{~S}$ staff member recording the results must immediately notify the H\&S Manager. Dose-of-record will be tracked by the processing laboratory, while initial exposure estimates will be tracked by the H\&S staff.

\subsubsection{Internal Dosimetry}

Participants who are exposed to loose radioactive material or work in areas where radioactive material may be inhaled, may be asked to submit bioassay samples and participate in whole-body, lung, or wound counting. The evaluation of an individuals Committed Effective Dose Equivalent (CEDE) will be based on bioassay data rather than air concentration values unless bioassay data are unavailable, inadequate, or internal dose estimates based on representative air concentration values are demonstrated to be as or more accurate.

A site-specific Bioassay Plan will be developed and included in the H\&S Plan. Preliminary CEDE estimates, based upon air sampling results, will be performed by an H\&S staff health physicist. Dose assessments, based on bioassay results, will be assigned after samples have been collected and analyzed.

Samples should be sent to a U.S. Department of Energy (DOE) accredited processing laboratory. After processing, CEDE can be determined by the internal dosimetrist at the laboratory facility, by an H\&S Staff Health Physicist, or by the individual's home organization Health Physics Staff (preferred).

Personnel shall be notified promptly of positive bioassay results and the results of dose assessments and subsequent refinements. Dose assessment results shall be provided in terms of rem or mrem.

\section{Bioassay Assessment Methods}

Bioassay is the term that is used to describe the assessment of the quantity of radioactive material present in the body. There are currently two types of bioassay measurements employed in nuclear industries: in vivo and in vitro. In vivo bioassay involves counting the living tissue. In vitro involves counting an excreted sample, such as urine. Personnel shall submit bioassay samples (urine and fecal samples) and participate in bioassay monitoring (whole body or lung counting), at the frequency specified by the bioassay program.

Bioassays may be required during general operations or may be initiated in response to an occurrence to determine if there has been an intake of radioactive material. Bioassay sampling may be requested to provide follow up to a known intake in order to quantify the intake and to monitor the status of the radioactivity to refine the dose assessment. 
Whether or not bioassay is warranted is usually based on the following, though bioassay may be requested as a precautionary measure at the discretion of H\&S staff in the field:

- How much material was released and what is the respirable fraction?

- How long was the person in an airborne radioactivity area?

- Were respiratory protection and anti-contamination measures employed?

Identifying the proper bioassay technique to use is aided by knowledge of the types of contamination present in a particular work area. Contamination control measures cannot be too stringent during collection, handling, and analysis of bioassay samples. Crosscontamination can cause erroneous assumptions and inaccurate dose assessments.

\section{In Vivo Measurements}

In vivo techniques consist of direct measurements of gamma or X-radiation emanating from the body. Because participants will be arriving from multiple deployment points, obtaining in vivo baseline bioassays will often be impractical. However, this method is very useful for any radionuclide which emits (or has daughters which emit) photons of sufficient energy to escape the body. The photon fluence must be large enough for measurement in a reasonable time period, even though the quantity of material in the organ is very small.

In vivo measurements may also be useful for thyroid, wound, or post-intake whole-body counting. Whole body counts, lung counts, thyroid counts, and biological sampling should be performed as soon as practical after a suspected intake of a photon emitter. Some examples of appropriate non-routine in vivo bioassays are:

- Lung counts following a suspected intake of thorium, uranium or any of the transuranics (though not as sensitive as analysis of bioassay samples)

- Whole body counts for detecting most gamma-emitting fission and activation products

- Thyroid counts for suspected radioiodine uptakes

- Urine and feces sampling and whole body counting to detect and assess intakes of the actinides.

The in vivo method is possible only for those radionuclides emitting penetrating radiation, (e.g., Co-60 and Cs-137) or bremsstrahlung, (e.g., P-32 and Sr-90). Many radionuclides (Na-22, Fe-59, Co-60, Zn-65, Rb-86, Sr-85, Te-132, I-131, Cs-137, Ba-140, Ce-144, $\mathrm{Au}-198, \mathrm{U}-235, \mathrm{~Np}-239$, and Am-241) emit electromagnetic radiation of sufficient energy to be measured by external counting. Such measurements are more acceptable to the person than the provision of samples of excreta, although they do require the person to be absent from work during the period of measurement. 


\section{In Vitro Measurements}

The amount of material present in the body is estimated using the amount of materials present in excretions or secretions from the body. Samples could include urine, blood, breath, sputum, sweat, saliva, hair, nasal discharges, tissue, and feces. Fecal bioassays are typically used for alpha-emitting radionuclides if a lower minimum detectable activity is required. However, due to the rapid deployment, acquiring fecal samples may also be impractical.

Urine bioassays will be the sampling method of choice for most applications. As a default, a one-liter (or 24-hour) sample should be collected prior to exposure to contaminants (as practical), every two weeks and at the conclusion of activities. Sampling frequencies can be adjusted, based upon the unique circumstances. A Urine bioassay may be required for detection of pure beta-emitters such as $\mathrm{Sr}-90$ and $\mathrm{Sr}-89$.

Calculation requires knowledge and use of metabolic models, which allow sample activity to be related to activity present in the body. The resulting dose calculations used to quantify committed and effective dose equivalents are estimates, representing an "average". This is due partly to use of default values for measurements that cannot be readily made (such as mass of particular organs, volumes of particular fluids, metabolism rate, etc.) in lieu of actual values for each individual involved.

\subsection{Air Monitoring}

Since committed dose equivalent (CDE) and CEDE is generally dominated by the inhalation pathway component, dose estimates can be made by using air-sampling data. Air monitoring is performed to assess airborne contaminants. Though directed primarily toward monitoring of airborne radiological contaminants, much of this section also applies to toxicological hazards.

Monitoring of airborne radioactivity should be conducted to characterize potential exposure conditions, verify the effectiveness of any engineering and administrative controls, and estimate daily CEDE and/or CDE from inhaled radionuclides. It is important to note that the CEDE and CDE are not normally determined from air sampling analysis data, unless other information, such as bioassay data, is unavailable, inadequate, or internal dose estimates based on representative air concentration values are demonstrated to be as, or more, accurate.

The primary goal of the air monitoring program is to determine if the level of protection provided to the worker is sufficient to minimize the internal dose equivalent. Allowable concentration values, such as derived air concentrations (DACs), are used as an index of the degree of control needed and achieved. Documented measurements of the airborne radioactivity concentrations are required to demonstrate that satisfactory control is achieved and maintained.

For many operations, Personal Air Samplers (PAS), sometimes called breathing zone area (BZA) samplers, will yield the most useful data for estimating dose. When counting samples caution should be taken to account for radon and thoron progeny present on 
samples. Results may be influenced for several days until the radon and thoron progeny decays. While the effect is significant for any sample, it is particularly a problem when analyzing for radionuclides with low DACs such as ${ }^{239} \mathrm{Pu}$.

Air sampling is required when the potential exists for air concentration intake results to exceed $2 \%$ of the annual limit of intake (ALI) (40 DAC-hours). Other reasons to sample are:

- To determine the need for respiratory protection of workers

- To assist in determining the type and frequency of bioassay measurements needed for a worker to provide an estimate of worker exposures for situations where bioassay measurements may not be available or their validity is questionable.

Personal air samplers, high-volume area air samplers, or continuous air monitors (CAMs) may be used to measure the concentration of airborne radioactive material.

Personal air samplers generally yield the most representative data for estimating personnel exposures. High-volume area samples will yield better statistical results than PAS (greater volume sampled). However, they may not be good indicators of airborne radioactivity in a person's breathing zone. This is especially true in outdoor environments where air patterns cannot be accurately predicted. Breathing zone air monitoring should be performed continuously in areas where workers are likely to exceed 40 DAC-hr exposure in a year. Breathing zone air monitoring is used to identify possible internal exposure risks for workers and the need for follow-up bioassay measurements.

Grab-air sampling is used for temporary or non-routine (e.g., emergency response) situations and as a backup for other types of air sampling in the event of equipment failure. Portable air sampling equipment is typically used for operations requiring a grab sample. Sample flow rates may vary depending upon the specific application, but should always allow collection of a sample volume adequate to ensure that the minimum detectable activity of the sampling and counting system is no greater than concentrations which result in intakes exceeding $2 \%$ of the annual limit of intake (ALI)(40 DAC-hours).

The PAS are small, portable, battery-powered devices which sample the air in the breathing zone of the worker's environment, reducing the degree to which the samplers may interfere with a worker's activities. Some characteristics are:

- The device contains a small battery-powered pump that is calibrated to a flow rate approximately $1 / 10$ (2 liters per minute) the breathing rate of a worker performing light activity.

- The sampling line terminates in a filter cassette, which contains the filtration medium for the radioactive particulate contaminants.

- The sample filter cassette is attached as near as possible to the breathing zone of the individual, typically on the lapel or upper quarter of the torso. 


\section{High Volume/Flow Rate Samplers}

High volume/flow rate samplers provide an estimate of the airborne radioactivity concentration at a particular location in a short period of time. Portable high-flow rate samplers are used to collect airborne aerosols on a filter paper (filtration) or on a greased planchet (impaction). Portable high-flow rate samplers can also be used to collect radioiodine samples using activated charcoal cartridges (adsorption) as long as the maximum flow rate of the cartridge is not exceeded or a correction factor is used. These samplers do not have installed detectors and the sample must be removed from the sampler and analyzed on separate analysis equipment. The high volume/flow rate samplers may:

- Provide a routine "slice-of-time" estimate of the general area airborne radioactivity

- Verify boundaries of areas posted for airborne radioactivity

- Monitor the airborne radioactivity related to a specific work activity.

High volume samplers typically use flow rates of at least 10 cubic feet per minute (cfm). Although these samplers are noisy and not intended for continuous duty, the shorter sample times allow for greater sensitivity.

\section{Low Volume/Flow Rate Samplers}

Low volume/flow rate samplers provide an estimate of airborne radioactivity concentrations averaged over a longer period of time at a particular location. Portable low volume/flow rate samplers are used to collect samples for aerosols on filter paper (filtration) and radioiodine on an adsorption medium, such as an activated charcoal cartridge. Low volume/flow rate samplers may be used to provide average airborne radioactivity estimates over a period of time for:

- Commonly traversed areas that normally have a low probability of airborne radioactivity problems

- Areas not commonly traversed with a higher probability of airborne radioactivity problems

- Back up samples in areas where airborne radioactivity problems are discovered by other means.

Low volume samplers generally have flow rates set at approximately 0.5 to $5 \mathrm{cfm}$, often matching the breathing rate of a worker performing light activity (20 liters per minute [lpm]). Although these samplers must run longer for reasonable sensitivity, they are generally quiet and can be used for continuous duty.

\section{$\underline{\text { Portable Continuous Air Monitors }}$}

Portable CAMs provide an estimate of airborne radioactivity concentrations averaged over time at a particular location, and provide immediate readout and alarm capabilities for preset concentrations. These air monitors are portable low-flow rate sampling systems, containing the necessary sampling devices and built-in detection systems to monitor the 
activity on the filters, cartridges, planchettes, and/or chambers in the system. The system may provide a visual readout device for each type of sample medium, a recording system for data, and computer functions such as data trending, preset audible and visual alarms/warning levels, and alerts for system malfunctions. Typical CAMs provide information on alpha and/or beta/gamma particulates (filtration), radioiodine activity (adsorption), and noble gas activity (volumetric chamber or in-line detector). Portable CAMs can be utilized as:

- Monitors with alarm capabilities for areas where airborne radioactivity conditions may quickly degrade

- Trending devices in selected areas.

Continuous air monitors are useful where airflow patterns are well established, but have limited use in outdoor environments with changing airflow patterns. However, progress has been made on environmental CAMs that allow data transmission over a radio frequency $(\mathrm{RF})$ link, thus permitting users to assess airborne radioactivity concentrations in real time and at a distance.

\subsubsection{Assessment of Air Monitoring Needs}

It is critical that the proper air sampling method and equipment be selected because the data obtained must be meaningful and accurate to adequately assign radiological control measures. Improper selection and use may incorrectly indicate a safe environment where an airborne radiological hazard exists or leads to unneeded actions where no hazard exists. There are several factors to consider when selecting an air sampling method.

\section{The environmental conditions in the area where the sample is to be obtained}

Humid conditions may preclude the use of some methods, such as paper filtration devices or charcoal canisters, because water vapor loading of the medium will change the collection efficiency and flow rate. High temperature environments may cause some samplers to overheat if run for long periods of time. Explosive gases may be present which could present an explosion hazard for samplers with electric motors not designed for such environments. Dusty areas could cause excessive sample loading, which will reduce sampler flow rates and potentially overheat the sampler. Corrosive environments may lead to the deterioration of the sampling device.

\section{The physical characteristics of the area in which the sample is to be obtained.}

An electrical outlet may not be available or close, and a battery-powered sampler or portable generator may be required. If portable generators are used ground fault circuit interrupters shall be employed. Care should be taken while fueling hot generators. The generator should be turned off during refueling and a fire extinguisher should be available. When extension cords are used, care should be taken not to exceed the load capacity of the cord. Close spaces or passages may preclude the use of movable CAMs or heavy samplers. 


\section{The expected concentration level}

This will determine the length of sample time and type of sampler required. Low-level concentrations will require large volumes to reduce statistical errors and meet minimum sensitivity levels of the analysis equipment. When large volume samples must be taken over a long time period it is best to use samplers designed to run for long periods. If immediate readout of information is needed, an initial screening can be performed in the field. If not, then samples may be taken and removed to a central analysis location.

\section{The physical state of the airborne contaminant}

The sampler and sample medium required is dependent upon whether the contaminant is gas, vapor, or aerosol.

\section{The type of survey required}

The type of survey required will be dictated by the type of samples needed (breathing zone samples, routine general area samples, general work area samples, general area trending over time, etc.). This will also determine the type of equipment that is selected.

Air monitoring will be performed to monitor the workplace concentrations of airborne contaminants. Airborne contamination surveys of accessible areas will be performed as follows:

- During any work or operation known or suspected to cause airborne contamination, such as any grinding, welding, burning, cutting, vacuuming, sweeping or use of compressed air. Decontamination work with volatile chemicals on contaminated equipment or during waste compacting operations is also included.

- During initial entry (and periodically thereafter), into any area known or suspected to contain airborne radioactivity concentrations in excess of $10 \%$ of a DAC.

- During initial entry (and periodically thereafter) into any area known or suspected to contain an appreciable area of loose surface contamination in excess of 5,000 disintegrations per minute $(\mathrm{dpm}) / 100$ centimeters $(\mathrm{cm})^{2}$ alpha or $50,000 \mathrm{dpm} / 100 \mathrm{~cm}^{2}$ beta/gamma. These levels are based on ${ }^{239} \mathrm{Pu}$ and ${ }^{90} \mathrm{Sr}$, respectively. If lower hazard contaminants are involved, the levels may be increased accordingly.

- Immediately following the discovery of a significant spill or spread of radioactive or toxic materials or any other time airborne contamination levels may have increased.

- Periodically in radiological areas where the potential for airborne radioactivity exists.

\subsubsection{Representative Samples}

Several factors must be considered to maximize the efficiency of airborne radioactivity detection. Self-absorption losses (e.g., dust loading) should be minimized. This is especially critical for alpha radiation detection. Air in-leakage between the sample intake 
and the sample collection medium should be eliminated to the greatest degree possible. Finally, the sample collection system and mechanisms within the instrument should be designed and constructed to minimize deterioration and to facilitate decontamination. This is more critical in areas with corrosive atmospheres.

When obtaining an air sample be sure to take the sample at the point of interest (the breathing zone). Depending on the source of the airborne contaminant, the concentrations within a work area can vary over several orders of magnitude. The sample taken should be representative of the air entering the nose and mouth of the individual workers since the data obtained may be used to estimate potential worker intakes. Obviously, the best sampling method then is to sample the air as near as possible to the breathing zone of the individual (typically on the lapel or upper quarter of the torso).

This sampling method may not always be practical and general work area sampling may be the alternative. Care must be exercised in the selection of the number and placement of the general area air samplers to ensure that the sample is as representative as possible.

\subsubsection{Calibration of Air Sampling Instruments}

It is anticipated that Mine Safety Application PAS (or equivalent) will be used. The PAS will be calibrated and inspected monthly, with maintenance being performed as needed. If other PAS are used, they will be calibrated and maintained in accordance with manufacturer's instructions. If the manufacturer does not provide calibration instructions, calibration will be performed before and after each use.

\subsubsection{Counting Procedures}

Filters should be counted using a scaler which allows counting of both alpha and beta types of radiation. Scalers should be operated in accordance with counting swipe samples (see Instrument Section 2.6). Care should be taken to account for the presence of radon and thoron progeny. Three methods are possible:

1. Samples can be counted via alpha or gamma spectroscopy. This would allow the radon and thoron progeny contribution to be determined and accounted for. This solution would yield the most accurate results in the least amount of time. However it would require additional counting equipment and staff training to operate the equipment.

2. Counting could be delayed to allow for decay of the radon and thoron progeny. Though this is generally the most common solution, there is a time delay in producing useful data.

3. One of several multi-count methods could be used to determine the radon and thoron progeny component of the total alpha/beta count. These methods are labor intensive, as they require multi-counts at specific time intervals. Though the radon and thoron progeny component can be determined, the statistical errors incurred can be significant. 


\subsubsection{Estimating Dose Based on Air Sampling Data}

The analysis of the sample provides the activity of the sample at the time of the sample analysis. This value may be corrected for decay from when the sample was taken to when it was analyzed.

The sample volume must be determined from the recorded sample data (flow rates at the beginning and end of the sample, and sample time period). The conversions necessary for the desired units such as dpm/liter to $\mu \mathrm{Ci} / \mathrm{cc}$ must also be included in the basic calculation below.

$$
\text { CONCENTRATION }=\frac{\text { decay corrected activity }}{\text { sample flow rate } x \text { sample time period }}
$$

The calculation would also include correction factors, as necessary, for:

- Interference of other radionuclides, such as radon and thoron daughters

- Collection efficiency

- Counter efficiency

- Self-absorption by the sample media

- Counter background

- Temperature and pressure as applied to flow rate.

Many errors are inherent or induced in the sampling analysis process and affect the accuracy of the resulting data. The operator of the sampling and analysis equipment must be aware of these points of error to ensure the resulting data is as accurate as possible. Quality assurance that is applied to all phases of the air-monitoring program will minimize many errors.

\section{Documenting Results}

The results of airborne radioactivity surveys shall be documented and retained in accordance with Section 7. Each record shall include the following (or data from which the following can be derived):

- Date and time the air sample was taken (both start and stop date/time)

- The location of the air sample

- The volume of air sampled

- The results of the sample counting

- The instrument number of the air sampler used

- The instrument number of the counter(s) used

- The name of the person obtaining the sample

- The name of the person counting the sample.

The air-monitoring program for radiological operations (occupational, not environmental) primarily consists of breathing zone area monitoring (personal air samplers) and high- 
volume area monitoring. Both types require some calculations to determine useful information (dose, percent DAC, etc.).

Breathing zone area monitoring is used both to determine respirator needs and to estimate committed dose. Each application requires a different type of calculation. Respirator needs are determined using the equation above. If the resulting concentration is greater than $10 \%$ of the DAC, then respiratory protection is required. Committed dose is estimated using Allowable Limit of Intake (ALI) and the ratio of air sampling rate ( $2 \mathrm{lpm}$ for BZAs) to the average breathing rate of reference man $(20 \mathrm{lpm})$ or $\sim 0.1 \times$ ALI or using DAC-hrs exposure.

\section{ConversionFactor $($ dpm $/$ mrem $)=(A L I / 5,000 \mathrm{mrem}) *($ PASrate/breathingrate $)$}

This calculation can be used to assign dose, provided there is no background subtraction. Background subtraction requires a dose calculation based upon DAC hours and will not generally be used.

\subsection{Contamination Control}

Contamination control is required when either radiological or chemical contamination is detected.

\subsubsection{Radiological Contamination Monitoring}

In order to acquire the radiological information necessary for contamination control, there are several components to a radiological monitoring program. These include:

- Area and equipment surveys

- External personnel surveys.

\subsubsection{Area and Equipment Surveys}

Area and equipment surveys are conducted routinely both in the field and around the deployment location, to locate sources of contamination and to detect potential changes in radiological conditions. Pre-job surveys are performed prior to work in radiological areas (when practical) in order to evaluate the hazards and determine work limitations and physical safeguards.

\section{Direct instrument surveys}

Various types of portable survey instrumentation are used to measure the presence of radioactive contamination on the ground, a floor or other surface. This is the only method available to detect "fixed" surface contamination; however, this method will detect removable contamination activity as well. As a result, a direct survey is often combined with a "smear" survey to determine if the surface contamination present is removable or fixed. Measurement of positive ground contamination does not warrant smear surveys to determine if contamination is removable or fixed. 


\section{Smear surveys}

Smear surveys are required before the release of equipment, vehicles, etc. A disk smear is wiped over an area of 100 square $\mathrm{cms}$ and counted by using specific instrumentation to determine the activity of the nuclides present. Contamination levels are specified in units of $\mathrm{dpm} / 100 \mathrm{~cm}^{2}$ after applying applicable instrument correction factors. For objects less than $100 \mathrm{~cm}^{2}$, the units are reported as dpm/object area. Disk smears are small so they are usually used in an area of suspected contamination. An experienced surveyor can deduce where contamination is most likely to occur and survey those areas with disk smears. Disk smears are required if contamination levels are to be quantified.

\subsubsection{External Personnel Surveys}

Personnel surveys are performed whenever contamination of the body or clothing is suspected, or as required for exit monitoring. Personnel surveys may be conducted by the individual (self-monitoring) using hand-held or automated instruments, or by the $\mathrm{H} \& \mathrm{~S}$ staff. Self-monitoring is typically performed upon exiting a contaminated area at established boundary points. Personnel monitoring by an H\&S staff member is usually conducted whenever contamination of the body or clothing is suspected, or as required by exit monitoring when self-monitoring is not feasible (remote location) or not allowed. Portable instruments with sensitive hand-held detectors are used by personnel to identify contamination (on them) whenever contamination is suspected. These monitors are used whenever exiting contaminated regions. Geiger-Mueller (GM) detectors are most often used for beta-gamma monitoring and scintillation detectors for alpha monitoring.

\subsubsection{Methods of Contamination Control}

For an emergency response, contamination control refers to both an impacted area and support resources. Field teams will have a high probability of encountering radioactive contamination. They should incorporate contamination control into their work routines to minimize their potential dose, prevent contamination of their equipment, and to reduce cross-contamination of samples. Contamination control is also an integral part of support resource operations. Operations conducted at the hotline (personnel, sample, equipment, etc.), decontamination activities, and laboratory activities can be impacted by spread of radioactive contamination.

Once the presence of radioactive material has been located, the basic goal underlying any effective contamination control program is to minimize contaminated areas and maintain contamination levels as low as reasonably achievable (ALARA).

In some situations, this is not always possible due to economic conditions and/or radiological conditions. For example, the cost of time and labor to decontaminate a location(s) may out-weigh the hazards of the contamination present. Or perhaps radiation dose rates or other radiological conditions present hazards which far exceed the benefits of decontamination. Other means of contamination control must be initiated when decontamination is not possible. Engineering control (dust control/containment), administrative procedures, and PPE are alternatives. 
Good housekeeping is critical to an effective contamination control program. It involves the cooperation of all personnel and groups within the facility. A sound preventive and corrective maintenance program can prevent the spread of radioactive material and help to confine contamination to the smallest possible area. All material taken into or out of contaminated areas must be controlled, and H\&S staff can assist with implementing controls or identifying violations of the basic principles of contamination control.

Controlling the spread of contamination will be one of the most difficult and challenging tasks encountered. The H\&S staff will assist the monitoring group with using the following basic principles of contamination control:

- Access/administrative controls

- Engineering controls

- Protective measures for personnel

- Decontamination guidance

- Preventive methods.

\subsubsection{Access/Administrative Controls}

Once contamination has been located and impacted areas have been determined, access control to these areas must be adequately established. For areas that are identified and under direct control of $\mathrm{H} \& \mathrm{~S}$ personnel, an access control point is set up to control access between contaminated areas and non-contaminated areas. Yellow and magenta rope, chain, tape or other effective barriers may be used to identify the boundaries and provide a recognizable visual barrier. When the radiological conditions are severe, an H\&S staff member may continuously monitor the access control point.

In circumstances where a large area is impacted, access control, as stated above, may be impractical. Radio communication and work direction to field teams will be used to control response personnel access to impacted areas. Law enforcement personnel and/or National Guard personnel may be used to restrict public access.

All materials exiting the area shall be monitored to ensure they are below acceptable levels of contamination. All unmonitored tools and/or equipment used in a contaminated area should be placed in clean plastic bags or securely wrapped in plastic before being removed from the area and label accordingly.

Another administrative control used for contamination containment is to perform routine surveys in order to detect trends in the movement and/or buildup of contamination.

\subsubsection{Engineering Controls}

\section{Containment}

On tasks with very high contamination potential, a plastic tent (greenhouse or hut) can be built around a work area to confine all contamination to as small an area as possible. A portable ventilation exhaust system (such as high efficiency particulate air [HEPA]) may 
be used to control airflow in the work area and remove airborne contamination. Small containment devices, such as glove boxes, glove bags, or hoods can be used to contain the contamination, depending on the nature and location of the work being performed. Drums or other approved containers can also utilized.

\section{Bagging}

The most widely used method of containment is bagging or wrapping. Contaminated tools or equipment are placed in plastic bags, or securely wrapped in plastic, before being moved outside a contaminated area. When possible, wrapping tools or equipment prior to entry can help control contamination during use inside the contaminated area.

\subsubsection{Personal Protective Measures}

The purpose of protective clothing is to keep contamination off the skin and clothing of the workers. Protective clothing allows personnel to work in a contaminated area with removable contamination and to exit the area without spreading contamination to uncontrolled areas. The use of PPE alone will not guarantee complete elimination of personal contamination and is not a substitute for implementing proper controls, but if used properly, protective clothing will afford a high degree of protection.

Any personnel entering areas with removable contamination may be required to wear certain items of protective clothing. The types of clothing required will vary depending upon the contamination levels and the nature of the work to be performed. Some additional factors for the selection of protective clothing include the type and form of contamination, potential for increased levels of contamination, area of the body at risk, and competing hazards (e.g., heat stress, asbestos, etc.).

In the majority of situations, some type of respiratory protective equipment will be required for work in areas where very high contamination levels exist or airborne contamination is present.

\subsubsection{Decontamination Guidance}

Reasonable efforts should be made to decontaminate or unconditionally release items, rather than dispose of them as radioactive waste. When the risks or costs faced during item decontamination outweigh the benefits gained by decontaminating the item for reuse, the item should be disposed of properly instead.

\subsubsection{Preventive Methods}

The following are practical methods used for the prevention/control of contamination:

- Establish adequate work controls before starting tasks.

- While conducting pre-work briefs, discuss measures that will help reduce or prevent contamination spread. 
- Change out gloves or protective gear as necessary to prevent cross-contamination of equipment.

- Pre-stage areas to prevent contamination from spreading outside of the work activity area.

- Cover/tape tools or equipment used during tasks to minimize decontamination after use.

- Control and minimize all material taken into or out of contaminated areas.

\subsubsection{Limits}

Any area in which radiation levels exceed those in Table 2.4.3a will be considered a Radiation Area and controlled accordingly. Any area in which contamination levels exceed Table 2.4.3b will be considered a Contamination Area and controlled accordingly.

Table 2.4.3a. Radiation Area Limits*

\begin{tabular}{|l|c|c|}
\hline \multicolumn{1}{|c|}{ Area } & Level & Distance \\
\hline Radiation Area & $5 \mathrm{mrem} \leq \mathrm{X} \leq 100 \mathrm{mrem}$ in one hour & $30 \mathrm{~cm}$ \\
\hline High Radiation Area & $\begin{array}{c}100 \mathrm{mrem}(\text { at } 30 \mathrm{~cm})<\mathrm{X} \leq 500 \text { rad in } \\
\text { one hour (at } 1 \mathrm{~m})\end{array}$ & $30 \mathrm{~cm}, 1 \mathrm{~m}$ \\
\hline Very High Radiation Area & $\mathrm{X}>500$ rad in one hour & $1 \mathrm{~m}$ \\
\hline
\end{tabular}

*based upon 10 CFR 20 and 10 CFR 835

Table 2.4.3b. Contamination Survey Limits*

\begin{tabular}{|c|c|c|c|}
\hline $\begin{array}{l}\text { NUCLIDE } \\
\text { (see Note 1) }\end{array}$ & $\begin{array}{c}\text { REMOVABLE } \\
\left(\mathrm{dpm} / 100 \mathrm{~cm}^{2}\right) \\
(\text { see Note } 2)\end{array}$ & $\begin{array}{c}\text { TOTAL } \\
\text { Fixed \& Removable } \\
\left(\mathrm{dpm} / 100 \mathrm{~cm}^{2}\right) \\
(\text { see Note } 3) \\
\end{array}$ & $\begin{array}{c}\text { Hot Spot } \\
\text { Fixed \& Removable } \\
\text { (see Note 3) }\end{array}$ \\
\hline $\begin{array}{l}\text { U-natural, }{ }^{235} \mathrm{U},{ }^{238} \mathrm{U} \text { and associated } \\
\text { decay products }\end{array}$ & $1,000 \alpha$ & $5,000 \alpha$ & $15,000 \alpha$ \\
\hline $\begin{array}{l}\text { Transuranics, }{ }^{226} \mathrm{Ra},{ }^{228} \mathrm{Ra} a{ }^{230} \mathrm{Th}, \\
{ }^{228} \mathrm{Th},{ }^{231} \mathrm{~Pa},{ }^{227} \mathrm{Ac},{ }^{129} \mathrm{I},{ }^{125} \mid\end{array}$ & 20 & 100 & 300 \\
\hline $\begin{array}{l}\text { Th-nat, }{ }^{232} \mathrm{Th},{ }^{90} \mathrm{Sr},{ }^{223} \mathrm{Ra},{ }^{224} \mathrm{Ra}, \\
{ }^{232} \mathrm{U},{ }^{226}\left|,{ }^{131}\right|,{ }^{133} \mid\end{array}$ & 200 & 1,000 & 3,000 \\
\hline $\begin{array}{l}\mathrm{B}+\gamma \text { emitters (nuclides with decay } \\
\text { modes other than } \alpha \text {-emission or } \\
\text { spontaneous fission) except }{ }^{90} \mathrm{Sr} \\
\text { and others noted above. Includes } \\
\text { mixed fission products containing } \\
{ }^{90} \mathrm{Sr} \text {. }\end{array}$ & $1,000 ß+\gamma$ & $5,000 ß+\gamma$ & $15,000 B+\gamma$ \\
\hline $\begin{array}{l}\text { Tritium organic compounds, } \\
\text { surfaces contaminated by HT, HTO } \\
\text { and metal tritide aerosols }\end{array}$ & 10,000 & 10,000 & 30,000 \\
\hline
\end{tabular}

${ }^{*}$ From 10 CFR 835 and NRC Regulatory Guide 1.186 
Note 1. The values in the above Table apply to radioactive contamination deposited on, but not incorporated into the interior of the contaminated item. Where surface contamination by both alphaand beta-gamma-emitting nuclides exists, the limits established for the alpha- and beta-gammaemitting nuclides apply independently.

Note 2. The amount of removable radioactive material per $100 \mathrm{~cm}^{2}$ of surface area should be determined by swiping the area with dry filter or soft absorbent paper while applying moderate pressure and then assessing the amount of radioactive material on the swipe with an appropriate instrument of known efficiency. NOTE: Filters used for tritium sampling should be moistened with tritium-characterized water prior to swiping. For objects with a surface area less than $100 \mathrm{~cm}^{2}$, the entire surface should be swiped, and the activity per unit area should be based on the actual surface area. Except for transuranics, Ra-228, Ac-227, Th-228, Th-230, Pa-231, and alpha emitters, it is not necessary to use swiping techniques to measure removable contamination levels if direct scan surveys indicate that the total residual contamination levels are below the values for removable contamination.

Note 3. The levels shall be averaged over one-square meter $\left(\mathrm{m}^{2}\right)$ provided the maximum activity in any area of $100 \mathrm{~cm}^{2}$ is less than three times the values in the table.

\subsubsection{Posting and Labeling}

It may be impractical to post all radiological areas due to mission or size restraints. However, those radiological areas and activities routinely controlled by participants should be posted, according to applicable regulations (e.g., 10 CFR 835, 10 CFR 20, etc.). These areas may include source storage areas, laboratory areas, sample-receiving areas, hotlines, and decontamination areas. All postings should be based upon the limits found in Tables 2.4.3a and 2.4.3b (prior page). As resources increase, posting of access control points will be performed, as practical.

\subsubsection{Access Control}

To keep internal and external exposure ALARA for all personnel, access to the radiological areas must be controlled. The following is a list of access control requirements for entries into radiological areas. These requirements are in addition to other requirements previously described.

\subsubsection{Entry and Exit Requirements for Radiological Areas}

- Understand and abide by all regulations and conditions for entry into radiological areas.

- Nonessential personal property items shall not be taken into radiological areas.

- Persons whose work requires regular or occasional contact with radioactive materials and have the potential to receive a CEDE of greater than 100 mrem per year, shall be monitored routinely for intakes of radionuclides by the use of bioassay and/or whole-body counting techniques.

- Smoking, eating, chewing, application of make-up or other hand-to-face contact is not allowed in radiological areas. 
- Drinking is not allowed except in specified circumstances.

- Personnel must ensure they take appropriate measures to keep their exposures ALARA.

- Avoid contact with potentially contaminated surfaces.

- Obey any posted, written or oral requirements including "Evacuate", "Hold Point" or "Stop Work" orders from H\&S personnel.

- Handle all tools and equipment properly inside radiological areas.

- When possible, wrap or sleeve materials, equipment, hoses, etc.

- Place contaminated tools, equipment, etc. inside plastic bags when work is finished.

- Wear dosimeters when required and in the prescribed locations on the body.

- Exit immediately if a wound occurs or if dosimetry is off-scale, lost, or damaged.

- Report all injuries.

- Monitor clothing and exposed skin, as required, and report the presence of radioactive contamination.

- Place contaminated items and waste in the proper receptacles.

- Personnel should wash their hands when leaving a radiological area and prior to eating or using tobacco products.

Hold points are explicit times noted in a procedure, plan, etc. that specify that work must stop for H\&S evaluations. The evaluation may lead to a Stop Work order. Stop Work orders are usually a result of:

- Inadequate controls or controls not being implemented

- Hold point not being observed

- Changing conditions which may include unanticipated elevated radiation levels indicated or identified by an off-scale dosimeter or radiological alarms.

When a Stop Work order is issued, all work activity is to cease immediately. All personnel should be notified of the order and everyone must immediately exit the area. 


\subsubsection{Hotline Procedure}

The H\&S Manager will identify areas of potential contamination. A hotline will be established at the most practical location adjacent to the contamination control area. The hotline should be located where field teams can process through the hotline without the possibility of tracking contamination into "clean" areas or areas of lower contamination. A secondary hotline may be set up adjacent to the incident area to assure that no contaminated personnel, equipment, or vehicles can enter a "clean" area. The H\&S Manager, Monitoring Manager, and Operations Manager will determine the location of the hotline.

The hotline should be established at a location that can accommodate a field sample preparation area; decontamination equipment and associated facilities; and the entire hotline operation that includes personnel, vehicles, equipment, and frisking areas.

The hotline will be stocked with appropriate PPE and equipment for counting swipes and performing contamination surveys. The H\&S personnel will staff and control the hotline(s).

Designated areas will be established for field monitoring teams to park and exit their vehicles, turn in their field samples, turn in their monitoring instruments and personnel dosimetry, shed their anti-c clothing, be monitored ("frisked") for radioactive contamination, and be decontaminated, if needed.

Instructions will be written on signs or posters that will guide the field team members to and through the contamination control station. The H\&S personnel manning the hotline will also be giving instructions to personnel as they enter and go through the hotline.

Personnel, vehicles, equipment, samples, etc., enter the hotline through the designated entry point. Personnel will be instructed to exit the vehicles, turn in the field samples at the Sample Check-In Table, turn in the health physics instruments at the Instrument Return Table, turn in the TLD and/or pocket dosimeter at the Dosimetry Table, and to proceed to the Personnel Contamination Control area for monitoring.

\subsubsection{Personnel Surveys}

Personnel will doff their protective clothing in the prescribed manner and discard them in the appropriate container. Respirators will be separated and surveyed for possible reuse. Personnel will proceed through the "frisking" area and be monitored for contamination by the hotline technician. If no contamination is detected, the person is released. If contamination is found anywhere on the person's clothing or skin, the person will be directed to the Decontamination Facility where he/she will be decontaminated by other H\&S technicians. After decontamination, the person will be re-monitored and released if no contamination is detected. If the person is still contaminated, qualified personnel will initiate additional decontamination measures.

The H\&S staff will have extra clothing available for participants whose personal clothing is contaminated and has to be laundered or confiscated. 
The type, location, and levels of external radioactive contamination found on personnel will be documented using the Personnel Contamination Survey Sheet (Appendix A).

The whole body should be surveyed, with special attention to areas, which are more likely to become contaminated. Contamination on the feet (shoes) would indicate removable surface contamination on the ground or floor just traversed. The hands are extremely prone to becoming contaminated when working directly with radioactive materials.

The nose and mouth should be surveyed upon discovery of any level of facial skin contamination, since contamination in this area might indicate the need for bioassay sampling. The nose can be swabbed with Q-tips ${ }^{\circledR}$ and the swab counted in a smear counter to determine a potential deposition. Nasal or facial contamination may indicate intake of radioactivity.

Other body areas, which are prone to contamination, include the buttocks, knees, and elbows and head. All open wounds must be monitored since contaminants can be readily absorbed into the body. Anyone with contamination in or around a wound should report to the H\&S Manager for referral to the medical team.

In addition to these specific body areas, the surveyor should pay special attention to any area of the body and/or clothing which he or she suspects might be contaminated. Upon detecting personnel contamination, follow-up area and/or equipment surveys may be necessary to determine the source of contamination and the extent the contamination has spread, if any.

Depending on environmental conditions, the presence of radon and thoron progeny may cause elevated readings. If radon is suspected, measures should be taken to isolate the affected clothing or equipment, confirm the half-life, and store for decay below release limits.

Movement of the instrument probe over the monitored areas should proceed at a rate of $1 / 2$ inch per second when using an alpha probe. This allows meter response to register as localized contaminations are encountered. During a typical beta/gamma personnel survey, the instrument probe should move over the monitored areas at a rate of approximately 2 inches per second, unless the individual has already been surveyed by a portal monitor and the hand-held survey is being done to localize and verify contamination discovered by the portal monitor. An alternate method of delaying over a surface for about two seconds, then moving the length of the probe, may also be used.

\subsubsection{Equipment Surveys}

All equipment and materials used by personnel in contaminated areas shall be monitored at the hotline before release to the public. Returning field teams will turn in their survey equipment at the Equipment Return Table at the hotline. H\&S technicians will survey the equipment using hand-held instruments and/or swipes. Clean instruments will be made available for continued use. Contaminated instruments (any instrument that could lead to erroneous measurements) will be sent to the equipment decontamination area for 
decontamination, and equipment that exceeds the contamination limits (Table 2.4.3b) will not be released.

\subsubsection{Vehicle Surveys}

All vehicles used by the field teams or that may have encountered radioactive contamination must be surveyed at the hotline. Vehicles will be driven into a designated parking area and be surveyed by a hotline technician. Areas on each vehicle to be surveyed include seats, floor and floor mats, steering wheel, door handles, tires, and wheel wells. More extensive monitoring may be needed, depending on the extent of contamination that is suspected.

Vehicles that are not grossly contaminated ( $<10$ times [Table 2.4.3b]) will be released for continued use, provided the contamination present does not pose a health or exposure hazard to the responders. The H\&S Manager will determine these criteria.

Decontamination of vehicles will be done at the designated Vehicle Decontamination Area that is part of the "hotline" operation.

At the termination of activities, and before release of vehicles to the public (such as return of rental cars), all vehicles will be surveyed and decontaminated in accordance with the agreed upon Remediation Plan.

\subsubsection{Sample Monitoring and Control}

Soil, water, and vegetation samples brought in by the field monitoring teams will be considered contaminated and be treated accordingly. Samples will be segregated and treated accordingly if surface exposure rates exceed $2 \mathrm{mR} / \mathrm{hr}$. Upon turning them over at the Sample Collection Table, all samples will be surveyed and additional contamination control will be implemented, as needed, prior to delivery to the radioanalysis lab. In the lab, contamination control procedures will be used throughout the analytical process.

\subsection{Personal Protective Equipment (PPE)}

Personal protective equipment as prescribed by $\mathrm{H} \& \mathrm{~S}$, should be selected based on known or anticipated contamination levels in the work area, anticipated work activity, worker health considerations, and regard for non-radiological hazards that may be present. Table 2.5.1 provides general guidelines for selection.

Personnel are required to wear PPE when entering areas containing contamination levels above specified limits in order to prevent contamination of skin and clothing. The degree of protective clothing required is dependent on radiological conditions in work areas and the nature of the job. Full protective clothing generally consists of coveralls, cotton glove liners, gloves, shoe covers, rubber overshoes and possibly a hood. There are several basic factors, which determine the type and extent of protective clothing required:

- Type and form of contamination

- Levels of contamination

- Type of work being performed. 
Some additional circumstances to consider include the potential for increased levels of contamination, the area of the body at risk, and competing hazards, (e.g., heat stress, asbestos, etc). Once the types of protection needed are established, the most efficient protective clothing must be selected from the different articles of protective clothing available for use. The appropriate safety gear should be worn for work activities requiring additional strength, abrasion resistance, or when required by other, non-radiological, safety procedures.

\subsubsection{Types of PPE}

\section{Whole body protection}

Coveralls provide protection from low to moderate levels of dry contamination protection. Protection is low when body contact with contaminated surfaces is prolonged (since contamination can be ground into or through the cloth) and when the surface is wet. Wearing more than one pair of coveralls at a time can increase the degree of body protection.

Cloth coveralls are permeable, and so are not effective against radionuclides with high permeability properties (gases, tritium, etc.).

Plastic coveralls provide protection from high levels of dry contamination and wet contamination. They provide limited protection from tritium and other highly permeating radionuclides (which may be transported through coveralls to the skin surface).

Disposable coveralls (e.g., Tyvek® suits) provide moderate protection from radioactive contamination and are used for work involving mixed hazards where reuse is not desirable or practical. Disposable coveralls can be torn easily, so be cautious in circumstances that might cause rips or tears.

Workers should inspect PPE before use for tears, holes, or split seams that would diminish protection. Inspect PPE for proper operability. Any defective items should be repaired or replaced with intact PPE.

Avoid getting coveralls "wet." "Wet" coveralls provide a means for contamination to reach skin/clothing. This is called "wicking."

\section{$\underline{\text { Hand protection }}$}

Surgical gloves are fairly easily torn or punctured and are normally only used in light contamination work areas, which require a high degree of dexterity.

Rubber gloves are lightweight and provide a good gripping capability. They are normally used in moderate to heavy contamination locations. Rubber gloves have greater puncture, abrasion, and solvent resistance, but afford a lower degree of dexterity than surgical gloves. 
Leather or canvas work gloves should be worn in lieu of or in addition to standard gloves for work activities requiring additional strength or abrasion resistance.

Cotton glove liners may be worn inside standard gloves for comfort, but should not be worn alone or considered as a layer of protection. Gloves are often taped to the sleeve of the lab coat, coveralls, plastic suit, etc. for maximum protection and are "tabbed" to permit easy removal.

\section{Foot protection}

Booties are used to protect the lower leg area (below coveralls) from contamination. Different materials such as plastic and cloth (sometimes called cloth shoe covers) are used. Plastic bags are often used as shoe covers or inner boots. The plastic bags allow easier donning and doffing of booties.

Shoe covers are worn over booties as a second layer of protection and to provide traction for the wearer. They are normally constructed of plastic or rubber, and may be taped to the pants leg of the coveralls or plastic suit depending on the level of contamination and type of job. Shoe covers and gloves should be sufficiently durable for the intended use.

\section{$\underline{\text { Respiratory protection }}$}

Full-face masks are used to filter particulate radionuclides and/or radioactive iodine from the breathing air of the wearer when the surrounding atmosphere is not immediately dangerous to the life and health of the wearer. A self-contained breathing apparatus (SCBA) is used to provide a portable source of breathing air to the user when entering an atmosphere which may be immediately dangerous to life and health or unknown atmospheres.

\section{General Information}

Supplemental pocket or electronic dosimeters should be worn outside the PPE, in a manner accessible to the worker. Workers may protect such dosimeters from contamination by placing them in an outer coverall pocket or in plastic bags or pouches.

Personal effects such as watches, rings, jewelry, etc., should not be worn during work activities. The following table provides basic guidelines for selecting personal protective equipment.

For more information on the Respiratory Protection Program refer to the Industrial Hygiene chapter (Section 3.6.1, Respiratory Protection Program). 
Table 2.5.1. Guidelines for Selecting Personal Protective Equipment

\begin{tabular}{|l|l|l|l|}
\hline \multirow{2}{*}{ WORK ACTIVITY } & \multicolumn{2}{|c|}{$\begin{array}{c}\text { KNOWN OR ANTICIPATED REMOVABLE } \\
\text { CONTAMINATION LEVES }\end{array}$} \\
\cline { 2 - 4 } & \multicolumn{1}{|c|}{ LOW } & \multicolumn{1}{c|}{ MODERATE } & \multicolumn{1}{c|}{ HIGH } \\
(< Table 2.4.3b values) & $\begin{array}{l}\text { (1-100 times Table } \\
\mathbf{2 . 4 . 3 b} \text { values) }\end{array}$ & $\begin{array}{c}\text { (>100 times Table } \\
\mathbf{2 . 4 . 3 b} \text { values) }\end{array}$ \\
\hline $\begin{array}{l}\text { Routine "clean" area } \\
\text { surveys and hotline } \\
\text { frisking }\end{array}$ & $\begin{array}{l}\text { Gloves and booties or } \\
\text { shoe covers }\end{array}$ & Full set of PPE & $\begin{array}{l}\text { Full set of PPE, tape } \\
\text { openings, respirator } \\
\text { and hood }\end{array}$ \\
\hline Field Teams & $\begin{array}{l}\text { Gloves and booties or } \\
\text { shoe covers }\end{array}$ & Full set of PPE & $\begin{array}{l}\text { Full set of PPE, tape } \\
\text { openings, respirator } \\
\text { and hood }\end{array}$ \\
\hline $\begin{array}{l}\text { Laboratory } \\
\text { operations, sample } \\
\text { preparation and } \\
\text { sample hotline }\end{array}$ & $\begin{array}{l}\text { Lab coat, gloves and } \\
\text { shoe covers or booties }\end{array}$ & Full set of PPE & $\begin{array}{l}\text { Full set of PPE, tape } \\
\text { openings, respirator } \\
\text { and hood }\end{array}$ \\
\hline $\begin{array}{l}\text { Work with large, } \\
\text { pressurized, or large } \\
\text { volume liquids (liquid } \\
\text { decontamination) }\end{array}$ & $\begin{array}{l}\text { Full set of non- } \\
\text { permeable PPE }\end{array}$ & $\begin{array}{l}\text { Full set of non- } \\
\text { permeable PPE, } \\
\text { rubber boots }\end{array}$ & $\begin{array}{l}\text { Full set of non- } \\
\text { permeable PPE, } \\
\text { rubber boots and } \\
\text { outer rain suit, tape } \\
\text { openings }\end{array}$ \\
\hline
\end{tabular}

\section{Table 2.5.1 Notes: Four levels of PPE}

Level 1: Gloves

Booties or shoe covers

Level 2: Lab coat

Gloves

Booties or shoe covers

Level 3: Full set of PPE

- Coveralls

- Cotton glove liners (optional)

- Outer gloves

- Booties

- Plastic bags/tyvex shoe covers

- Inner gloves (surgical, Pylox, or Nitrile)

- Hood (if required)
Level 4: Full set of PPE (airborne)

- Full set of PPE (including hood)

- Tape openings

- Respirator 


\subsubsection{Removal of PPE}

Potentially contaminated PPE should be removed without spreading contamination and especially without contaminating the skin. Workers should be instructed not to touch the skin or place anything in the mouth during PPE removal. Instructions for PPE removal (presented below) should be posted adjacent to the personnel hotline.

\section{Recommended Sequence for Removing a Full Set of PPE}

1. Remove exposed tape, as applicable

2. Remove rubber totes or outer shoe covers, as applicable

3. Remove outer gloves

4. Remove tape from cuffs, as applicable

5. Remove hood (if applicable)

6. Remove coveralls, inside out, touching inside only

7. Remove respiratory protection, as applicable

8. Remove tape or fastener from inner shoe cover (or boot bag)

9. Remove each boot bag or shoe cover, placing shoe onto clean step-off pad or designated clean area

10. Remove inner gloves

11. Commence whole-body frisking

12. Monitor the badge and dosimeter for contamination. The sequence for the removal of primary and supplemental dosimetry depends on where the dosimeter was worn and the potential for contamination.

\subsection{Survey Instruments and Techniques}

\subsubsection{Survey Instruments}

All instrumentation used for the health and safety of response personnel will be calibrated and maintained according to appropriate standards and guidance documents (e.g., ANSI N323). The selected instruments must be capable of detecting in the ranges and energies of the release criteria specified in Tables 2.4.3a and b. Calibration must be current and appropriate for the types, levels, and energies of radiation encountered. Before an instrument is placed into service, $H \& S$ staff members will perform the following checks:

- Inspect the instrument for physical damage.

- Ensure that the calibration and service stickers are current.

- Perform a battery check.

- Perform a source response check according to approved procedures (e.g., manufacturer's specifications).

If during instrument checks or usage, an instrument fails to respond properly, it fails the battery test, it is damaged, or its calibration is expired, the H\&S staff member should 
remove it from service immediately, tag the instrument "Out of Service" and replace it with a properly functioning instrument.

The H\&S staff member must determine what items were measured by the defective instrument and repeat the surveys with a properly functioning instrument to determine if the previous surveys were accurate. This evaluation must be documented on a Radiation Survey Report Form (Appendix A) and placed in the operational logbook.

Before return, all instruments should have an instrument (direct) and swipe (indirect) survey performed. The results should be recorded in a Survey Report. If the results are below detectable limits, return the instrument with a copy of the Survey Report. If the results are above detectable limits, the instrument must be decontaminated and resurveyed until results are below detectable limits.

Selection of appropriate instruments depends upon the monitoring application and the exposure rates anticipated. In high exposure rate situations, or when a high degree of precision is desired, multiple instruments may be required.

\subsubsection{Survey Techniques}

\section{Exposure Rate Surveys}

Area survey exposure rate measurements are usually made at $1 \mathrm{~m}$ (approximately 3 feet) above ground level, or $30 \mathrm{~cm}$ (approximately $12 \mathrm{in}$.) from a surface (wall), to estimate an average exposure rate to personnel.

\section{Beta/Gamma Contamination Surveys}

Direct method beta/gamma contamination surveys are normally performed with an instrument that has a plastic scintillator or GM probe. Beta/gamma contamination surveys should be performed as close to the monitoring surface as practical, preferably $1 / 2$ inch away. However, care must be taken not to damage or contaminate the window or other parts of the probe. Plastic wrap or bags should be used to cover the probe to prevent contaminating the probe. It is sometimes helpful to hold the probe with the fingertips extending below the bottom edge of the probe. The surveyor must be aware of the potential for contaminating the fingertips. Beta/gamma contamination surveys should be performed at a rate of 2 inches per second, while listening for an audible response. Determine the peak audible response area and resurvey that area while viewing the scale.

\section{Alpha Contamination Surveys}

Direct method alpha contamination surveys are normally performed with an instrument that has a scintillator (zinc sulfide[ZnS]) probe. Alpha contamination surveys should be performed as close to the monitoring surface as practical, preferably $1 / 4$ inch away. However, care must be taken not to damage or contaminate the window or other parts of the probe. It is sometimes helpful to hold the probe with the fingertips extending below the bottom edge of the probe. The surveyor must be aware of the potential for contaminating the fingertips. Alpha contamination surveys should be performed at a rate of $1 / 2$ inch per 
second, while listening for an audible response. Determine the peak audible response area and resurvey that area while viewing the scale.

\section{Swipe Surveys (Indirect Method)}

A scaler is used to record the number of counts in a swipe or sample. A scaler efficiency check should be performed at the beginning of each shift for scalers used daily or prior to use on infrequently used scalers.

- Paper filters, ideally $4.25 \mathrm{~cm}$ or $9.0 \mathrm{~cm}$, are used as the swipe material. Flat paper water cups can be used as swipe holders.

- All swipes should be treated as potentially contaminated until they have been shown to be free of contamination through counting.

- Swipes should be numbered directly or number/label the swipe holders for later identification.

- Moderate pressure should be used to wipe a $100 \mathrm{~cm}^{2}$ area. Swipes are then placed inside the swipe holder.

- Swipes are next counted for both alpha and beta/gamma contamination on a scaler.

\section{Scaler Operation}

If a scaler is tagged "Out of Service" subsequent to its use, the H\&S staff member must determine what items were measured by the defective instrument. The H\&S staff member must resurvey those items with a properly functioning instrument to determine if the previous surveys were accurate. This evaluation must be documented on a Survey Report form and in the operational logbook. Swipes should be presurveyed for gross contamination prior to placing them in a scaler to prevent scaler contamination.

\section{Detection Limits}

The detection limit of a measurement system refers to the statistically determined quantity of radioactive material or radiation that can be measured or detected at a preselected confidence level. This limit is a factor of both the instrumentation and technique or procedure being used. The two parameters of interest for a detector system with a background response greater than zero are:

Critical detection level $\left(\boldsymbol{L}_{\boldsymbol{C}}\right)$ : the response level at which the detector output can be considered "above background"

Minimum significant activity level $\left(\boldsymbol{L}_{\boldsymbol{D}}\right)$ : the activity level that can be seen with a detector with a fixed level of certainty

These detection levels can be calculated by the use of Poisson statistics, assuming random errors and systematic errors are separately accounted for, and that there is a background response. For these calculations, two types of statistical counting errors must be 
considered quantitatively in order to define acceptable probabilities for each type of error. Type I occurs when a detector response is considered above background when in fact it is not (associated with $L_{C}$ ). Type II occurs when a detector response is considered to be background when in fact it is greater than background (associated with $L_{D}$ ).

If the two probabilities are assumed to be equal, and the background of the counting system is not well known, then the $L_{C}$ and the $L_{D}$ can be calculated. The two values would be derived respectively using the equations $L_{C}=k \sigma_{B}$ and $L_{D}=k^{2}+2 k \sigma_{B}$. If $5 \%$ false positives (Type I error) and 5\% false negatives (Type II error) are selected to be acceptable levels, (95\% confidence level), then $k=1.645$ and the two equations can be written as:

$$
\begin{aligned}
& L_{C}=1.645 \sqrt{\frac{R_{B}}{T_{B}}+\frac{R_{B}}{T_{S}}} \\
& L_{D}=2.71+3.29 \sqrt{\frac{R_{B}}{T_{B}}+\frac{R_{B}}{T_{S}}}
\end{aligned}
$$

where:

$L_{C}=$ critical detection level (count

rate)

$L_{D}=$ a priori detection limit

(minimum significant activity level

[count rate])

$R_{B}=$ background count rate

$T_{S}=$ sample count time

$T_{B}=$ background count time

If the sample count time $\left(T_{S}\right)$ is the same as the background count time $\left(T_{B}\right)$, then the above equations can be simplified as follows:

$$
\begin{gathered}
L_{C}=2.33 \sqrt{\frac{R_{B}}{T}} \\
L_{D}=2.71+4.65 \sqrt{\frac{R_{B}}{T}}
\end{gathered}
$$

where:

$L_{C}=$ critical detection level (count rate)

$L_{D}=$ a priori detection limit (minimum

significant activity level [count rate])

$R_{B}=$ background count rate

$T=$ count time (sample and background) 
Therefore, the full equations for $\mathrm{L}_{C}$ and $\mathrm{L}_{\mathrm{D}}$ must be used for samples with count times differing from the background determination time (95\% confidence level [CL] used). The critical detection level, $\mathrm{L}_{\mathrm{C}}$, is used when reporting survey results. It is safe to say that to a 95\% CL, samples above this value are radioactive.

The minimum significant activity level, $L_{D}$, (referred to as the LLD [Lower Limit of Detection] in some texts) is calculated prior to counting the samples. This value is used to determine minimum count times based on release limits and airborne radioactivity levels. In using this value, we are saying that to a $95 \% \mathrm{CL}$, samples counted for at least the minimum count time, calculated using the $L_{D}$, will be radioactive.

If minimum significant activity level, $L_{D}$, is greater than the limits listed in Table 2.4.3.b, increase sample count time until the $L_{D}$ falls below these limits.

\subsection{Decontamination}

Procedures for the decontamination of personnel, equipment, and vehicles have been established for the hotline operation. While written for radiological decontamination, the methods in this section also apply to toxicological decontamination. The Contamination Control Chief has authority over the decontamination process. Decontamination will continue until levels are below Table 2.4.3.b values or alternate values that have been agreed upon by responsible parties.

\subsubsection{Decontamination Planning}

A decontamination plan should be developed for all responses. Details of the plan will vary according to varying factors involved in the response (resources, location, type of contaminant, etc), however, the general principles outlined below will form the basis for decontamination planning.

\subsubsection{Personnel Decontamination}

\section{$\underline{\text { Hotline Decontamination }}$}

Hotline decontamination personnel shall:

1. Notify the hotline decontamination supervisor when personnel decontamination is necessary.

2. Wear anti-contamination clothing when performing decontamination.

3. Survey the person with portable health physics instruments to determine the location and extent of non-uniform exposure of the skin due to radioactive contamination. 
4. Removing loose contamination on clothing by applying tape to the area and lifting it off.

5. If the contamination is localized, mask off the affected area and cleanse it with moistened Kimwipes ${ }^{\mathrm{TM}}$ (general washing risks the spread of contamination). Tepid (lukewarm) water should be used, if possible.

6. For large area contamination, wash with soap and water, using a portable shower if necessary.

7. Follow the decontamination procedures until contamination levels are undetectable, unless medical personnel or the hotline decontamination supervisor determines that further actions would cause bodily harm.

8. At the end of the operation, survey the personnel performing the decontamination to ensure that they have not become contaminated.

9. Notify the H\&S Manager if skin contamination levels, due to mixed fission products, are greater than $10,000 \mathrm{dpm} / 100 \mathrm{~cm}^{2}$.

10. Complete the Personnel Contamination Survey Sheet (Appendix A).

\section{Handling Contaminated Injured Personnel}

Special decontamination procedures and considerations should be provided in case of a medical emergency. Decontamination procedures shall not be implemented if they may aggravate or cause more serious health effects. However, prompt life-saving first aid and conference with the Medical Officer will determine the appropriate decontamination procedures in these special cases.

1. Individuals with minor injuries should be decontaminated, except for the wound(s), before removal to a medical facility (as practical).

2. Medical attention for more serious injuries will have priority over personnel decontamination.

3. In cases of serious injury, hotline personnel should inform the medical facility of the radiological condition of the patient before their removal from the accident site.

4. Hotline personnel shall take steps to limit or prevent the spread of contamination during transfer of the victim as well as at the medical facility. This is often accomplished either by removing contaminated clothing or covering contamination with a clean sheet or blanket. However, preventive measures should be commensurate with the severity of the injury.

5. Health and safety personnel from the hotline may accompany the contaminated victim in the ambulance to an appropriate hospital. 


\section{External or Internal Personnel Contamination}

When personnel are found to have detectable external contamination on skin or clothing, notify the H\&S Manager immediately. The contaminated person shall be directed to the designated personnel decontamination area for decontamination. Decontamination measures include:

1. Removing loose contamination on clothing by applying tape to the area and lifting it off

2. Removing contaminated articles of clothing and segregating them for laundering or disposal

3. Gently scrubbing contaminated areas of skin with soap and lukewarm water

4. Rinsing thoroughly with water.

If internal contamination is suspected (contamination found in the facial area), hotline personnel may request the following on an as-needed basis:

1. Request a urine sample, or fecal sample after decontamination

2. Collect sputum samples, mouthwashes, and nasal swipes

3. Request whole-body and/or thyroid counting

4. Decontaminate personnel dosimeter holders and turn in the TLD for processing

5. If air samplers were used in the work area, check the filters for radioactive contamination.

\section{$\underline{\text { Reporting And Documentation }}$}

1. Any and all incidents will be documented in detail in the Hotline Logbook. Recorded information should include names of involved personnel, a description of the incident, and the actions taken to resolve the problem. The Hotline is a record of activity occurring at the Hotline. There is no formal procedure for recording information, except that each entry include the time, date and signature of the recording individual.

2. Complete the Personnel Contamination Survey Sheet, and provide appropriate annotation in the logbook.

\section{Confiscation Of Contaminated Personal Property}

1. Decontamination of personal clothing should be attempted by using tape to pick up particle matter on clothing or with soap and water. 
2. Personal clothing will not be released until readings are nondetectable or below applicable limits, indicated by the readings from a portable health physics frisking instrument.

3. Replacement clothing will be provided to enable the individual to return to quarters if the personal clothing cannot be released.

4. Bag the contaminated personal items and provide a receipt of contents to the individual.

5. Label the bag with the type and level of radioactive contamination present.

6. Contaminated personal items are decontaminated or stored for decay of radioactivity.

7. Personal items will be kept secured until the items are returned to the individual or their home organization or disposed of as radiological waste.

8. Final deposition of personal items will be based upon the policy the the individuals home organization.

\subsubsection{Vehicle, Equipment, and Instrument Decontamination}

A decontamination area should be set up next to the Hotline for equipment and vehicle decontamination. The "pit" should be excavated to be lower than surrounding ground level. A watertight material should line the "pit." Waterpumps should be available to both spray contaminated equipment and vehicles, and remove contaminated rinsate.

Vehicles should be decontaminated by washing with soap and water or some other type of cleaning agent. The interior of the vehicles must be hand-washed, but the exterior can be cleaned using a high-pressure wash if such a system is available. Vehicles should be resurveyed and released for continued use if clean. Vehicles that cannot be decontaminated should be segregated and taken out of service. In special situations, and as approved by the H\&S Manager, contaminated vehicles may be put back into service for use only in contaminated areas.

Instruments and equipment returning from the field are surveyed at the Hotline. Contaminated equipment will be immediately segregated and sent to the Equipment Decontamination Area. Health \& Safety decontamination personnel will question the owners/users to determine the correct method for decontaminating equipment. Washing with soap and water will usually be sufficient to decontaminate the equipment. Decontaminated equipment and instruments will be resurveyed and, if clean, be released for continued use. Instruments that cannot be decontaminated will be taken out of service and stored in a designated area.

\section{Site Preparation}

1. A pit should be built so that water migrates to one pick-up point and is large enough to containerize the water until pumped out. The pit should be excavated to be lower than the surrounding ground level. 
2. Removing water can be done concurrently with decontamination, if available, or post decontamination if necessary.

3. The pit needs to be lined with a heavy plastic. The plastic needs to be able to handle moving the equipment in and out without tearing.

4. A pumping system, complete with a filter system and holding tanks, will be needed. Water pumps should be available to spray contaminated equipment and vehicles and to remove contaminated rinsate.

5. The area should be fenced and posted as a Contamination Area. Decontamination areas should be large enough to hold the entire piece of equipment.

6. A survey area (the same size as the decontamination area) should be established adjacent to the decontamination area, with access directly from the decontamination area to the survey area. The survey area should be posted as a "Contamination Area" when necessary.

\section{$\underline{\text { Decontamination Process }}$}

1. Equipment is brought into the decontamination area

2. Equipment is surveyed and contaminated locations marked

3. Decontamination methods used are from least abrasive (intrusive) to most abrasive (intrusive)

4. Liquid citrus cleaner and soft brush - water rinse

5. Tide and stiff brush - water rinse

6. Wire brush the equipment.

7. Electrical wire wheel brush

8. After each step, the equipment is rinsed, allowed to dry, and resurveyed

9. The routine is repeated as necessary with increasing abrasion

10. The equipment is moved into the confirmation survey area when survey results are below release criteria

11. Equipment or vehicles that cannot be decontaminated will be segregated and taken out of service. In special situations, and as approved by the H\&S Manager, contaminated vehicles may be put back into service for use only in contaminated areas 


\section{Confirmation Survey}

1. After decontamination is completed, the equipment is moved into the confirmation survey area.

2. Area should be posted as a Contamination Area until the post survey verifies otherwise.

3. If the confirmation survey detects contamination, the equipment is moved back into the decontamination area and the process is repeated.

4. Once the equipment is below release criteria, remove the equipment.

5. If no contamination was found during any confirmation surveys the posting may be removed.

6. If contamination was found on the equipment during the confirmation survey the confirmation survey area (ground) should be resurveyed and decontaminated (as necessary) and then the posting removed.

\subsubsection{Laundry Handling}

Anti-contamination clothing should be bagged and the bag tops securely taped at the hotline location. Laundry bags should be tagged with labels stating the type and level of contamination, date and location of collection, and surveyor's name. For short duration operations, the laundry bags can be held at the hotline location. For long-term operations, bags can be sent to a local provider, sent to a DOE facility, or a decontamination laundry can be set up in the field.

\subsection{Plans and Calculations for Turn-Back Limits}

A responsibility of the Health and Safety Division is to develop a variety of responsespecific plans. In particular, the Emergency Response Health and Safety Plan requires the calculation of turn-back limits. The following describes methodologies for calculations and plan development and includes some examples.

\subsubsection{Turn-Back Limits for Weapon Scenario}

Turn-back levels will always be based on some type of "marker" measurement. For a weapons type accident, the "marker" measurement would be plutonium and/or americium deposition. This would be a measurement of activity per unit area, commonly $\mu \mathrm{Ci} / \mathrm{m}^{2}$. The measurement is typically taken using a FIDLER or Violinist type instrument, but could also include in situ gamma spectrometry or alpha contamination measurements. The following equations demonstrate how to determine turn-back levels based upon ground deposition measurements.

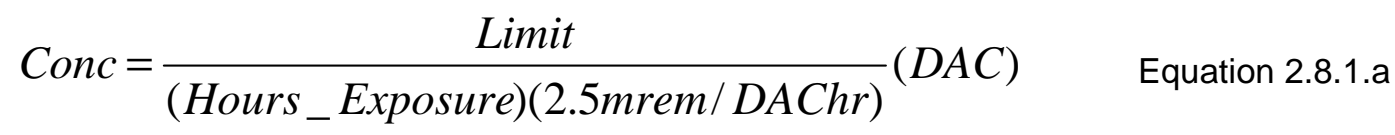




$$
\text { Dep }=(\text { Conc })\left(\frac{10^{6} \mathrm{ml}}{1 \mathrm{~m}^{3}}\right)\left(\frac{\text { resuspension _factor }}{1}\right) \quad \text { Equation 2.8.1.b }
$$

\section{Example of a default weapon scenario}

Assumptions:

- 1.5 rem investigation level for responders

- Seven days (one week) per responder at $8 \mathrm{hr} / \mathrm{day}$

- Assume a factor of three increase because:

$\checkmark$ DAC is based on time-weighted-average, not maximum

$\checkmark$ Individual's exposure over time (days) can be controlled

- Use most conservative ALI of $0.008 \mu \mathrm{Ci}$ and

DAC of $2 \times 10-12 \mu \mathrm{Ci} / \mathrm{mL}$ for alpha emitters

- Use Assessment Manual Resuspension Factors

- Use Assessment Manual Default Mix (15 year age)

- ${ }^{241} \mathrm{Am}$ values from FIDLER or Violinist System will be used.

Maximum concentration for 1.5 rem per 7 days:

$$
\text { Conc }=\frac{1500 \mathrm{mrem}}{(7 \text { days })(8 \mathrm{hr} / \text { day })(2.5 \mathrm{mrem} / \mathrm{DAChr})}\left(2.0 \times 10^{-12} \mu \mathrm{Ci} / \mathrm{ml}\right) \quad \text { Equation 2.8.1.c }
$$

$$
\text { Conc } \approx 2.0 \times 10^{-11} \mu \mathrm{Ci} / \mathrm{ml}
$$

Assuming non-arid conditions, resuspension factor is $10^{-6}$ :

$$
D e p=\left(2.0 \times 10^{-11} \mu \mathrm{Ci} / \mathrm{ml}\right)\left(\frac{10^{6} m l}{1 m^{3}}\right)\left(\frac{10^{6} m}{1}\right)
$$

Turn back $=20 \mu \mathrm{Ci} / \mathrm{m}^{2}, 1000 \mu \mathrm{Ci} / \mathrm{m}^{2}$ with full-face respirator $\left(60 \mu \mathrm{Ci} / \mathrm{m}^{2}\right.$ and 3000 $\mu \mathrm{Ci} / \mathrm{m}^{2}$ using a factor of three).

Can vary based upon:

- Age (mixture) of weapon material

- Measured or arid resuspension factors

- Dose estimates from Personal Air Sampler (PAS) Data. 
Personal Air Samplers can be used to estimate a persons dose due to inhalation. The following is a sample dose estimate for a default weapon scenario.

Assumptions:

- Use most conservative Allowable Limit on Intake (ALI) of $0.008 \mu \mathrm{Ci}$ and Derived Air Concentration (DAC) of $2 \times 10^{-12} \mu \mathrm{Ci} / \mathrm{mL}$ for alpha emitters

- Assume $20 \mathrm{lpm}$ breathing rate

- Use Assessment Manual Default Mix (15 year age)

- Total alpha values will be used

- Personal Air Sampler rate of 2 lpm

- Assume counting results in dpm

$\mathrm{A}_{\mathrm{F}} \rightarrow$ filter activity in dpm

$$
C E D E=\left(A_{F}\right)\left(\frac{\mu C I}{2.22 \times 10^{6} \mathrm{dpm}}\right)\left(\frac{1}{0.008 \mu \mathrm{Ci}}\left(\frac{20 \mathrm{lpm}}{2 \mathrm{lpm}}\right)(5000 \mathrm{mrem}) \quad\right. \text { Equation 2.8.1.e }
$$

Note: Must correct for radon/thoron progeny or allow to decay. Does not account for respirator.

\subsubsection{Sample Bioassay Plan for Weapons Scenario}

Methodologies and purposes of bioassay sampling have been discussed previously. The following is a sample bioassay plan for a weapon scenario:

- Collect a 1-liter (or 24-hour) baseline urine sample before any potential exposure.

- Collect a 24-hour urine sample every 7 days or at the conclusion of response.

- Collect a 24-hour urine sample if air sampling indicates a CEDE greater than 200 mrem.

- Follow-up urine or fecal sampling may be required.

Note: The plan is based upon Urinalysis MDA of $0.006 \mathrm{pCi} / \mathrm{sample}$. This would yield a minimum detectable dose (MDD) of approximately 1 rem.

\subsubsection{Turn-Back Limits for Reactor Scenario}

Assumptions:

- $\quad 1.5$ rem investigation level for responders

- Seven days (one week) per responder at $8 \mathrm{hr} /$ day

- Inhalation from resuspension is small

- Assume a factor of three increase because an individual's exposure over time (days) can be controlled and reduced, if necessary.

- Both a rate and integrated exposure value is determined. 
Table 2.8.3. LWR Core Damage Accident Turn-Back Guidance*

\begin{tabular}{|l|c|c|c|}
\hline Emergency Activity & $\begin{array}{c}\text { No KI } \mathbf{1}^{\mathbf{T a k e n}} \\
\mathbf{( m R )}\end{array}$ & $\begin{array}{c}\text { KI Taken Before } \\
\text { an Exposure } \\
\text { (mR) }\end{array}$ & $\begin{array}{c}\text { No Inhalation Dose } \\
\text { Possible (Post- } \\
\text { plume) (mR) }\end{array}$ \\
\hline Investigation Level & 75 & 300 & 1,500 \\
\hline Administrative level & 125 & 500 & 2,500 \\
\hline TEDE Limit & 250 & 1,000 & 5,000 \\
\hline $\begin{array}{l}\text { Protecting Major } \\
\text { Property }\end{array}$ & 500 & 2,000 & 10,000 \\
\hline $\begin{array}{l}\text { Life Saving or Protecting } \\
\text { Large Populations }\end{array}$ & 1,250 & 5,000 & 25,000 \\
\hline $\begin{array}{l}\text { Life Saving or Protecting } \\
\text { Large Populations } \\
\text { (voluntary basis only) }\end{array}$ & $>1,250$ & $>5,000$ & $>25,000$ \\
\hline
\end{tabular}

${ }^{*}$ Excerpted from FRMAC Assessment Manual

${ }^{1}$ Potassium iodide

Table 2.8.3 can be used as a guideline for determining turn-back levels. Assuming a responder will be available for 7 days, then approximately 200 mrem per day will reach their investigation level. If no Iodine is available for breathing, only exposure rates are used. A factor of three for the exposure rate (since an individual will not be exposed at a continuous rate), would yield a turn-back rate of $600 \mathrm{mR} / \mathrm{hr}$. Table 2.8 .3 can be used to alter these values based upon presence of iodine and any mitigative efforts. 


\section{Chapter 3}

INDUSTRIAL HYGIENE

\subsection{Overview}

Emergency events involving hazardous materials may pose a multitude of health and safety hazards to responders, any one of which could result in serious injury or death. These hazards are a function of the nature of the event site as well as a consequence of the work being performed. Several factors distinguish the environment of an emergency event site from other occupational situations involving hazardous materials. The major factor is the uncontrolled condition of the site. Hazardous substances that do not endanger human health and safety when contained and properly handled may pose a severe threat to responders and the general public during emergencies.

Responders are not only subject to the hazards of direct exposure to hazardous materials, but also to dangers posed by the disorderly physical environment of the emergency event site and the stress of working in protective clothing. The combination of all these conditions results in a working environment that is characterized by numerous and varied hazards which:

- May pose an immediate danger to life or health

- May not be immediately obvious or identifiable

- May vary according to location and the task being performed

- May change as emergency activities progress.

Information about the event site will be obtained by DOE, through direct contact with site personnel and relayed to the response team. A hazard analysis will be conducted during transit time to the site. Safety hazards, such as confined spaces, unstable structures, traffic, extreme temperatures, water, fire, etc., all need to be identified to the fullest extent possible, prior to arrival at the site. A general checklist (Hazard Checklist [Appendix A]) has been developed to identify such hazards. This checklist is intended for use while in transit to the site. The $\mathrm{H} \& \mathrm{~S}$ Manager will have the responsibility to acquire the appropriate information for the checklist and to assist in developing a plan for the initial on-site investigation.

Biological, chemical, physical, and confined space hazards may be encountered during deployment. Anticipated biological hazards may include viral, bacterial, fungal, and parasitic agents. Interaction with certain mammals, reptiles, insects, and poisonous plants is also a concern. Chemical hazards may include toxic metals (e.g., beryllium, lead), asbestos, solvents, corrosives, fuels, sealants, compressed gases, and cryogenics. Anticipated physical hazards may include temperature extremes, non-ionizing radiation, and elevated noise levels.

In approaching a site, the H\&S Manager is responsible for evaluating the hazards present to determine which ones must be controlled in a prioritized basis. As work progresses, 
conditions change, and new information becomes available. These controls and procedures must be adapted to the changing conditions.

The buddy system (a minimum of two people per entry) will be used for all on-site work. This is to minimize the risk of a person being injured and not having back-up support. Internal communications will be available for all situations, ensuring that emergency rescue and general work-site evaluations can be determined, resulting in appropriate action. The senior management official will ensure the availability of emergency medical support and the location of the nearest trauma center.

\subsection{Biological Hazards}

Biohazards, such as insects, poisonous plants, snakes, mice infected with Hantavirus, etc., may be encountered during responses. Personnel should avoid biohazards whenever possible (not take samples in tall grass, avoid animals (dead or alive), and animal droppings, etc). Personnel should also be cautious when taking samples around animals (wild or domestic), such as cattle, dogs, etc. Any potential or suspect exposures to hazards should be reported to the H\&S Manager as they are discovered. Appropriate safeguards will be instituted so that exposure to these hazards will be minimized.

In addition to Hantavirus, the following animal- or insect-vector hazards should be considered; e.g., Rocky Mountain Spotted Fever, Lyme Disease, Deer Fly Fever, Bubonic Plague and Coccidioidomycosis (Valley Fever). Unfortunately, these diseases are often delayed in onset and initially emulate less severe common conditions; e.g., a cough or cold, low-grade temperature and chills, influenza and sinus conditions. The onset of symptoms may not occur until after the deployment has been completed. During each day's safety briefing, it is imperative that the responders be made aware of the biological hazards associated with the response area at the time of the response. If symptoms occur after the deployment is complete, responders should inform their physician of their recent work and the deployment biological hazards.

\section{General Precautions}

Do not feed or harass wild animals that may carry rabies or other diseases. Avoid ticks and other small insects that may carry disease by:

- Wearing clothing that has long sleeves and closes at the wrists, collar, and ankles

- Using insect repellant on exposed skin and clothing

- Examining the skin daily for ticks.

- Wearing light-colored clothing (makes ticks easier to find).

Reduce the hazard of snakebite by avoiding locations where snakes are likely to be found (under debris piles, shrubs, or rocks; under parked cars). If snakebite occurs, keep the victim calm, elevate the bite area, and summon medical assistance. 


\subsection{Chemical Hazards}

Preventing exposure to toxic chemicals that are involved in the emergency event or present in the environment is of primary concern. These chemical substances may be in a gaseous, liquid, or solid form. They can enter the unprotected body by inhalation, skin absorption, ingestion, or through a puncture wound.

Chemical exposures are generally divided into two categories: acute and chronic. Symptoms resulting from acute exposures usually occur during or shortly after exposure to a sufficiently high concentration of a chemical. Chronic exposure generally involves exposure to low concentrations of chemicals over a long period of time, (weeks to months). The concentration required to produce health effects varies from chemical to chemical. During emergency response work, acute exposure is the primary concern.

The effect of hazardous chemicals may be temporary and reversible, or permanent and result in disability or death. Some chemicals may cause obvious symptoms such as burning, coughing, nausea, tearing eyes, or rashes. Other toxins may cause health damage without any such warnings (carbon monoxide, beryllium, asbestos, lead). Health effects such as cancer or respiratory disease may not manifest themselves for several years or decades after exposure.

In addition, some toxic chemicals may be colorless and/or odorless, may dull the sense of smell, or may not produce any immediate or obvious physiological sensations. Thus, a responder's senses or feelings cannot be relied upon in all cases to warn of potential toxic exposure. That is why it is essential to rely on available instrumentation and knowledge of the potential hazards rather than instincts alone.

The effects of exposure depend on the chemical, its concentration, route of entry, the duration of exposure, and personal factors such as age and level of fitness. The most consequential route of exposure for emergency responders is inhalation. The lungs are extremely vulnerable to chemical agents. Even substances that do not directly affect the lungs may pass through lung tissue into the bloodstream, where they are transported to other vulnerable areas of the body. Respiratory protection is extremely important if the atmosphere at the emergency event site contains toxic chemicals or gases. Although HEPA-filtered respirators provide protection from radioactive and chemical particulates, they do not provide protection against gases and vapors. Specific chemical protective respirator filters or supplied-air respirators may need to be used in these circumstances.

Direct contact of the skin and eyes to hazardous substances is another significant method of exposure. Some chemicals directly injure the skin. Others pass through the skin into the bloodstream where they are transported to vulnerable organs. Abrasions, cuts, heat, and moisture accelerate absorption into the skin. The eyes, nose, and other mucous membranes are particularly vulnerable because airborne chemicals can accumulate and dissolve in their moist surface. Wearing proper protective equipment and minimizing contact with liquid and solid chemicals can help protect against skin and eye injury through incidental contact.

The Occupational Safety and Health Administration (OSHA) has established a Hazard Communication (HazCom) Program for identifying hazardous chemicals in the workplace 
and communicating information about these hazards to employees. Key elements of the HazCom Program include identifying the hazards, assessing their consequences (material safety data sheets [MSDS]) and container labels), and training employees on how to protect themselves. The initial Hazard Assessment should identify the hazards. An MSDS will be available on site for all chemicals carried by the response team. Information on how to obtain additional MSDS information will also be readily available. All responders are expected to have received the appropriate hazard communication program training prior to deployment. The parent organization is expected to provide hazard communication program training in accordance with 29 CFR 1910.1200 for field operations.

\subsubsection{Personal Monitoring}

Monitoring and sampling will identify potential exposure to hazards. Personal air sampling will be done in accordance with OSHA requirements and the National Institute of Occupational Safety and Health (NIOSH) recommendations. Due to sample analysis turnaround times, direct reading instrumentation; e.g., electrochemical sensors, photoionization detectors and colorimetric detector tubes are preferred over indirect sampling.

All organic-vapor analyzers, combustible gas and oxygen meters, sound-level meters, and personal sampling pumps will be calibrated before and after use, according to manufacturer's instructions. Calibration will be documented on the forms used to record measurements or on specific calibration forms provided by the response organization. Where possible, equipment calibrations should be traceable to National Institute of Standards and Technology or other nationally recognized standards.

\subsubsection{Chemical Exposure Limits}

Personnel exposure limits for hazardous materials encountered during an emergency response incident will be defined as follows:

\section{Emergency Response Exposure Limits}

Emergency Response Planning Guideline (ERPG) values have been established by the American Industrial Hygiene Association (AIHA) as guidance on appropriate levels for emergency responders. During the initial response and up to the time when cleanup and site restoration begin ERPG-2 levels will serve as exposure limits. These values are defined as the maximum airborne concentration below which it is believed that nearly all individuals could be exposed for up to 1 hour without experiencing or developing irreversible or other serious health effects or symptoms that could impair their abilities to take protective actions. ERPG-2 values have been defined for a number of toxic materials by the AIHA.

When ERPG values are not available then the H\&S Manager will develop exposure values based on NIOSH recommendations, MSDS limits, or similar hazardous materials. 


\section{Clean-up and Site Restoration Exposure Limits}

Once the accident has advanced beyond the emergency response phase and proceeds into the long term operational phase of clean-up and site restoration, the most conservative of the occupational exposure limits (Permissible Exposure Limits - PELs) established by OSHA or the American Conference of Governmental Industrial Hygienists (Threshold Limit Values [TLVs]) will be used.

\section{Exceeding Established Exposure Limits}

When extremely unsafe conditions may pose a significant hazard to the local population and environment if not handled in a timely and appropriate manner, it may be necessary for an individual or small group of individuals to exceed established exposure limits for specific operations. Individuals must be informed of the risks involved and volunteer for these operations. Caution must be used in these instances to ensure that the individual(s) do not enter conditions that are immediately dangerous or life-threatening and that all proper controls are utilized. Permission must be granted in writing by the FRMAC Director for individuals to exceed established exposure limits.

\subsection{Physical Hazards}

Physical hazards include acoustic, electromagnetic, ergonomic, mechanical, and thermal agents that may be detrimental to health. Because the tissue penetration, target organs, health effects, and individual susceptibility vary greatly, corresponding exposure limits must be interpreted by individuals adequately trained and experienced in this type of evaluation. Certain physical hazards such as heat stress have been noted as significant problems during emergency response exercises and need special attention. Confined spaces or oxygen deficient atmospheres are often not identified and are significant hazards in that they can lead to immediate injury or death.

\subsubsection{Thermal Stress: Heat}

Heat disorders arising from high temperatures, PPE, non-acclimatization, etc. can affect the amount of work responders can do, the manner in which they do it, and lead to serious health problems. Heat stress is a common problem and evaluation of it in a field response is not simple. People can only function efficiently and safely in a very limited body temperature range (core temperature). Fluctuations exceeding $2^{\circ}$ or $3^{\circ} \mathrm{F}$ impair performance remarkably. Larger fluctuations can lead to death.

Heat stress is the combined heat load on the body from metabolic heat production and external environmental factors, which include air temperature and water vapor content, radiant heat, air movement, and the use of PPE. Heat stroke is the most serious of the heat related illnesses because of its potential to be life threatening or result in irreversible damage. Heat stroke is caused by exposure to an environment in which the body is unable to cool itself sufficiently. It is characterized by a loss of mental acuity, dizziness, and a cessation of sweating. It is critical to undertake emergency cooling of the body even when medical help is on the way. 
Heat cramps, while debilitating, are easily reversed with proper medical treatment. They result from exposure to high temperature for a relatively long period of time, particularly if accompanied by heavy exertion due to a loss of salt and moisture from the body. Signs and symptoms that generally occur include pain or muscle spasms in the legs, hands, feet, or abdomen.

Heat exhaustion can also result from physical exertion in a hot environment but can easily be reversed by drinking fluids and resting in a cool place. Signs of heat exhaustion are a mildly elevated temperature, pallor, weak pulse, dizziness, profuse sweating, and cool, moist skin.

The following measures and actions will be used to help control heat stress:

- Adequate drinking water must be made available to responders and they must be reminded to frequently drink small amounts, (8 ounces every $15-20$ minutes). The water should be reasonably cool and must be close to the working area so the responders have ready access to it. Responders must be encouraged to drink more than the amount required to satisfy thirst, since thirst is not an accurate indicator of adequate fluid replacement.

- For responses that last more than a few days, electrolyte replacement may also be necessary. Commercially available sports drinks or $1 \mathrm{~g}$ salt mixed into 1 liter of water provides adequate electrolyte replacement.

- A work/rest regimen based on Heat Stress Monitoring or Wet Globe Bulb Temperature (WGBT) readings must be established. Recommendations for these work/rest recommendations are available in the ACGIH TLV Booklet.

- Cooling suits or ice vests can be provided to be worn beneath protective garments to assist in cooling the body.

- Personal protective equipment use should be assessed from a risk perspective to determine an appropriate level of protection versus risk. This is particularly true of encapsulating suits and respirators.

\subsubsection{Thermal Stress: Cold}

Hypothermia conditions, including loss of body heat and frostbite, can represent lifethreatening conditions. Fatal exposures to cold have almost always resulted from accidental exposures involving failure to escape from low environmental air temperatures or from immersion in low temperature water. The single most important factor is the fall in the body's core temperature. Exposure to extreme cold for a short period of time may cause severe injury to skin tissues, particularly the ears, nose, fingers and toes. Local injury resulting from cold is included in the generic term of frostbite. Frostbite injuries should be given medical attention as soon as possible to prevent tissue loss and, in some cases, the loss of extremities. Systemic hypothermia is caused by exposure to freezing or rapidly dropping temperature. 
Symptoms are usually exhibited in five stages:

1. shivering;

2. apathy, listlessness, sleepiness, and cooling of the body;

3. unconsciousness, glassy state, slow pulse, and slow respiration;

4. freezing of the extremities; and finally,

5. death.

Cold stress is proportional to the total thermal gradient between the skin and the environment since this gradient determines the rate of heat loss from the body. When vasoconstriction is no longer adequate to maintain body heat balance, shivering becomes an important mechanism for increasing body temperature because it results in increased metabolic heat production. Two factors that influence the development of cold injury are ambient temperature and wind velocity. Wind chill describes the chilling effect of moving air in combination with low temperatures. For instance, $10^{\circ} \mathrm{F}$ with a 15 mile per hour (mph) wind is equivalent in chilling effect to no wind at $-18^{\circ} \mathrm{F}$.

Since water conducts heat 240 times better than air, care must be taken to ensure that responders remain dry. This is particularly a concern when responders remove outer layers of protective clothing exposing perspiration soaked clothing and skin. Dry and warm clothes such as gloves, footwear, coats and blankets need to be available.

Thermal socks, long cotton or thermal underwear, layers of clothing, and other cold weather gear can aid in the prevention of hypothermia. Warm, sweet, non-alcoholic drinks shall be available. If it is anticipated that operations will continue for an extended time period, work rotations, and acclimatization methods shall be practiced. Work protocols, and cold stress indices are available in the ACGIH TLV Booklet.

\subsubsection{High Noise Areas}

Any area where the noise level is 85 decibels (dBA) time-weighted average or higher is a hazardous noise area. Responders working for extended periods of time must wear hearing protection in these areas. Prior to entry, the location of high noise areas will be communicated to responders. Cumulative daily noise exposure will be estimated and responders will be required to wear hearing protection (ear plugs, muffs, or both) when 8hour time-weighted average exposures exceed the $85 \mathrm{dBA}$ threshold. Entry into areas with noise levels above $140 \mathrm{dBA}$ is not permitted even with double hearing protection. A sound level meter will be available to evaluate noise levels. The exposure criteria found in the ACGIH TLV booklet will serve as guidance during all activities. As a rule of thumb, if personnel have to raise their voice to talk to someone one foot away, the area is a hazardous noise area. Contact the H\&S Manager for noise monitoring and hearing protection.

\subsubsection{Non-lonizing Radiation (LASERS, UV, IR, MWFR Sources)}

Encountering non-ionizing radiation is not expected during typical responses. However, intense electromagnetic fields may be experienced around some types of operational 
equipment, such as antennas, operational aircraft, and laser equipment. Whenever the potential for non-ionizing radiation is identified, field-monitoring personnel will isolate the area, inform the H\&S Manager, and post warning signs. The H\&S Manager will notify appropriate personnel of the hazard and provide instruction for any other necessary measures to be taken. Exposure to non-ionizing radiation will be evaluated per the ACGIH TLV and the Institute of Electrical and Electronics Engineers C95.1-1991 requirements.

\subsection{Confined Spaces or Oxygen Deficient Areas}

Confined spaces will not be entered without an evaluation of potential chemical and physical hazards and a written entry procedure. Entry into confined spaces or oxygen deficient areas can result in immediate injury or death if not done appropriately. Confined spaces or oxygen deficient areas are commonly found in pits, sewers, tanks, or areas where large quantities of gases are stored or used. Structures that have recently burned may also be oxygen deficient. These spaces must not be entered by responders without first performing appropriate monitoring for oxygen, carbon monoxide, explosive gas, and hydrogen sulfide concentrations. If entry is imperative, SCBA must be used. The $\mathrm{H} \& \mathrm{~S}$ Manager will provide guidance and monitoring equipment in accordance with 29 CFR 1910.146, Permit Required Confined Spaces.

\subsection{Personal Protective Equipment}

Personal Protective Equipment consists of three components: standard safety equipment, special equipment (fall protection, water safety, electrical safety, high noise areas, etc.), and respiratory equipment. The $\mathrm{H} \& \mathrm{~S}$ Manager is responsible for ensuring this program is implemented.

Standard Safety Equipment: All non-office employees are expected to arrive on-site with appropriate clothing, closed-toed shoes, and safety glasses designed to meet the current ANSI standard Z87.

Special PPE: Activity-specific PPE such as full body harnesses for fall protection, life vests for over/on water work, linesman's gloves for work within close proximity to high voltage sources, ear plugs for high noise areas, steel-toed shoes for lifting operations, and hard hats for construction areas, are to be provided by the response organization. An assessment shall be conducted by the H\&S manager prior to starting the specific task. The general checklist shall be completed, which identifies specific tasks and any special PPE requirements necessary.

Respiratory Protective Equipment: Respirators shall be used in accordance with the OSHA standard 29 CFR 1910.134 "Respiratory Protection."

\subsubsection{Respiratory Protection Program}

To comply with the Federal Respiratory Protection Standard (29 CFR 1910.134) as required by OSHA, the following program has been established to ensure the protection of all employees from respiratory hazards through the proper use of respirators. Respirators 
are to be used only where engineering control of respiratory hazards is not feasible, while engineering controls are being installed, or in emergencies.

\subsubsection{Types of Respirators}

Full face air purifying respirators (APRs) are designed to be used in areas where an airborne contaminant exposure has exceeded its designated OSHA PEL or ACGIH TLV, while not exceeding a chemical's "immediately dangerous to life or health" (IDLH) concentration. They must be used with appropriate cartridges (i.e. organic vapor, acid gas, chlorine, ammonia, and HEPA).

Powered air purifying respirators will also be available. They must be used in conjunction with HEPA cartridges, for airborne lead, silica, metals, asbestos or other airborne particulate that is considered a potential health concern to humans. These respirators cannot be used in IDLH or potential IDLH environments.

Self Contained Breathing Apparatus will be used when there is evidence suggesting that an airborne contaminant (or combination of airborne contaminants) is present in a quantity that exceeds the IDLH for that particular contaminant(s). Appropriate communication needs to be established prior to conducting work in SCBAs. Such as radio or hand signals. Hand signals should only be used when visual contact by personnel can be maintained.

\subsubsection{User Qualification Summary}

All employees who have the responsibility to wear respirators shall be medically qualified in accordance with 29 CFR 1910.134 (b)(10). Each person must have successfully completed a fit-test, within the last 12 months, for the type of respirator (manufacturer, model and size) to be worn.

Respirator selection will be completed by H\&S professionals as part of the Hazard Assessment. The following list provides the basic expectations for respirator fitness.

1. Only certified respirators will be selected and used.

2. Field personnel are expected to be medically qualified by their home organization, fittested, and trained prior to deployment. If absolutely necessary, medical qualification, fit testing, and training can be done in the field.

3. Employees will not be assigned to tasks requiring the use of respirators unless a physician at their home organization has determined, that they are physically able to perform the work and use the equipment.

4. The user should have been instructed and trained in the proper use of respirators and their limitations. The respirator user must also be satisfactorily fit-tested before wearing the respirator.

5. Respirators will not be worn when conditions prevent a good face seal. Employees who are required to wear respirators will not have facial hair that interferes with the 
face seal of the respirator. Also the absence of one or both dentures can seriously affect the fit of a face piece.

6. Respirators will be assigned to individual workers for their exclusive use.

7. If respirators are to be reused in the field, they should be cleaned and disinfected after each use by the respirator user. Respirators will be stored in a clean and sanitary location. Filters will be replaced according to the manufacturer's instructions.

8. It is not anticipated that personnel will use supplied air respirators.

9. Appropriate surveillance of work area conditions and degree of employee exposure or stress will be maintained.

\subsubsection{Respirator Inspection And Field Testing Instructions}

Employees shall conduct an inspection of the respirator prior to each use by performing the following checks on the respirator components. If any problems are discovered a new respirator will be issued and the damaged one will be returned to $H \& S$ for replacement.

1. Headbands: Check to see that headbands still have their elasticity. Inspect for breaks or tears in the material and make sure all cups, fasteners, and adjusters are in place and working properly.

2. Facepiece: Check the facepiece for dirt, cracks, tears, or holes. Inspect the shape of the facepiece for possible distortion that may occur from improper storage. Make sure the rubber is flexible and not unbending or brittle. Check the aluminum yoke for cracks.

3. Inhalation and exhalation valves: Check for cracks, tears, distortion, dirt, or buildup of material between the valve and valve seat.

4. Cartridge holders: Check to make sure gaskets are in place and check for cracks and any damage to threads.

5. Cartridges and filters: Cartridges and filters must be clean. Never try to clean a filter or cartridge by washing or using compressed air. Inspect filters and cartridges for dents, scratches, or other damage, particularly in the metal sealing bead around the bottom.

\subsubsection{Respirator Cleaning and Maintenance}

Each user will be responsible for the respirator(s) that has been assigned to him/her for the specific emergency response. It is the responding organization's responsibility to provide each user with a respirator that is clean and ready for use. It is the user's responsibility to keep the assigned respirator in a clean and operable condition so that the respirator can be used at any time. The responding organization will provide cleaning kits or cleaning supplies for respirator maintenance. In addition, each user shall store the respirator in a bag or compartment ensuring that the respirator is properly protected from weather conditions, contaminants and any other elements that may compromise the performance of the respirator. 


\subsubsection{Protective Clothing}

Field teams are expected to wear a long-sleeved top and closed-toed shoes. If required by the H\&S Manager, personnel deployed in the field must wear PPE. This could be minimal protection such as gloves and shoe covers, or it could be as complete as coveralls, inner and outer gloves, inner and outer boots, hoods, and respirators. Additionally, hearing protection such as earplugs and/or muffs may be required. The H\&S Manager, in consultation with the supervisor, will determine the type of PPE needed for each area in the event.

\subsection{Sanitation}

Provisions will be made for toilet facilities, hand washing facilities (with hot and cold water and soap), break/dining areas, and drinking water. Trash collection and pest control will be provided as necessary.

\subsubsection{Toilet Facilities}

The following table outlines guidelines presented in 29 CFR 1910.141 establishing requirements for toilet facilities.

\begin{tabular}{|c|c|}
\hline Number of participants & Minimum number of toilets \\
\hline 01 to 15 & 1 \\
\hline 16 to 35 & 2 \\
\hline 36 to 55 & 3 \\
\hline 56 to 80 & 4 \\
\hline 81 to 110 & 5 \\
\hline 111 to 150 & 6 \\
\hline Over 150 & $\begin{array}{l}\text { 1 additional fixture for each additional } \\
\text { 40 employees. }\end{array}$ \\
\hline
\end{tabular}

\subsubsection{Water Supply for Hand Washing, Decontamination, and Human Consumption}

Adequate potable water should be supplied for drinking, washing, and decontamination purposes. Water or wet wipes will be supplied at hand washing stations accompanying toilet facilities. Bottled water or drinking fountains must be readily available to responders during working hours.

\subsubsection{Food and Beverage Consumption}

Food and beverage will not be consumed in any area exposed to radiation contamination or hazardous material. Eating and drinking must take place outside of the defined contamination area. Receptacles will be provided to dispose of food and beverage not consumed. The receptacles will be emptied daily. 


\section{Chapter 4}

SAFETY

\subsection{General Safety Guidance}

Required site-specific activities may present a broad range of safety hazards and concerns to all responders and participants involved. The H\&S Manager will gather information and develop a safety guide specifically addressing the deployment site requirements. This information will be disseminated during the site safety briefing and at the badging location. The H\&S Manager, or designee, will conduct periodic Hazard Assessments in order to update hazard identification and the H\&S Plan.

Additionally, all participants have a role to play in protecting themselves and their fellow employees. Any participant may identify hazards at any time and make recommendations or request assistance to help ensure participant safety at all times. If a serious safety problem is observed, employees will stop all activities immediately and contact a member of the H\&S staff. Here is an initial checklist for on-site safety.

- Prior to beginning any work task, check the area to determine what problems or hazards may exist.

- Uneven surfaces, holes, or sharp objects are likely to be present and caution must be taken when walking in unfamiliar areas.

- If your activity may endanger fellow workers or nearby equipment or materials, take the necessary steps to safeguard and protect the people and materials.

- Review the H\&S requirements for each work task with your lead task person prior to starting work. You are not required to do a work task that may result in injury or illness to yourself or to others.

- Become familiar with, understand, and follow emergency procedures.

- Your team leader is responsible for maintaining proper H\&S conditions in your assigned work area. Report any hazardous conditions, unsafe acts, or unsafe equipment to your supervisor and/or the H\&S Division.

- Obey all warning signs and tags (such as "Keep out," "No Smoking," "Eye Protection Required," "Authorized Personnel Only," etc.).

- Electrical cords, hoses, and leads shall be protected or elevated. They must be elevated, covered and/or cleared away from walkways and other locations where they may be damaged or create tripping hazards.

- Horseplay is strictly prohibited. 
- Certain tasks require use of PPE, such as respirators, eye protection, safety belts, hearing protection, and foot protection. When personal protective equipment is specified, its use is mandatory.

- All participants must notify the H\&S Manager and their supervisors immediately of all job-related injuries, illnesses, vehicle or property damage accidents, and near-miss incidents.

- Personnel identified as fork truck operators shall attend a qualification course or requalification course and carry on their person the proof of qualification.

- Only trained and qualified electrical workers will be allowed to perform work on electrical equipment, components, and systems.

- Participants shall maintain a valid state drive's license or a commercial driver's license with the proper endorsements and current medical certificate, (when warranted), in their possession for the size of the vehicle to be operated. Licenses must be from the state in which participants are gainfully employed, or claim permanent residence. Participants shall know and follow all local and state traffic regulations.

- Responders working at locations where they are exposed to fall hazards four feet $(1.2 \mathrm{~m})$ above the floor or ground shall be protected from falls. Participants shall be protected by the installation of standard guardrails and toe boards or the participants shall wear and use a safety harness and lanyard or self-retracting lifelines.

- Trailers and mobile equipment using internal combustion engines, or containing hazardous materials shall not be used near doorways, windows, garage door openings, or fresh-air intake ventilation systems. See the Safety and/ or Industrial Hygiene Manager for assistance with the staging of this equipment.

\subsection{Scope of Operations}

Operations in which explicit safety concerns are addressed include:

- Setup operations

- Helicopter operations

- Vehicle operations

- Field team operations

- Night operations.

\subsubsection{Setup Operations}

Primary concerns during setup are centered on unloading palletized cargo and staging of equipment, and include the following:

- All tripping hazards will be clearly marked or guarded. 
- Qualified personnel will closely monitor electrical hazards during setup.

- Staging of laboratory trailers will be done in a manner that minimizes the hazards associated with generator emissions.

- All participants need to be aware of motorized equipment operating in the area.

\subsubsection{Helicopter Operations}

Complete regulations regarding the use of helicopters can be found in 29 CFR 1910.183 Helicopters. General guidance includes the following:

- A predetermined helicopter landing-zone will be identified.

- Passengers should receive a safety briefing from helicopter operators including safety features and equipment, their location on the individual aircraft, and emergency information cards before taking off.

- Passengers and ground crew members approaching helicopters shall stay in a crouched position, and shall be in clear view of the pilot while approaching or departing a helicopter.

- Passengers and ground crew should approach/depart from the FRONT of the helicopter ONLY when signaled by the pilot, and should NEVER walk under or around the tail.

- Loose fitting clothing, hats, hard hats, or other gear, which might be caught in rotor downwash must be secured or removed within 100 feet of operating helicopters.

- Only authorized participants will be permitted within 100 feet of the helicopter. Other personnel must be accompanied by a flight crewmember.

- During helicopter landing and takeoff operations, all participants are to maintain a clear distance of at least 100 feet from the helicopter.

- Passengers and ground crew shall wear hearing protection (including communications headsets or helmets) at all times around operating helicopters.

- Passengers shall generally assist the pilot in watching for other traffic or ground obstacles as directed by the pilot.

\subsubsection{Vehicle Operations}

- All vehicle occupants shall wear seat belts.

- Vehicle operators shall follow all local and state traffic regulations. 
- When in the area of pedestrian traffic, drivers shall maintain a maximum speed limit of $10 \mathrm{mph}$, except in emergency situations.

- Drivers will have headlights on at all times.

- Hazard flashers will be used during those field operations requiring low speeds or frequent stopping.

- Smoking is not permitted in any vehicle.

- No one is allowed to ride outside of any moving vehicle, including fork lifts, pickup truck beds, backhoe buckets, etc.

\subsubsection{Field Team Operations}

- When conducting field team operations, participants will observe a buddy system at all times.

- Field teams will be cognizant of their surroundings and watch out for harmful plants and animals.

- Field teams shall be in communication with the operations center.

\subsubsection{Night Operations}

- During night operations, lighting is essential and will be provided.

- Everyone must be especially careful during all aspects of night operations to avoid unforeseen or unanticipated hazards.

- Teams conducting night operations will be limited to essential personnel for that specific operation only, to avoid risk to other responders and participants.

- Safety personnel will be on duty during night operations to provide assistance as needed.

- When walking along or across any roadways, all personnel involved in night operations will look out for vehicle traffic. Reflector traffic vests will be provided and worn as required.

\subsection{Guidance for Frequently Encountered Situations}

Guidance is provided below on frequently encountered situations, however the subjects are not all inclusive. It is anticipated that the majority of emergency response activities will comply with OSHA general trade and construction standards as found in 29 CFR 1910 and 1920. Any deviations based upon the emergency situation must be appropriately approved and documented. 


\section{$\underline{\text { Lockout/Tagout }}$}

During investigative activities, personnel may encounter a piece of equipment that will need to be investigated. Contact with electrical or mechanical equipment shall require personnel to follow lockout/tagout procedures. Appropriate lockout/tagout procedures may require the services of maintenance personnel or local utilities. These services can be arranged when needed.

\section{Electrical Hazards}

Electrical hazards need to be identified prior to the start of work. Typical electrical hazards include working near power lines, worn out cords, working with wet electrical equipment, and poor or inadequate grounding. A qualified electrical worker shall complete any electrical repairs or work that requires any direct contact with an electrical source. Electrical protective equipment, such as linesmen gloves and rubber mats, will be used by personnel to protect themselves from possible direct contact with any electrical hazards.

\section{Fall Protection}

Fall protection will be used whenever personnel are required to position themselves 4 feet or more above ground level.

\section{Construction Sites}

Construction sites have a variety of hazards, besides those specifically identified in this H\&S Manual. Uneven grading; slip, trip and fall hazards; overhead objects; and poor lighting represent a threat to personnel safety. Appropriate lighting will be available so personnel can recognize these hazardous situations and avoid injury.

\section{$\underline{\text { Heavy Traffic }}$}

Any work near or on heavily trafficked areas will require safeguards such as illumination, reflective day-glow traffic vests, and caution signs. Blocking an intersection, entire road, or lane will require the assistance of the local municipality (i.e. police department, fire department, etc.). A designated individual will have the responsibility to ensure that the appropriate precautions have been taken.

\section{Work In or Near Water}

Working within the proximity of waterways (rivers, oceans and lakes) can result in hypothermia and drowning. Working slowly and cautiously is necessary, and requires team pre-planning. Fall protection equipment and procedures may be necessary. The senior management official will have the responsibility to decide whether these controls are required. 


\section{Work Involving Fire}

Personnel will not enter into an environment where there is active fire or recently extinguished flames. Personnel may enter a fire-damaged facility only after the professional firefighting unit and team has approved the scene for entry and determined the oxygen content of air in the facility is acceptable. Personnel will strictly adhere to any procedures or commands the firefighting personnel specify.

\section{High Explosives}

Personnel will not enter into any environment where high explosives have been identified or suspected to be present. If, during entry into an area-of-concern, personnel identify any such substance, all members are required to leave the area and report the findings to the senior management official. Handling, disarming, detonation, removal, etc., will be performed by a trained explosive ordinance disposal team, which is associated with a branch of the United States Military or the municipal police or fire department.

\section{Pressurized Vessels}

Work near or involving pressurized vessels, such as reactors, compressed gas bottles, boilers, etc. needs to be approached with extreme caution. These pieces of equipment, impacted by incidental forces contributing to the emergency, could cause serious injury from instantaneous pressure-release. It is important that these containers are thoroughly examined for damage by pressure vessel experts before actual contact is made. Should damage be noted, personnel are required to communicate to the senior management official and request appropriate action to be taken.

\subsection{Emergencies}

If emergency medical, fire, and/or other emergency response support are needed to respond to an incident, lights and sirens will normally be used to provide visual and audible warning signals to participants. In the event that lights or sirens are seen and/or heard, participants will clear the area for emergency crews to conduct emergency operations.

Participants in need of emergency assistance while in the field should:

1. Call "911" or use the radio and say "Mayday-Mayday-Mayday," and

2. State the nature of the emergency and their location, so that emergency medical, fire, and police personnel can be dispatched to their location.

Medical assistance will generally be available on site. Emergency assistance information will be disseminated at the safety briefing. If you have a medical emergency, contact the medical coordinator, physician, nurse, or paramedic or refer to the H\&S Plan or Participants' Guide for phone numbers and guidance. 


\section{Chapter 5}

\section{ENVIRONMENTAL COMPLIANCE}

\subsection{Waste Identification Overview}

Field operations could result in the generation of two basic types of waste: solid waste which includes hazardous waste, radioactive waste, and mixed hazardous/radioactive waste; and waste water.

It is essential to identify the potential wastes that could be generated at each response site in order to comply with federal and state regulations which govern the management and disposal of these wastes. The identification of potential wastes will be based upon the contaminants at each site and the chemicals and other materials used by the response team. By identifying potential wastes prior to mobilization to the site, the H\&S manager will be able to select the appropriate containers for the wastes and arrange in advance for necessary permits or approvals.

Title 40 CFR 262.11 requires the person generating a solid waste to determine if the waste is hazardous. Generally, wastes should be characterized prior to or upon generation. This means that by the time the material becomes a waste, on-site personnel should know the proper handling and disposal method for the waste. Wastes that are not characterized before they are created may require extensive research to properly characterize the waste. When this happens, the waste must be managed as a hazardous or mixed waste (depending upon the radiological status) until a definite determination is made. Typically, wastes accumulated as a part of a radiological emergency response will not be characterized prior to generation and will require research to be characterized.

An area or areas should be designated to store wastes during field operations. If the waste is a hazardous waste, it must be managed in accordance with the applicable regulations of 40 CFR 262 ( Generator Standards). In addition, an emergency permit may be obtained for managing hazardous waste generated from an emergency response action as provided by 40 CFR 270.61 (Emergency Permits). Each container or location for different types of waste (solid, hazardous, or radioactive) must be clearly marked. Containers holding hazardous waste should have the words "Hazardous Waste" clearly marked on the container. As a best management practice, each container should be clearly labeled or marked with the contents (i.e., radioactive waste, solid waste, etc.). This gives some assurance that waste will be segregated and managed correctly and could reduce waste management activities.

All waste should be compatible with the storage container and secondary containment should be provided for waste containers. Secondary containment should be able to hold $110 \%$ of the total volume stored to insure containment in the event of an accident.

Secondary containment could take the form of an overpack container, a small pit lined with plastic, a containment structure, or a spill pallet.

Hazardous and radioactive waste requires additional documentation to assure that the waste is properly managed. Information to be maintained includes: time, date, and 
location of accumulation, container identification, type of waste, name of person managing the waste, quantity and volume of waste, survey readings such as radiation or swipe results, and any sampling or analysis that has been done. This information can be maintained in field or waste management logbooks that will be maintained indefinitely. Subsequent additions of waste to the same container should be logged separately with the date and volume recorded.

It is imperative that records be kept for all containers of waste for several reasons. The Environmental Protection Agency requires generators to track hazardous waste containers, and tracking low-level waste containers is a best management practice. These records assist in determining length of accumulation time, which is a critical piece of information in hazardous waste regulations. Also, in the event of personnel changes, the records will provide continuity for the waste management process.

\subsection{Types of Waste}

\section{Solid Waste}

Title 40 CFR 262.2 defines solid waste. Generally, solid waste is defined as discarded items from the home or workplace. Items disposed of as solid waste are ordinary household trash, office trash, and cafeteria waste. Responsibility for management and disposal of solid waste generally falls to the state or municipality. Each state or local government has its own laws defining which wastes are eligible for disposal as regular trash. Often special permission is required for disposal of industrial waste or any waste not generated in a household. The H\&S manager will make arrangements for trash disposal within a week of mobilizing on site. Large, heavy-duty trash bags and/or trash receptacles should accompany the field team or should be purchased upon arrival at the site.

\section{Hazardous Waste}

Title 40 CFR 262.2 defines a Hazardous Waste. Generally, a hazardous waste is defined as solid waste that is either listed in the federal regulations or that exhibits one of four characteristics described in the federal regulations (40 CFR 261.24-33). States have the option of designating additional wastes as hazardous waste. Typical hazardous wastes that could be generated on a project are acids and other laboratory wastes, fuels, spill residues, spent solvents, expired or unwanted chemicals, and lead-contaminated items. Hazardous waste must be managed at the point of generation, and cannot be transported away from that point without a special license and a hazardous waste manifest. If a field crew generates hazardous waste, it must be placed into a leak-proof container with a tightclosing lid. The container must be made from a material that is compatible with the waste. For example, corrosives should not be accumulated in metal containers, and organic solvents should not be stored in plastic containers. Consult the corresponding material safety data sheet (MSDS) for further information on product compatibility.

Some wastes may have alternate management, transportation, and disposal requirements under the Resource Conservation and Recovery Act (RCRA). Examples may include used oil and other petroleum products, antifreeze, grease, biological items, and lead batteries. 
The H\&S manager will make special arrangements for disposition of these items with the local government or the owner of the items.

Up to 55 gallons of properly managed hazardous waste may be accumulated without any time limit for treatment/disposal. Once 55 gallons has accumulated, the generator must either transfer it to a permitted treatment, storage, or disposal, facility, or may keep it for another 90 days, if certain conditions apply. The manager of the waste must receive proper training; prepare, distribute, and implement emergency contingency plans; and inspect the waste weekly.

\section{Radioactive Waste}

Federal regulations and DOE Orders govern management and disposal of radioactive waste. Radioactive waste generated at field sites may include anti-c clothing, other PPE, rags, compactable trash, tools, sampling equipment and residue, filters, sources, contaminated soil, and decontamination fluids. These items must be placed in a container with a label indicating the contents and the known or suspected radiological contaminants. The H\&S manager will make arrangements for disposition of these items with the owner of the material.

\section{Mixed Radioactive/Hazardous Waste}

Mixed waste is managed as hazardous and radioactive waste. Mixed waste is extremely difficult to dispose of, so field teams must strive to prevent the accidental mixing of waste streams. For example, chlorinated solvents should not be used for cleaning items in radioactive areas. If the mixture of hazardous and radioactive waste is unavoidable (for example, the radioactive contamination of lead shielding), the field teams should make every effort to minimize the amount generated.

\section{Waste Water}

State or local governments govern the disposal of wastewater. The disposal of domestic wastewater (household-type wastewater) generally does not require any special permits. The disposal of industrial wastewater often does require a permit, which is issued by the authority that manages the treatment works. Besides domestic sewage, wastewater from field operations could be generated as a result of laboratory operations, decontamination of equipment and personnel, and contamination of stormwater or other existing water source. The best solution for wastewater disposal is discharge to a local treatment facility, but this depends upon the cooperation of local authorities. A permit to discharge may mandate pre-treatment of water to eliminate or reduce certain contaminants. If a discharge permit cannot be obtained, the water must be containerized or impounded, and other treatment/disposal options investigated.

\subsection{Protection of Resources}

Responder teams must take extra care to protect the environment when on any assignment. Spill prevention and minimal disturbance of natural areas are especially important. Spill prevention applies to product storage areas as well as wastewater, sewage, petroleum 
products in equipment reservoirs, and waste containers. The spillage of any of the aforementioned substances may prompt a written or verbal report to the regulatory authorities. Immediately after the release, the following information must be documented:

- The date and time of the release

- The released substance

- The amount of release

- The affected media, and

- Containment and clean-up efforts.

The H\&S Manager will determine which authorities or agencies should receive the report. The submittal of additional information, site clean up, and reporting may be required, depending upon the amount and nature of the release. 


\section{Chapter 6}

MEDICAL

\subsection{Overview}

The need and availability of medical support will vary depending on the type, size, and location of the emergency response. In some cases, the response may be large enough to have a staff physician. In all cases, procedures must be identified for attending to major and minor injuries or illnesses. Patient transport methods and medical facility availability need to be briefed to all participants when each responding organization arrives at the site.

Each participant must have a medical qualification by their home organization as to the level of duties they are physically qualified to perform. This qualification shall be by the organizations Medical Director or designee in the form of a written document, which shall include any limitations, special needs, medications or conditions for each participant.

\subsection{Reporting Requirements}

1. All injuries will be reported to the On-Scene Medical Director or designee and to the $\mathrm{H} \& \mathrm{~S}$ Manager when they occur.

2. Personnel who take medication on a routine basis should bring at least a fourteen-day supply when deployed. Any special requirements should be conveyed to the person's organization's Medical Director, the On-Scene Medical Director and the H\&S Manager.

3. Personnel with pre-existing, potentially serious medical conditions (i.e., cardiac problems, recent surgery, etc.) should fully inform the On-Scene Medical Director or designee of the situation. A detailed medical history is usually not required. If a doubt exists regarding the participant's ability to work on the site, their organization's Medical Director will be consulted as to the level of participation in the response.

4. Documentation of any required immunizations will be provided to the On-Scene Medical Director or designee and the H\&S Manager before being allowed to work in the field.

\subsection{Response Procedures}

\subsubsection{Medical Emergencies at the Operations Center}

- If able, injured or sick personnel should report promptly to the On-Scene Medical Director or designee.

- If an injured or sick person is discovered, call for help immediately and notify the OnScene Medical Director or designee.

- The On-Scene Medical Director or designee will determine the need for an ambulance. If necessary, the On-Scene Medical Director or designee may refer the victim to a local physician or hospital for evaluation and treatment. 


\subsubsection{Medical Emergencies in the Field}

All response personnel should be trained and prepared to perform first aid. Response personnel should be prepared to voluntarily perform first aid and to assist others during emergencies:

- Check for hazards in the area, call for help, make sure the uninjured remain safe, and safely attend to the injured person.

- Do not move an injured person unless the person's life is threatened and it is safe for you to approach the victim.

- Provide first aid. If necessary, call for emergency medical assistance. Have the injured person seen by the On-Scene Medical Director or designee regardless of how minor the injury.

- As soon as possible, report the emergency to the H\&S Manager and On-Scene Medical Director or designee.

\subsubsection{Management of Radiologically Contaminated Injured Persons}

1. At the discretion of the On-Scene Medical Director or designee, and based on the victim's medical status, decontamination may be done at the accident scene, in the treatment area, or in the hospital.

2. When decontamination is needed, the H\&S Manager will arrange health physics assistance for the medical team.

3. When appropriate, the REAC/TS Medical Team Leader may advise the H\&S Manager regarding recommendations for prophylactic use of potassium iodide (KI) and/or other substances.

4. The Radiation Emergency Assistance Center/Training Site (REAC/TS) physician will establish standing orders for REAC/TS personnel. The REAC/TS team will report to the REAC/TS medical coordinator or designee regarding medical matters. The REAC/TS medical coordinator or designee will report to the H\&S Manager. When supporting the Accident Site Health Group, REAC/TS personnel will report to the Manager, Accident Response Group. The function of the REAC/TS team in conjunction with the H\&S staff is as follows:

a. Provide advice and consultation regarding medical and related health physics problems in radiation incidents/accidents.

b. Provide advice and assistance regarding the health and safety of the team.

c. Provide emergency medical evaluation and treatment to personnel when necessary.

\subsubsection{On-Site Medical Monitoring (Entry Team)}

Entry team personnel (for SCBA only) are to be monitored for blood pressure, pulse rate, temperature (oral), and body weight by the On-Scene Medical Director or designee. There 
are numerous factors which affect allowable ranges so that each individual must be evaluated on a case-by-case basis by the On-Scene Medical Director or designee and the H\&S Manager.

The following typical values are provided only as an initial guideline:

- Max Blood Pressure: 140 systolic/90 diastolic

- Max Pulse Rate: 100 beats per minute

- Body Temperature: $\quad$ (Maximum) 99.2 degrees $\mathrm{F}\{37.3$ degrees $\mathrm{C}\}$ (Minimum) 98.0 degrees $\mathrm{F}\{36.7$ degrees $\mathrm{C}\}$ or

- Body Weight Loss: $\quad 1.5 \%$ (rule of thumb)

Results will be recorded and maintained on the form "Medical Monitoring of Entry Team" (Appendix A).

\subsubsection{Routine Sick Call}

A location will be identified where personnel may report for sick call. If no physician is present, arrangements will be made for personnel to be transported to an appropriate medical facility for treatment.

If a physician is present, personnel with non-emergency health problems can be examined and advised or treated. They may be referred to local physicians or health care facilities at the discretion of the On-Scene Medical Director or designee. 


\section{Chapter 7}

\section{RECORD MAINTENANCE}

\subsection{Overview}

This chapter contains the prescribed practices for preparing and retaining $H \& S$ records. Health and Safety records shall be maintained to document the H\&S aspects of an exercise or call-out. Records will be maintained in accordance with applicable regulations (e.g., 10 CFR 835, 10 CFR 20, etc.). Generated records should be high quality, readily accessible, and managed/updated for the prescribed retention period. Records should be handled in a manner that protects personal privacy.

\subsection{Records Management Program}

The types of H\&S records generated for an exercise or call-out will be clearly defined. An appropriate records management program shall ensure that audit-defendable records and reports are controlled from cradle to grave (creation, distribution, use, arrangement, storage, retrieval, media conversion, and disposition).

When radiological and/or industrial hygiene services (i.e., dosimetry and laboratory analyses) are purchased, there should be a clear, prior, written agreement regarding records responsibility during the performance of the services. Records of the results should reside in the custody of both organizations.

Information concerning an individual's exposure or medical information shall be made available to that individual, upon request, consistent with the Privacy Act of 1974.

\subsection{Record Keeping Standards}

Health and Safety records (i.e., radiological and industrial hygiene records) shall be accurate and legible. The records should:

- Identify the facility, specific location, general function, and process

- Be legible -- entries should be typewritten or printed clearly in black ink

- Contain initialed and dated corrections identified by a single line strike-out

- Identify the preparer (signature or other identifying code) and the date prepared.

\subsection{Participant Records}

Participants should provide any prior radiation exposure information. Current-year exposure information should be gathered to ensure compliance with applicable exposure regulations. Participant information provided to the H\&S Manager or designee should also include social security number, date of birth, home organization with address, home address, and any assigned identification numbers. 
Records of radiation doses shall be maintained. These records shall be sufficient to evaluate compliance with applicable dose limits. If dosimetry was needed during activities, final exposure reports for participants will be forwarded to their home organizations. A copy of the dosimetry data should be maintained as part of $H \& S$ activity records.

\subsection{Health and Safety Monitoring Records}

Health and safety may require the performance of radiation and/or chemical surveys that include area surveys, airborne activity assessments, and contamination surveys to determine existing conditions in a given location.

Health and safety is interested in the following data elements from surveys:

- Date, time, and purpose of the survey

- Location or personnel surveyed

- Name of surveyor or analyst

- Pertinent information needed to interpret the survey results

- Equipment number

- Resulting data recorded in units consistent with data collected.

\subsection{Instrumentation and Calibration Records}

All instrumentation records should be completed and maintained in accordance with ANSI N323. Calibrations for fixed, portable, and laboratory equipment shall be maintained by the supplying organization and records should be available. Records should include calibration frequency, calibration methodology, calibration dates, and National Institute of Science and Technology mandated traceability of calibration.

\subsection{Records Retention}

At the conclusion of activities, records shall be maintained in accordance with established rules or regulations regarding record-retention requirements. Health and safety records will be transferred to DOE for retention. Personnel dosimetry records and medical records have a 75-year retention requirement.

Records shall be stored in a manner that will protect them from physical damage caused by temperature extremes, moisture, biological infestation, electromagnetic fields, excessive light, stacking, theft, and vandalism. 


\section{ACKNOWLEGEMENTS}

The Federal Radiological Monitoring and Assessment Center (FRMAC) Health and Safety Working Group and several additional individuals contributed their time and efforts in writing and/or review of this document. These individuals are recognized below.

\section{FRMAC Health and Safety Working Group}

Chair, Carson Riland

Colleen O'Laughlin

Charlotte Carter

Stacy Junio

Mark McMahon

Stephanie Prothro

Steve Orth

Colleen Petullo

Richard Stump

Robb Hadley

John Haynie

George Mosho

Angela O'Riley

George Weaver

Ron Fraass

Aubry Godwin

Additional Contributors:

Phyllis Raddack

Al Ogurek

Mary Ellen Berger
Bechtel Nevada

U.S. Department of Energy-Nevada Operations Office (DOE/NV), FRMAC Program Manager

DOE/NV

Bechtel Nevada

Bechtel Nevada

Bechtel Nevada

U.S. Nuclear Regulatory Commission

U.S. Environmental Protection Agency

Sandia National Laboratories, (ARG)

Lawrence Livermore National Laboratory (ARG)

Los Alamos National Laboratory

Argonne National Laboratory (RAP)

Argonne National Laboratory (RAP)

Savanna River Site (RAP)

State of Kansas, (CRCPD)

State of Arizona, (CRCPD)

Bechtel Nevada Bechtel Nevada

DOE - Radiation Emergency Assistance Center and Training Site (REAC/TS) 


\section{APPENDIX A}

\section{Forms, Checklists, Plans, and Logs}

The documents within this Appendix were current at the time of publication. However, they are subject to continuing review and change based on input received from emergency response planners and participants. Some of these documents may require multiple copies or carbons. If multiple copies are required, individual form will list the destination of each copy. Please consult the FRMAC website at www.nv.doe.gov/programs/frmac for any updates to these documents. 
Date and time:

Location:

Type of Response (Brief Explanation):

\section{Type of Hazard}

Confined Spaces

Lockout/Tagout

Electric/Power Lines

Work near Heavy Traffic

Work on/near Water

Temperature Extremes

Open Flames or Fire

Any Explosive Materials

Pressurized Vessels

High Noise Areas

Airborne Contaminants

Biohazard Concerns

Non-lonizing Radiation

Exposure Rates

Surface Contamination Levels

Airborne Radioactivity Levels

Additional Remarks

Checklist completed by:

\section{Yes No Description (if yes)}

$\square \quad \square$

$\square \quad \square$

$\square \quad \square$

$\square \quad \square$

$\square \quad \square$

$\square$

$\square \quad \square$

$\square \quad \square$

$\square \quad \square$

$\square \quad \square$

$\square \square$

\section{Radiation Levels}




\section{EMERGENCY RESPONSE \\ HEALTH AND SAFETY PLAN}

\section{Version:}

Date:

Location:

Approved by:

Health and Safety Manager

Date

Name/Title

Date

Name/Title

Date

Name/Title

Date 


\section{A. Site Description}

Working name of site:

Location:

Surrounding population: industrial residential rural urban unpopulated other/more details:

\section{Topography:}

\section{Primary Hazards:}

Chemical Exposure

Fire/Explosion

Oxygen Deficiency

Confined/Enclosed Space Entry

Ionizing Radiation
Biological Hazards

Safety Hazards

Heat Stress

Cold Exposure

Noise

Other:

Path of radiological or other hazardous material dispersion:

Plume has been noted on the site map:

Yes

No

\section{B. Work Plan and Entry Objectives}

1. All operations shall be conducted in accordance with procedures established during field team briefings, in attached plans, and in the Emergency Response Health and Safety Manual.

2. Daily entry objectives may include documenting site monitoring, sample collection, and related activities. Detailed objectives will be developed daily and will be described during the field team safety briefing. 


\section{- Site Safety Briefings/Meetings}

1. All personnel, employees, contractors, and subcontractors shall be provided with an initial site safety briefing to communicate the nature, level, and degree of hazards expected on site.

2. Personnel will also receive regular briefings before and after each shift and when significant changes are made in the work procedures or safety plans. The Health and Safety Manager or designee shall hold these site safety meetings/briefings. At a minimum these meetings will describe the work to be accomplished, discuss safety procedure changes, and note any items which need to be communicated to other personnel. General safety training topics should also be covered based on points raised in previous meetings and safety plan attachments.

- The Senior Management Official (SMO) is the pre-designated federal official (from the Lead Federal Agency [LFA]) responsible for incident management in accordance with the FRERP.

Name:

Phone:

- The Senior Energy Official (SEO) is the designated lead for Department of Energy resources.

Name:

Phone:

- The Emergency Response Director (FRMAC, RAP etc.) is responsible for direct management of site operations.

Name:

Phone:

- The Health and Safety (H\&S) Manager is responsible for the health and safety of all responders. The responsibilities of the Health and Safety Manager include (but are not limited to):

$\checkmark$ coordination of all safety and health concerns for the entire work site

$\checkmark$ keeping this plan current, and

$\checkmark$ liaison with site safety officers from other organizations.

The Health and Safety Manager for this incident is:

Name:

Phone:

- The Public Affairs Officer is responsible for communication with the media. 
Name:

Phone:

\section{Other key officials:}

Name/Title/Organization Phone

Name/Title/Organization Phone

Name/Title/Organization Phone

Name/Title/Organization Phone

\section{Site Control Information}

1. Anyone entering or departing an impacted area, shall report to the Monitoring Manager or designated representative.

2. No person shall enter the site without subscribing to this or another applicable Health and Safety plan.

3. The buddy system is mandatory for all field-monitoring teams.

4. Training

- Personnel shall be adequately trained to perform their assigned tasks safely.

- All personnel entering the impacted area shall be fully informed about potential hazards and applicable procedures at the site.

5. Personnel monitoring required for entry to impacted areas include:

Dosimetry:

Personal Dosimeter (TLD) Self-Reading Dosimeter (EPD or PIC)

Other monitoring:

Personal Air Sampling

Bioassay (type, frequency, etc.)

6. A map, which includes the location of applicable items such as: zone boundaries, washing, toilet/hygiene facilities, first aid equipment, fire extinguishers, command 
posts, equipment staging/storage, eating/rest areas, and locations of identified hazards, will be provided.

\section{E. Hazard Evaluations}

A chemical hazard evaluation shall be made as part of each work plan. Generic hazardous substance information sheets (MSDSs) are attached, as applicable.

Environmental monitoring for radiological or chemical hazards shall be conducted. Monitoring equipment shall be calibrated and maintained in accordance with the manufacturer's instructions.

Type of Monitoring

Frequency

Radiation continuous, _ hourly, _ daily, other:

Combustible gas continuous, _ hourly, _daily, other:

Oxygen continuous, _hourly, __daily, other:

PID continuous, _ hourly, _ daily, other:

WBGT/heat stress continuous, _hourly, _ daily, other: Noise continuous, _hourly, __daily, other:

\section{Other chemical specific monitors (colorimetric/electronic)}

Type of Monitoring

\section{Frequency}

chemical: continuous, _ hourly, __daily, other:

chemical : continuous, _ hourly, _ daily, other:

chemical: continuous, _ hourly, _daily, other:

chemical: continuous, _ hourly, __daily, other:

\section{F. General Safe Work Practices}

Depending on the circumstances, any or all of the safe work practices listed below will be adhered to while on site. Place a check next to those that are appropriate for this deployment and add any additional ones that may be required.

BUDDY SYSTEM: The buddy system shall be observed inside the work area. Personnel must work within sight of their assigned partner at all times. The site supervisor shall assign a partner as personnel check in.

FIRES: Each manned response area shall have at least 1 each of the following:

$\checkmark$ a fully charged Class A fire extinguisher for ordinary fires,

$\checkmark$ a fully charged Class B fire extinguisher for liquid fires. 
The above items shall be maintained in a readily accessible location and clearly labeled.

LIGHTING: $\quad$ Fixed or portable lighting shall be maintained for dark areas or work after sunset to ensure that sufficient illumination is provided. (Table $\mathrm{H}-120.1$ of CFR $1910.120(\mathrm{~m})$ for minimum illumination intensities.)

WORK NEAR WATER: All personnel working in boats, on docks, or generally within 10 feet of water deeper than 3 feet, shall wear approved Personal Floatation Devices (PFDs) or work vests.

HEAT STRESS: The site safety and health supervisor shall follow the American Conference of Governmental Industrial Hygienists (ACGIH) guidelines in determining work/rest periods. Fluids shall be available at all times and encouraged during rest periods.

COLD STRESS: The site safety and health supervisor shall follow the ACGIH guidelines in determining work/rest periods. Workers shall be provided with adequate warm clothing, rest opportunities, and exposure protection. Warm and/or sweet fluids shall also be available during rest periods.

HIGH NOISE LEVELS: Hearing protection shall be used in high noise areas (exceeding $85 \mathrm{dBA}$--generally where noise levels require personnel to raise their voices to be heard) or where designated by an H\&S Representative.

ELECTRICAL HAZARDS: Electrical hazards are designated on the site map, and shall be marked with suitable placards, barricades, or other appropriate warning .

TRAP HAZARDS:

Open manholes, pits, trenches, or similar hazards are noted on the site map. The site safety supervisor shall ensure that these locations are periodically checked during the day.

CARBON MONOXIDE: Equipment operators shall ensure that personnel do not linger or work near exhaust pipes.

UV LIGHT EXPOSURE: Sunscreens of protection factor 15 (or greater) and UV tinted safety glasses shall be made available for response personnel as needed.

HELICOPTER OPERATIONS: Pilots shall provide a safety briefing to all passengers.

MOTOR VEHICLES: Drivers shall maintain a safe speed at all times, and shall not be allowed to operate vehicles in a reckless 
manner. Seat belts will be worn. Vehicles should pull off road to take measurements.

\section{ALL TERRAIN VEHICLES} (ATV's):

Drivers shall maintain a safe speed at all times, and shall not be allowed to operate vehicles in a reckless manner. ATV drivers shall not operate ATVs outside of areas and lanes specified by the Health and Safety Manager.

\section{DRUM HANDLING \& HEAVY LIFTING:}

$\checkmark$ Drums and containers must be handled in accordance with 29 CFR 1910.120. Containers must be labeled and constructed in accordance with EPA (40 CFR 264-265, and 300), and DOT (49 CFR 171-178) regulations.

$\checkmark$ Temporary holding/staging areas for drums and containers containing waste materials shall be constructed to contain spillage, runoff, or accidental releases of materials.

$\checkmark$ Manual lifting and handling of drums and/or containers shall be kept to a minimum. Mechanical devices, drum slings or other mechanical assisting devices designed for that purpose shall be used whenever possible.

CONFINED SPACES: Confined spaces will normally not be entered by response personnel. If a confined space must be entered or hotwork conducted in a confined space, a specific confined space entry work plan and confined space work authorization checklist will be developed for that operation.

Flora \& Fauna Awareness: The following listed items represent the types of dangers that may be associated with the plants, insects, and animals native to the area of deployment. The H\&S Manager will get the information to determine the specific dangers faced in the particular area covered by the site-specific plan.

INSECT STINGS: $\quad$ Bee (European and Africanized), hornet, or wasps

POISONOUS SPIDERS: Black widow, Brown recluse, Scorpions, Tarantula TICKS:

Carriers of Rocky Mountain spotted fever and Lyme disease

ANIMAL BITES

Skunks, prairie dogs, foxes, bats, dogs, cats, raccoons, and horses may not necessarily be lifethreatening but bites or scratches may pose an infection hazard, and/or rabies, as well as problems associated with open wounds. 


\section{General Precautions}

During morning safety briefings, provide information on the location of hazards and how to deal with problems.

Personnel should be provided with the following, as needed:

long-sleeve clothing insect repellent snake leggings

Personnel should inspect each other for ticks and signs of infected bites during breaks when working in designated areas.

Personnel with severe allergies must work in areas away from known/suspected hazards.

Personnel with allergies to bee stings or other insect bites should notify their supervisors and the Health and Safety Manager when reporting on this site. They should also carry emergency antidotes on them whenever possible. Supervisors on site should be prepared to deal with the medical emergencies that may result when personnel with allergies receive bites or stings.

Additional areas of concern:

\section{G. Personal Protective Equipment (PPE)}

The following PPE ensembles shall be used while on site. Circle the required level.

\section{Location}

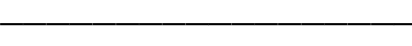

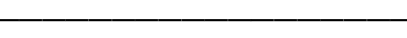

Team/Task

Monitoring teams

Decontamination teams

Hotline teams

Team/Task
Level

1234

1234

1234

Additional PPE Requirements: Location

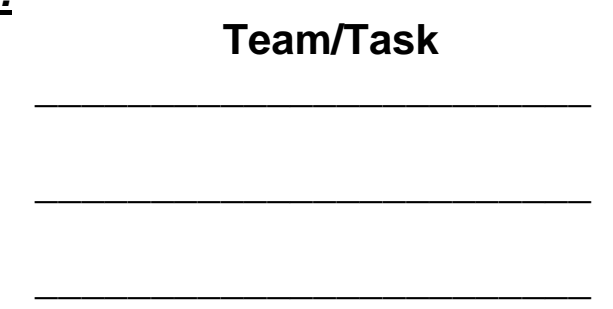

Level

\section{Notes:}




\section{H. Emergency Procedures}

1. When an on-site emergency occurs, personnel shall not reenter the area or restart work until:

- the condition resulting in the emergency has been investigated by supervisory personnel, and has been corrected

- hazards have been reassessed

- personnel have been briefed on any changes in the operation and site safety plan

- Hospitals listed in the communications section (Section I) have been contacted Note: The emergency hospital must agree to take radiological patients

- Fire departments listed in the communications section have been contacted.

- Ambulance services listed in the communications section have been contacted. Note those which will take radiological emergencies.

- Police forces listed in the communications section have been notified.

2. Emergency Medical Procedures

- Contact designated EMT

- Do not attempt to move seriously injured personnel, call for an ambulance to come to the injured person.

- The closest hospital for regular emergencies is: (see communications section for phone number)

- The closest hospital for radiological emergencies is: (see communications section for phone number)

- Contact ATSDR (404) 639-0615 (24 hours) for chemical exposure emergencies.

- Contact REAC/TS (865) 576-3131 (24-hour line: (865) 576-1005) for radiological exposure emergencies.

3. Emergency Fire Procedures

- DO NOT attempt to fight fires other than small fires. A small fire is generally considered to be a fire in the early stages of development, which can readily be extinguished with personnel and equipment in the immediate area in a few seconds.

- You MUST notify proper personnel and call the fire department if the fire can not be put out quickly. Do not take extraordinary measures to fight fires.

\section{Evacuation Procedure}

\section{EVACUATION NOTIFICATION}

Field Elements:

Technical Operations Center(TOC):

PRIMARY EVACUATION ROUTE

Field Elements:

TOC: 
Field Elements:

TOC:

ASSEMBLY POINT

Field Elements:

TOC:

\section{Communication Methods}

1. General signals

SIGNAL

Thumbs up

Thumbs down

Hands across throat

Grab a hand/arm

Hands on head

\section{MEANING}

I'm OK / I agree

I don't agree

I'm out of air / trouble breathing

Come with me

I need assistance

\section{Radio communications}

Working:

frequency: channel:

VHF

UHF

$\mathrm{CB}$ __ Other

Emergency:

frequency: channel:

VHF

UHF

CB Other

\section{Phone communications}

Senior Management Official:

Voice/phone:

Fax:

Cellular Pager: 
Voice/phone:

Fax:

Cellular Pager:

Health and Safety Manager:

Voice/phone: Fax:

Cellular Pager:

Radiation Emergency Assistance Center and Training Site (REAC/TS):

phone number: (865) 576-3131 24 hour line:(865) 576-1005

Agency for Toxic Substance and Disease Registry (ATSDR):

24 hour line (voice): (404) 639-0615 Fax: (404) 639-0655

Police:

Fire:

Ambulance/EMT/Hospital:

Other numbers:

\section{J. Attachments}

The following are attachments that may be required, depending on the needs and circumstances at the site. If other forms or attachments are required, add those to the list. Then place a checkmark on the line in front of the pertinent plans for this site.

_ Turn Back Levels (Turn Around Levels)

_ Health and Safety Air Monitoring Plan

_ Bioassay Plan

_ Contamination Control Plan (area surveys, personnel surveys, etc.) 
Decontamination Plan

Survey Plan

Hotline Plan (sample, personnel, equipment, etc.)

Others:

name of plan

name of plan

name of plan

name of plan

name of plan 


\section{Memorandum}

Date:

To:

From:

Subject: Pregnancy Declaration

This is to inform you, as my supervisor, of my pregnancy or my intention to become pregnant. This form also provides me with information concerning the effects of radiation exposure to the unborn child. The signing of this document and release of this information are done solely in the interest of protecting my unborn child.

The reason for informing you of my intention to become pregnant is to prevent an unwanted, exposure from occurring before I become aware that I am pregnant.

I understand the possible effects of ionizing radiation exposure to the unborn child as stated in paragraphs A and B of this section. The following information comes from Radiation Protection Guidance to Federal Agencies for Occupational Exposure Approval of Environmental Protection Agency Recommendations Vol., 52 No. 17 Tuesday, January 27, 1987, and addresses the effects of radiation on children who were exposed while in the womb.

A. Not only may the unborn be more sensitive than adults to the induction of malformations, cancer, and hereditary effects, but recent studies have drawn renewed attention to the risk of severe mental retardation from exposure of the unborn during certain periods of pregnancy. The risk of less severe mental retardation appears to be similarly elevated. Although it is not yet clear to what extent the frequency of retardation is proportional to the amount of dose (the data available at occupational levels of exposure are limited), it is prudent to assume that proportionality exists.

B. The recommendations also incorporate guidance for limiting exposure of the unborn as a result of occupational exposure of the female workers. It has long been suspected that the embryo and fetus are more sensitive to a variety of effects of radiation than are adults. Although our knowledge remains incomplete, it has now become clear that the unborn are especially subject to the risk of mental retardation from exposure to radiation at a relatively early phase of fetal development. Available scientific evidence appears to indicate that this sensitivity is greatest during the period near the end of the first trimester and the beginning of the second trimester of pregnancy, that is the period of from 8 weeks to about 15 weeks after conception. Accordingly, when a worker has declared her pregnancy, guidance recommends not only that the total exposure of the unborn be more limited than that of adult workers but that the monthly rate of exposure be further limited in order to provide additional protection. Due to the incomplete state of knowledge of the transfer of radionuclides from the mother to the unborn (and the resulting uncertainty in dose to the unborn), in those few work situations where intake of radionuclides could normally be possible it may also be necessary to institute measures to avoid such intakes by pregnant women in order to satisfy these recommendations. 


\section{PREGNANCY DECLARATION (cont.)}

I understand that the possible risks, my rights, possible limitations and responsibilities are as follows:

1. The health protection objectives of this guidance for the unborn should be achieved in accordance, with the health provisions of Title VII of the Civil Rights Act of 1964, ad amended, with respect to discrimination in employment practices. The guidance applies only to situations in which the worker has voluntarily made her pregnancy known, in writing to her employer.

Protection of the unborn may be achieved through such measures as temporary job rotation, worker self-selection or use of protective equipment. The guidance recognizes that protection of the unborn is a joint responsibility of the employer and the worker. As a result, temporary arrangements necessary to modify exposures may be made. The responding organization will make such arrangements in a manner that allows minimization of the impact to the worker.

2. The responding organization further recognizes that while they share concern for the protection of unborn children of their employees, it is also the decision of the Supreme Court of the United States in UAEW v. JOHNSON CONTROL, INC._U.S._111S. Ct. 1 196, 113, 1 Ed.2d 158 (March 20, 1991) that:

"Decisions about the welfare of future children must be left to the parents who conceive, bear, support and raise them rather than to employers who hire those parents."

3. The Civil Rights Act of 1964, as amended, provides that "It shall be an unlawful employment practice for an employer (1) to fail or refuse to hire or to discharge any individual, or otherwise to discriminate against any individual with respect to his compensation, terms, conditions, or privileges of employment, because of such individuals...sex...; or (2) to limit, segregate, or classify his employees or applicants for employment in any way which would deprive or tend to deprive any individual of employment opportunities or otherwise adversely affect his status as an employee, because of such individual's...sex..." [42 U.S.C. 2000e-2(a)]. The Pregnancy Discrimination Act. Or 1978 defines "because of sex" to include because of or on the basis of pregnancy, childbirth, or related medical conditions [42 U.S.C. 2000e(k)].

4. The radiation dose equivalent that my unborn child shall receive from conception until birth (the entire gestation period) shall be limited to $0.5 \mathrm{rem}$ (500 mrem), unless pregnancy declaration occurs after this limit has been exceeded.

5. My unborn child is further limited to an equivalent radiation exposure rate of 0.05 rem (50 mrem) per month. This is to prevent further fluctuations above a uniform monthly exposure rate that would satisfy the limiting value.

6. I shall exchange my dosimeter on a monthly basis to ensure compliance to the monthly administrative limit. 
7. If the radiation dose to my unborn child is determined to have already exceeded 0.5 rem by the time I notified you by signing this Declared Pregnancy Notification Form, I agree to be assigned to tasks where additional occupational exposure is unlikely.

8. Once the pregnancy is concluded, or at such time as I wish to revoke my pregnancy declaration, I shall notify you by signing a Pregnancy Condition Form, so I can resume my normal duties.

Employee:

\section{Printed Name}

Signature

SSN

Privacy Act Statement: The information on this form is protected by the Privacy Act of 1974. The purpose of requesting this information is to minimize risks to an unborn child/children in the womb. This information will be used by the U.S. Department of Energy, Nevada Operations Office, its contractors, and the employing agency of the mother. Failure to provide this information could result in our inability to limit the exposure to the unborn child.

Responding Organization Representative:

Printed Name

Home Organization Representative:
Signature 


\section{POCKET DOSIMETER ISSUE LOG}

\begin{tabular}{|c|c|c|c|c|c|c|c|}
\hline Name & $\begin{array}{c}\text { Team } \\
\text { Number }\end{array}$ & $\begin{array}{c}\text { Social } \\
\text { Security } \\
\text { Number }\end{array}$ & $\begin{array}{l}\text { Dosimeter } \\
\text { ID Number }\end{array}$ & $\begin{array}{l}\text { Date/ } \\
\text { Time } \\
\text { Issue }\end{array}$ & $\begin{array}{c}\text { Date/ } \\
\text { Time } \\
\text { Return }\end{array}$ & $\begin{array}{c}\text { Initial } \\
\text { Reading } \\
(\mathrm{mR})\end{array}$ & $\begin{array}{c}\text { Return } \\
\text { Reading } \\
(\mathrm{mR})\end{array}$ \\
\hline & & & & & & & \\
\hline & & & & & & & \\
\hline & & & & & & & \\
\hline & & & & & & & \\
\hline & & & & & & & \\
\hline & & & & & & & \\
\hline & & & & & & & \\
\hline & & & & & & & \\
\hline & & & & & & & \\
\hline & & & & & & & \\
\hline & & & & & & & \\
\hline & & & & & & & \\
\hline & & & & & & & \\
\hline & & & & & & & \\
\hline
\end{tabular}

Privacy Act Statement: The information on this form is protected by the Privacy Act of 1974. The purpose of requesting this information is to conduct dose tracking. This information will be used by the U.S. Department of Energy, Nevada Operations Office, its contractors, and the home organization of the participant. Failure to provide this information will result in not receiving a dose assessment or proper dose tracking. 
Privacy Act Statement: The information on this form is protected by the Privacy Act of 1974. The purpose of requesting this information is to conduct dose tracking. This information will be used by the U.S. Department of Energy, Nevada Operations Office, its contractors, and the home organization of the participant. Failure to provide this information will result in not receiving a dose assessment or proper dose tracking.

Personnel TLD Data Sheet

Personnel TLD Data Sheet \# 40134

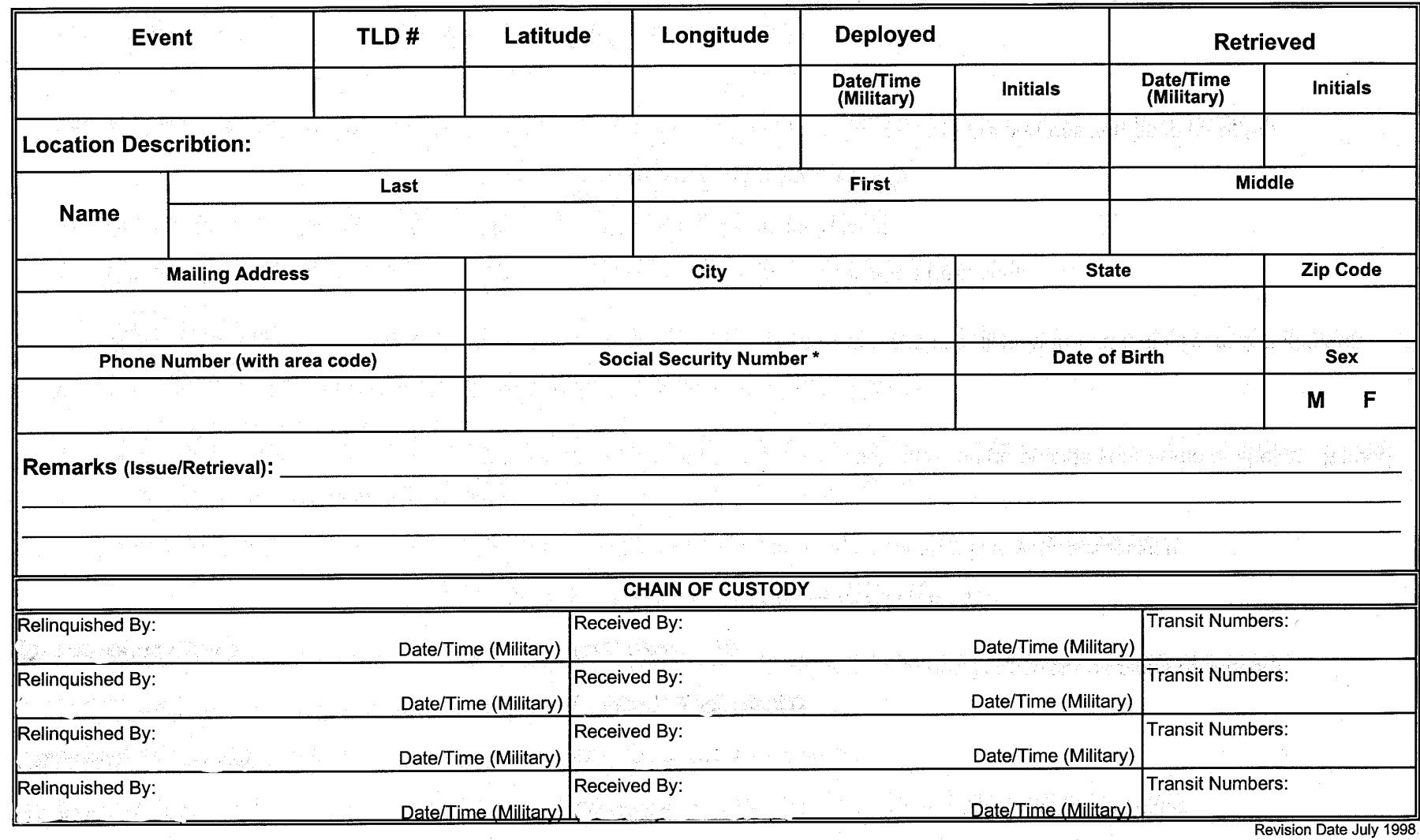

* SSN Disclaimer: The Health and Safety Group requires that Social Security number information be provided. This information is held in strict confidence; it is not released. Original to Data Center Yellow Copy to Health \& Safety 


\section{BIOASSAY SAMPLE FORM}

Last Name:

First Name:

Middle Initial:

S.S.N./P.I.N.:

Organization:

Address:

Date (dd-mm-yy):

AWP Number:

Sample Media:

Urine

Fecal

Thyroid

Lung

Wound

WBC

Nasal

Other (specify):

Sample Number :

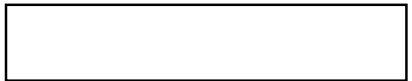

Time (hhmm)

Comments:

Sample Type:

Baseline

Routine

Post-Work

Other

Analyses:

Time/Date of Sample Collection: Begin:

End:

\section{Chain of Custody}
Relinquished By
Date/Time
Date/Time
Received By
(Signature)
(Relinquished)
(Received)
(Signature)

Privacy Act Statement: The information on this form is protected by the Privacy Act of 1974 . The purpose of requesting this information is to conduct dose tracking. This information will be used by the U.S. Department of Energy, Nevada Operations Office, its contractors, and the home organization of the participant. Failure to provide this information will result in not receiving a dose assessment or proper dose tracking. 
RADIATION SURVEY REPORT FORM

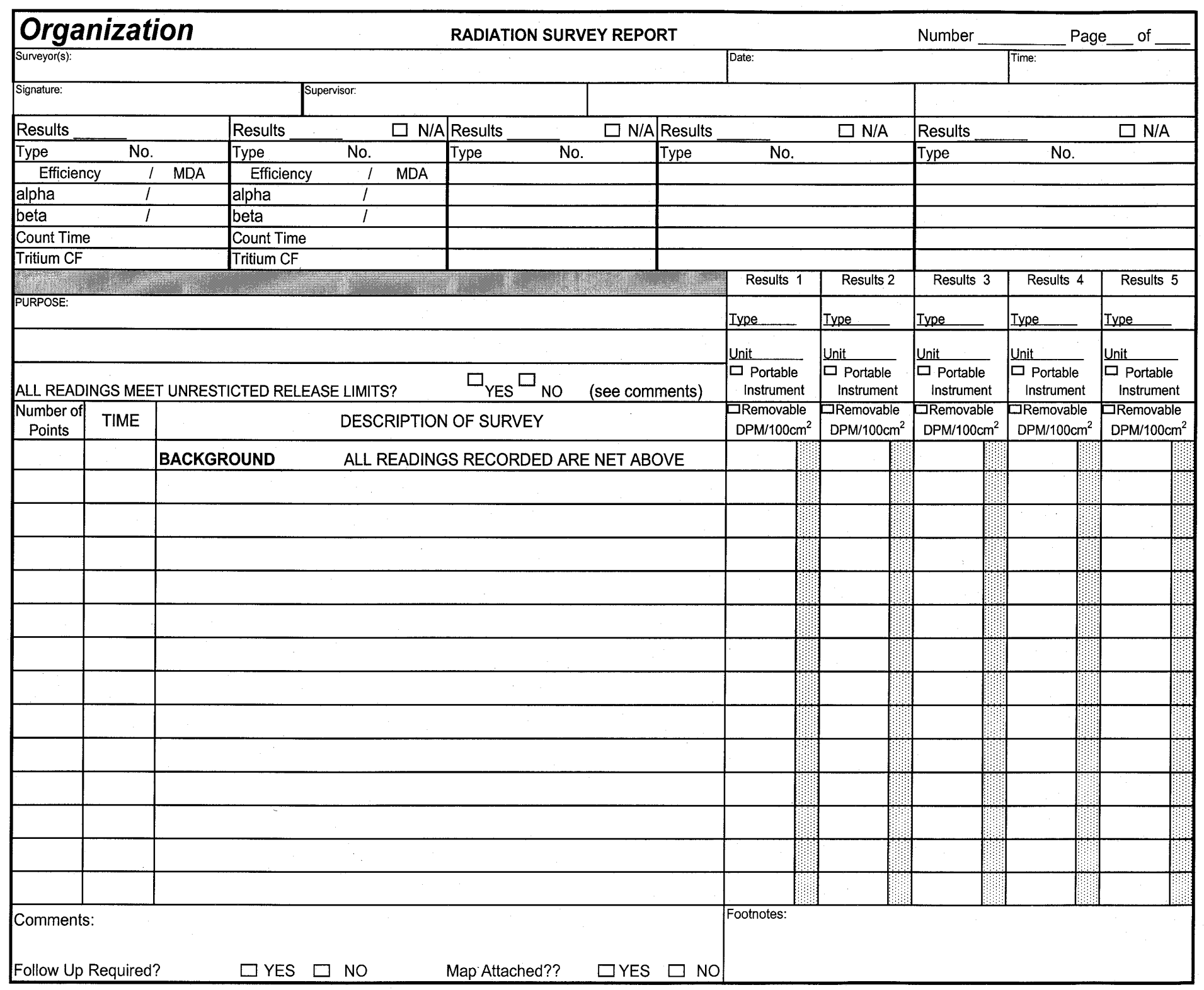




\section{PERSONNEL CONTAMINATION SURVEY SHEET}

Name:

Date/Time:

Team:

Mark contamination locations on the diagrams below.

Bioassay Collected: Yes No

FRONT

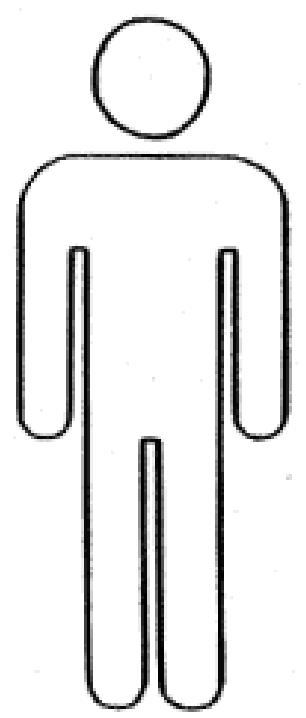

Measurements:

1.

2.

3.

4.

5.

6.

7.

8

9.
BACK

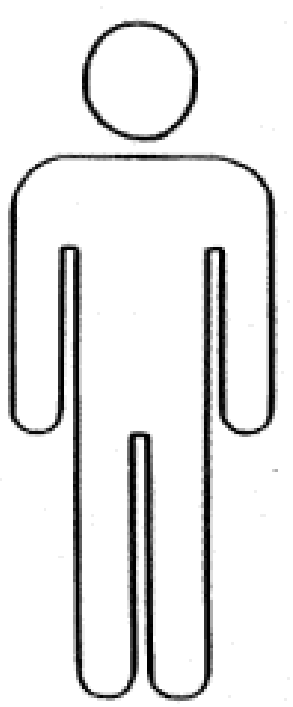

Measurements:

1.

2.

3.

4.

5.

6.

7.

8.

9.

Comments:

Number:

Privacy Act Statement: The information on this form is protected by the Privacy Act of 1974. The purpose of requesting this information is to conduct dose tracking. This information will be used by the U.S. Department of Energy, Nevada Operations Office, its contractors, and the home organization of the participant. Failure to provide this information will result in not receiving a dose assessment or proper dose tracking. 
NAME:

CASE: CASE \#:

DATE/TIME: EXPOSURE RISK:

$\mathrm{HIGH}$ MED LOW

PROTECTIVE EQUIPMENT:

SUBSTANCE(S) INVOLVED:

CONCENTRATION/LENGTH OF EXPOSURE:

MEDICAL TESTING:

COMMENTS:

\section{PRE-ENTRY MEDICAL MONITORING}

WEIGHT:

TEMPERATURE:

METHOD:

PULSE: BLOOD PRESSURE: SYSTOLIC /DIASTOLIC METHOD:

MONITORING CONDUCTED BY:

\section{POST-ENTRY MEDICAL MONITORING}

WEIGHT: TEMPERATURE: METHOD:

PULSE: BLOOD PRESSURE: SYSTOLIC /DIASTOLIC METHOD: MONITORING CONDUCTED BY:

Privacy Act Statement: The information on this form is protected by the Privacy Act of 1974. The purpose of requesting this information is to conduct medical monitoring of entry teams. This information will be used by the U.S. Department of Energy, Nevada Operations Office, its contractors, and the home organization of the participant. Failure to provide this information will result in not receiving medical monitoring and could preclude participation on the entry team. 


\section{DISTRIBUTION}

\section{DOE/HQ}

J.M. McBroom

J.C. Coughlin

T.M. Black

M.M. O'Shaughnessy

DOE/AL

R.W. Arkin

J.D. Stickney

DOE/NV

D.D. Monette

J.D. Barrett III

T.D. Wiard

D.M. Daigler

C. T. O'Laughlin

DOE RAP

Region 1

Region 2

Region 3

Region 4

Region 5

Region 6

Region 7

Bechtel Nevada

L.A. Van Arsdale

T.G. Mosier

\section{CRCPD}

P. Gorman

Voting Members

Board of Directors

E-6

EPA/HQ

W.C. Conklin

EPA/AL

E.L. Sensintaffer
EPA/NV

G.D. Dempsey

EPA

Regions 1-10

(1 each)

FEMA HQ

N. Goldstein

B. Russell

R. Salter

FEMA

(4)

Regions 1-10

NRC

S.A. McGuire

C.L. Miller

J.M. Gunn

Regions 1-4

NASA

J.W. Lyver

ARAC

J.S. Ellis

\section{REAC/TS}

R.C. Ricks

LANL

(6)

J.C. Pratt

W.J. Flor

LLNL

D.A. Kruchten

SNL

H.T. Season, Jr.

(1 each)

(1 each)
State of NV

S. Marshall

IAEA

T.J. McKenna

USDA

R. Conely

CDC/HHS

E.K. Gray

DOD/DTRA

Major S. Little

Cpt. J. Willoughby

Col. J. Faulkner

Ltc. D. McGill

K. Gamache

NOAA

D. Randerson

FBI

J. Kayask

\section{ORISE}

J. McDonnell

\section{DOS}

S. Goodwin

Resource Centers

Public

(1)

TIRC

(1)

OSTI

(1)

RSL Andrews

RSL Nellis

\section{ORNL}

\section{K.S. Gant}

